University of Rhode Island

DigitalCommons@URI

Open Access Master's Theses

1977

\title{
A Gravity Study of Earthquake-Related Structures in the St. Lawrence River Valley
}

Robert Louis Albert

University of Rhode Island

Follow this and additional works at: https://digitalcommons.uri.edu/theses

\section{Recommended Citation}

Albert, Robert Louis, "A Gravity Study of Earthquake-Related Structures in the St. Lawrence River Valley" (1977). Open Access Master's Theses. Paper 990.

https://digitalcommons.uri.edu/theses/990

This Thesis is brought to you for free and open access by DigitalCommons@URI. It has been accepted for inclusion in Open Access Master's Theses by an authorized administrator of DigitalCommons@URI. For more information, please contact digitalcommons-group@uri.edu. 
A GRAVITY STUDY OF EARTHQUAKE-REHATED STRUCTURES IN THE ST. IAWRENCE RIVER VALLEY

\author{
BY \\ ROBERT LOUIS ALBERT
}

A THESIS SUBMITTED IN PARTIAL FULFILLMENT OF THE REQUIREMENTS FOR THE DEGREE OF

MASTER OF SCIENCE

IN

GEOLOGY

UNIVERSITY OF RHODE ISLAND

1977 
MASTER OF SCIENCE THESIS

OF

ROBERT LOUIS ALBERT

Approved:

Thesis Committee

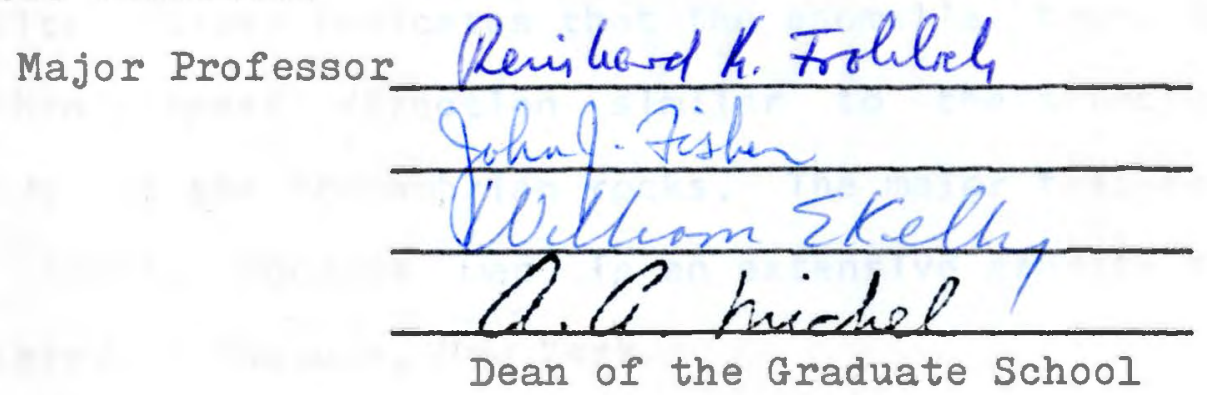

UNIVERSITY OF RHODE ISIAND 
The causes of the seismicity of the St. Lawrence River Valley are not well-understood. As is the case for the entire east coast of North America, epicentral zones often occur in regions where no correlation exists between seismicity and mapped geologic structures. There are several explanations for such a phenomenon: a) earthquakes occur along unmapped surface faults, b) earthquakes occur along subsurface faults showing no surface expression, or c) the structures are not fault-related.

Conventional filtering techniques, such as the upward continuation, downward continuation, and second derivative methods were applied to gravity data from the St. Lawrence River Valley in an attempt to delineate possible seismic-related structures. The gravity survey indicates that the anomalies trend in a north-northeast direction similar to the structural trends of the Precambrian rocks. The major feature of the simple Bouguer map is an extensive gravity high centered at llassena, New York.

Analyses by the filtering methods and subsequent modeling by the two-dimensional Talwani technique reveal the existence of two anomaly-producing bodies responsible for the Massena High: 1) a wedge $(8 \times 35 \mathrm{~km})$ located $6 \mathrm{~km}$ below sea-level with a density contrast of $+.11 \mathrm{~g} / \mathrm{cc}$, and 2) a smaller body $(2 \times 6 \mathrm{~km})$ located $3.3 \mathrm{~km}$ 
below sea-level with a density contrast of $+.2 \mathrm{~g} / \mathrm{cc}$. The large wedge may represent a sequence of interlayered metasediments and metavolcanics related to the Grenville sequence. The smaller body may represent a mafic intrusive. In addition, the simple Bouguer map reveals a circular gravity low of low intensity (diameter $=20 \mathrm{~km}$ ) centered at Cornwall, Ontario.

The Cornwall Low suggests the existence of a subsurface block-fault between Massena, New York and Cornwall. The proposed Massena- Cornwall Fault has been the site of recent earthquake activity including an Intensity VIII shock in 1944. However, the gravity study failed to reveal fault structures over other epicentral regions in the study area.

Numerous authors have suggested an association of high gradients of gravity (toward positive) produced by mafic intrusives and earthquakes in the southeastern United states. The possible existence of a mafic intrusive near Massena, New York and its proximity to epicentral zones suggest a similar origin for some earthquakes in the study area. 


\section{ACKNOWL EDG EM ENTS}

I would like to thank the following for their assistance in making this study possible:

1. My advisor, Dr. Reinhard K. Frohlich, Dept. of Geology, University of Rhode Island for his time, advice, and encouragement.

2. Dr. Frank A. Revetta, Dept. of Geological Sciences, SUNY College at Potsdam who supervised the collection of gravity data and made this study possible.

3. The National Science Foundation for support of the 1974 gravity survey.

Finally, I would like to dedicate this thesis to my wife, Maria, whose help and encouragement made this thesis possible. 
1. Introduction-

1.1 Statement of Problem-n-

1.2 Method-

1.3 Previous Gravity Studies-

1.4 Regional Geology--

1.41 Physiography--

1.42 Stratigraphy--

1.43 Tectonics-

1.44 Seismicity-

2. Gravity Investigation-

2.1 Introduction- 17

2.11 Reduction of Gravity Data-_-

2.12 Observed Gravity-_-

2.13 Theoretical Gravity-- 23

2.14 Free-Air Correction-

2.15 Bouguer Correction-_-

2.16 Terrain Correction--

2.17 Types of Anomalies-_-

2.2 Data Analysis-_-_-

2.21 Introduction--

2.22 Basic Formulae-- 28

2.221 Upward Continuation of Gravity-_-

2.222 Downward Continuation of Gravity-_...-33

2.223 Second Derivative of Gravity-_-_- 36

2.224 Comparison of Techniques Used in

Delineating Local Structures-- 
2.3 Computer Analyses-_-

2.31 Programs Test--

2.4 Application of Programs to Study Area--

3. Interpretation of Data-

3.1 Analysis of Region A-

3.11 Simple Bouguer Gravity-

3.12 Upward Continuation-

3.13 Downward Continuation-_-

3.14 Second Derivative-10-

3.15 Gravity Modeling-

3.16 Geological Interpretation of the

Massena Gravity High--

3.17 Secondary Massena Anomaly-_-

3.2 Analysis of Region B-C

3.21 Simple Bouguer Gravity-_-

3.22 Upward Continuation-_. 73

3.23 Downward Continuation and Second Derivative--.---- 74

3.3 Summary of Gravity Analysis-_-

4. Discussion-

4.I St. Lawrence Rift System-

4.2 Subsurface Faulting and Seismicity-_-

4.3 Non-Fault Structures and Seismicity---_---

4.4 Relationship of Gravity Data to

Seismic-Trend Hypotheses-- 
5. Conclusion- 84

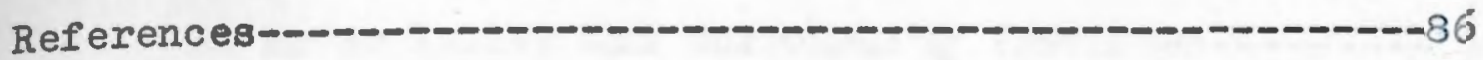




\section{IIST OF FIGURES}

Fig. I: Location of Study Area--

Fig. 2: Physiographic Map of St. Lawrence

River Valley and Surrounding Provinces------.--5

Fig. 3: Generalized Geologic Map of the

St. Lawrence River Valley-n-n

Fig. 4: Generalized Stratigraphic Section of

St. Iawrence River Valley-n-_-ne-n

Fig. 5: Gravity Anomalies and Structural

Features of the Northeastern United States------9

Fig. 6: Location Map of St. Lawrence Rift System--------Il

Fig. 7: Epicenter Location Map of Intensity V+

Earthquakes in New York and Adjacent Areas-----13

Fig. 8: Seismicity of Northeastern North America

1928-1959 and Location of Kelvin Seamount

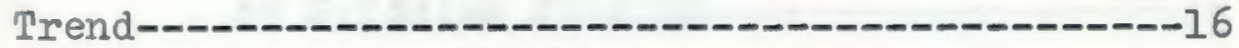

Fig. 9: Geologic Structure of New York and

Adjacent Areas-

Fig. 10: Distribution of Earthquake Epicenters in

New York and Adjacent Areas for the

Period 1800-1972

Pig. Il: Relationship of Structural Features to

Epicenter Distribution in New York

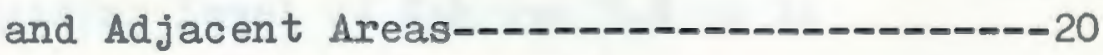

Fig. 12: Location of Gravity Base Stations in

St. Lawrence River Valley---_-_---_------22

Pig. 13: The 'Half-Width' Relationship in

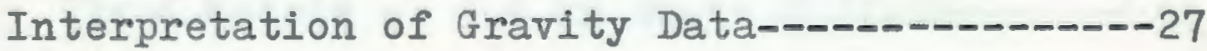




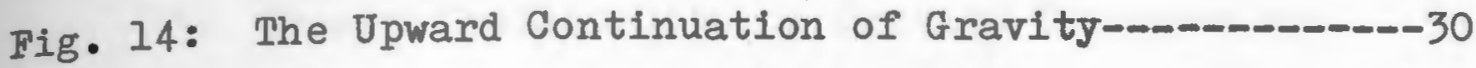

Fig. 15: Center-Point and Ring Method of

Calculating the Continuation of

Gravity Fields

Fig. 16: The Downward Continuation of Gravity-m-n-m-m-35

Fig. 17: Flowchart of the Three-Dimensional

Continuation Process--_-

Fig. 18: Model Developed to Test the Operation of

the Three-Dimensional Continuation

Program Sequence--n--

Fig. 19: Observed Gravity Over Model Illustrated in

Figure 18 for 30x25 Matrix--n-n-m--n---48

Fig. 20: Observed Gravity Over Model Illustrated in

Figure 18 for $27 \times 24$ Matrix After Analysis.

by Gridding Program--

Fig. 2l: Simulation of Upward Continuation Process by

Lowering Level of Spheres $3.6 \mathrm{~km}$ in

$30 x 25$ Matrix-

Fig. 22: Simulation of Upward Continuation Process by

Lowering Ievel of Spheres $7.2 \mathrm{~km}$ in

$30 \times 25$ Matrix-

$-52$

Fig. 23: Simulation of Downward Continuation Process by Raising Level of Spheres $3.6^{\circ} \mathrm{km}$ in

$30 \times 25$ Matrix-

Fig. 24: Upward Continuation of Gravity Produced by Three-Dimensional Continuation Program in $27 \times 24$ Matrix at $3.6 \mathrm{~km}$ Above Surface-------54 
Fig. 25: Upward Continuation of Gravity Produced by Three-Dimensional Continuation Program in $27 \times 24$ Matrix at $7.2 \mathrm{~km}$ Above Surface------- 55 Fig. 26: Downward Continuation of Gravity Produced by Three-Dimensional Continuation Program in $27 \times 24$ Matrix at $3.6 \mathrm{~km}$ Below Surface------56 Fig. 27: Second Derivative of Gravity Produced by Three-Dimensional Continuation Program in 27x24 Matrix at Surface-Fig. 28: Iocation of Regions $A$ and B-nFig. 29: Possible Model for Structure Producing Massena Gravity High---_- 


\section{LIST OF TABLES}

Table 1: Pertinent Information on Earthquakes

Presented in Figure 7-- 14,15

Table 2: Upward Continuation Coefficients-_._.

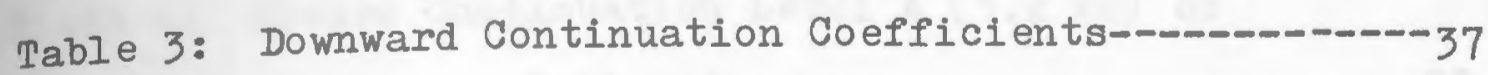

Table 4: Second Derivative Coefficients-_- 39

Table 5: Density Values for Rocks Cropping-Out

in Study Area- 


\section{IIST OF PLATES}

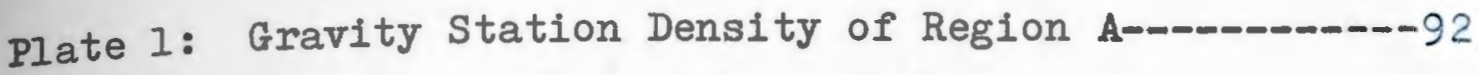
Plate 2: Gravity Station Density of Region B-_-_-_-_----93 Plate 3: Simple Bouguer Gravity Map of Region A--_-_----94 Plate 4: Upward Continuation Level l $(3.2 \mathrm{~km})$ of

Region A-- - - -

Plate 5: Upward Continuation Level $2(6.4 \mathrm{~km})$ of

Region A--

Plate 6: Upward Continuation Level $3(9.6 \mathrm{~km})$ of

Region A-C-

Plate 7: Downward Continuation Level I $(-3.2 \mathrm{~km})$ of

Region A-c-

Plate 8: Generalized Geologic Map of Region A-_-_-_-_--99

Plate 9: Second Derivative Map at Surface for

Region A-C-

Plate 10: Simple Bouguer Gravity Map of Region B-------10I

Plate 1I: Upward Continuation Level I $(3.2 \mathrm{~km})$ of

Region B-c-

Plate 12: Upward Continuation Level $2(6.4 \mathrm{~km})$ of

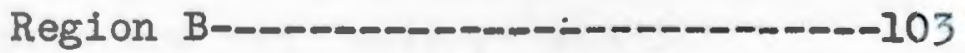

Plate 13: Upward Continuation Level $3(9.6 \mathrm{~km})$ of

Region B-C-n

Plate 14: Downward Continuation Level I $(-3.2 \mathrm{~km})$ of

Region B--

Plate 15: Second Derivative at Surface for Region B----106 Plate 16: Generalized Geologic Map of Region B--..-----107 


\section{Introduction}

\subsection{Statement of Prohlem}

Little is known about the causes of the seismicity of the St. Lawrence River Valley. The area is one of moderate seismicity with the majority of earthquakes averaging between 111 and $V I$ on the Modified Mercalli Scale (Hadley and Devine,1974). Larger earthquakes, up to intensity VIII, such as the Massena earthquake of 1941, are less frequent but do occur in the rerion.

As is typical for most parts of the east coast of the U.S., earthquake focal zones are often located in areas where earthquake-related structures are not shown at the surface. There are several explanations for this phenomenon: a) the earthquake structures are fault-related and lie at the surface, hut geologic mapping failed to reveal them, h) the earthquake structures are fault-related and lie below the surface, hidden heneath younger, inactive structures. or c) the earthquake structures are not fault-related.

The hasic problem, that this study is concernet with, is to analyze gravity data in order to delineate the subsurface structure and its relationship to earthquake foci.

\subsection{Method}

The gravity method was chosen for this study. In general, the gravity method allows for the detection 
and measurement of lateral variations in the earth's gravitational pull that are associated with changes in rock density. The use of various analytical techniques applied to gravity data have been shown to be successful in areas where the structures of interest are deep-seated ( Dobrin,1760). Throuph the application of conventional filter methods, such as the upward and downward continuations of potential fields and second derivative methods, maps are produced in which deep and shallow anomaly-producing hodies are enhanced, respectively. Such methods produce a three-dimensional picture of the anomaly-producing structures not available through surface geologic mapping ( Henderson,1960).

These methods were applied to gravity data from the 5t. Lawrence River Valley in an attempt to delineate possible earthquake-related structures. The area surveyed is lllustrated in figure 1. This approach was deemed best suited to an area in which the structures of interest show little or no surface expression.

\subsection{Previous Gravity Studies}

Less extensive gravity surveys have been conducted by Simmons (1964) and Simmons and Diment (1372). Stations occupied during these surveys were witely separated, averaging five to ten kilometers apart. Such surveys are inadequate to reveal local geoloric structures. 
Figure 1

Location map of study area. 


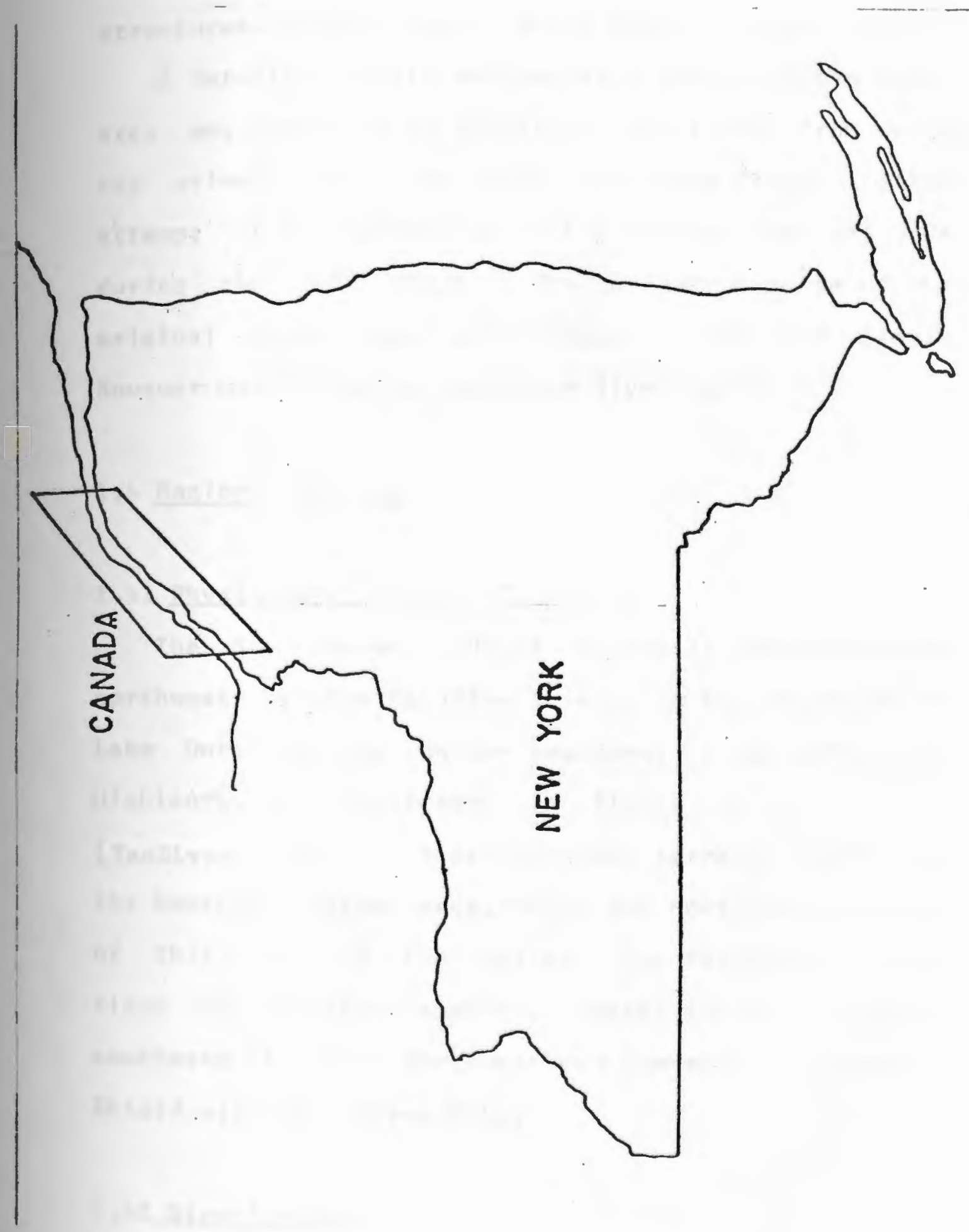


Private investigations have been conducted by names and Moore (1972) using gravity traverses over suspected structures. Unfortunately these data are unpublished.

A detailed gravity and magnetic survey of the study area was conducted by 1 lbert, et al. (1974) from which the primary data for thls study were drawn. Little attempt at interpretation of the gravity data was made during the 1974 study. The primary purpose of the original survey was to produce a detailed simple Bouguer map of the St. Lawrence River Valley.

\subsection{Regional Geology}

\subsection{Phys looraphy}

The St. Lawrence River Valley is bounded on the northivest hy the Canadian Shleld, on the southwest hy Lake Ontario, and on the southeast by the Adirondack Highlands as illustrated in flgure 2

(Vandiver. ,1971). A graben-basin terrain, similar to the Montreal- ottawa area, forms the northwest boundary of this part of the valley. The Frontenac Axis, a ridge of uplifted basement, crosses the area from the southeast to the northwest and connects the Canafian Shield with the Adirondacks.

\subsection{Stratigraphy}

The southern portion of the study area consists of a melange of Precambrian Grenville igneous and 
Figure 2

Physiographic map of St. Lawrence Valley and surrounding provinces.

From: Van Diver (1971) 


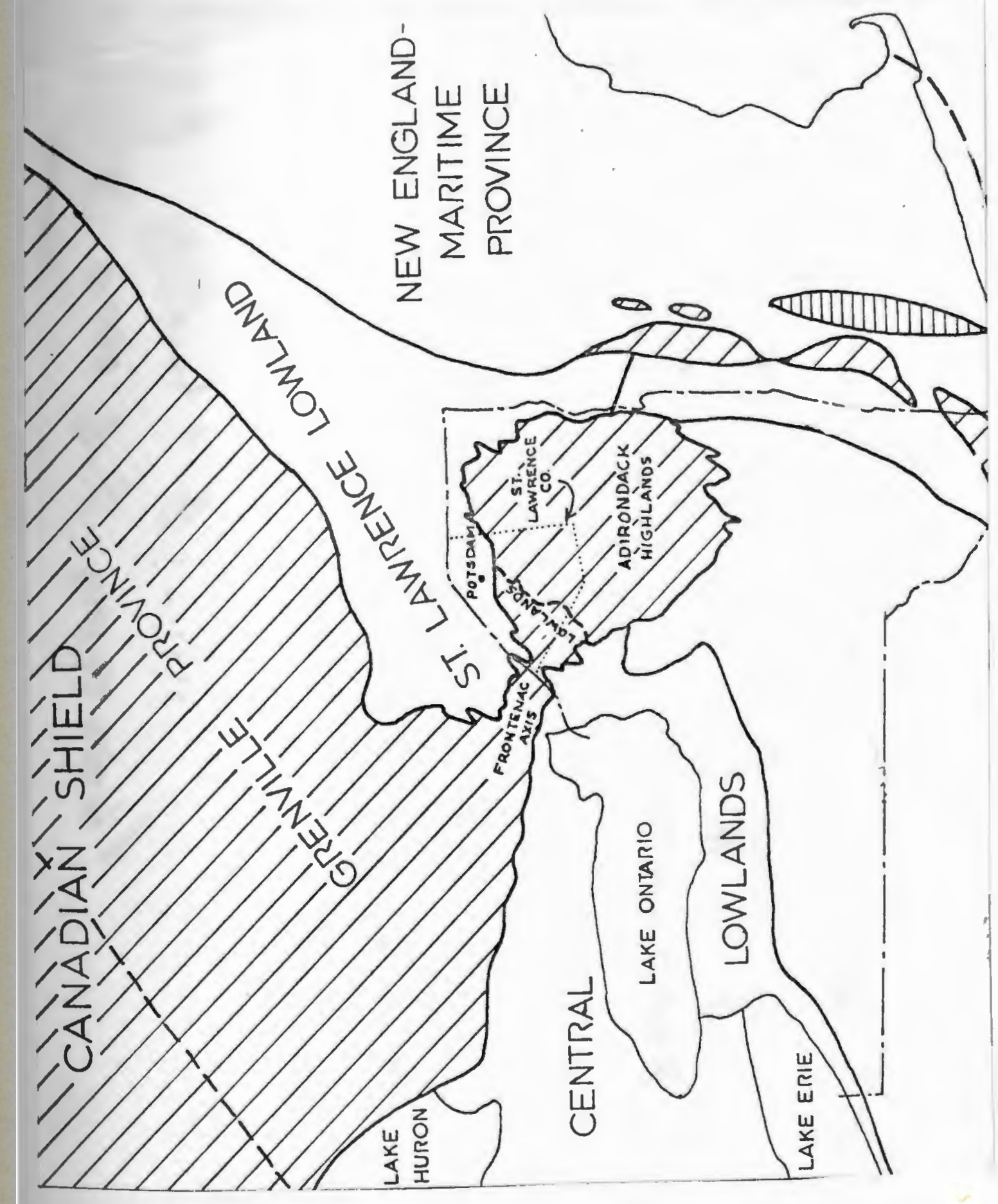


metamorphic rocks with local pockets of Quaternary glacial and alluvial deposits (flgure 3). The Grenville consists of a thick metasedimentary sequence of quartzites, gneisses, marbles, and amphibolites (Buddington,1939; Engel and Engel, 1953). Franitic rocks are extensively injected throughout the Grenville sequence. Approximately $75 \%$ of the known Grenville is composed of marble. A large section of the area is dominated by bodies of varying size composed of syenite gneiss. Such rocks are dark in color, tisplay a granitic texture, and are composed of quartz, hornblende, green feldspar, and pyroxene (VanDiver , 1971).

The northern portion of the study area is dominated by Paleozoic sediments consisting of sandstones and limestones. Resting unconformably upon the Precambrian basement lies the Cambrian Potsdam Sandstone. ordovician strata consisting of sandy dolomitic limestones, dolomitic sandstones, and sandy calcareous dolomites lie above the Potsdam Formation. Ordoviclan strata include the Chazy and Beekmantown Groups and Theresa nolomite.

A generalized stratigraphic section is shown in figure 4.

\subsection{Iectonics}

The dominant regional trends of structural features and gravity anomalies are 111 ustrated in figure 5. As 
Figure 3

Generalized geologic map of the St. Lawrence River Vall From: Kirchgasser and Theokritoff (1971) 


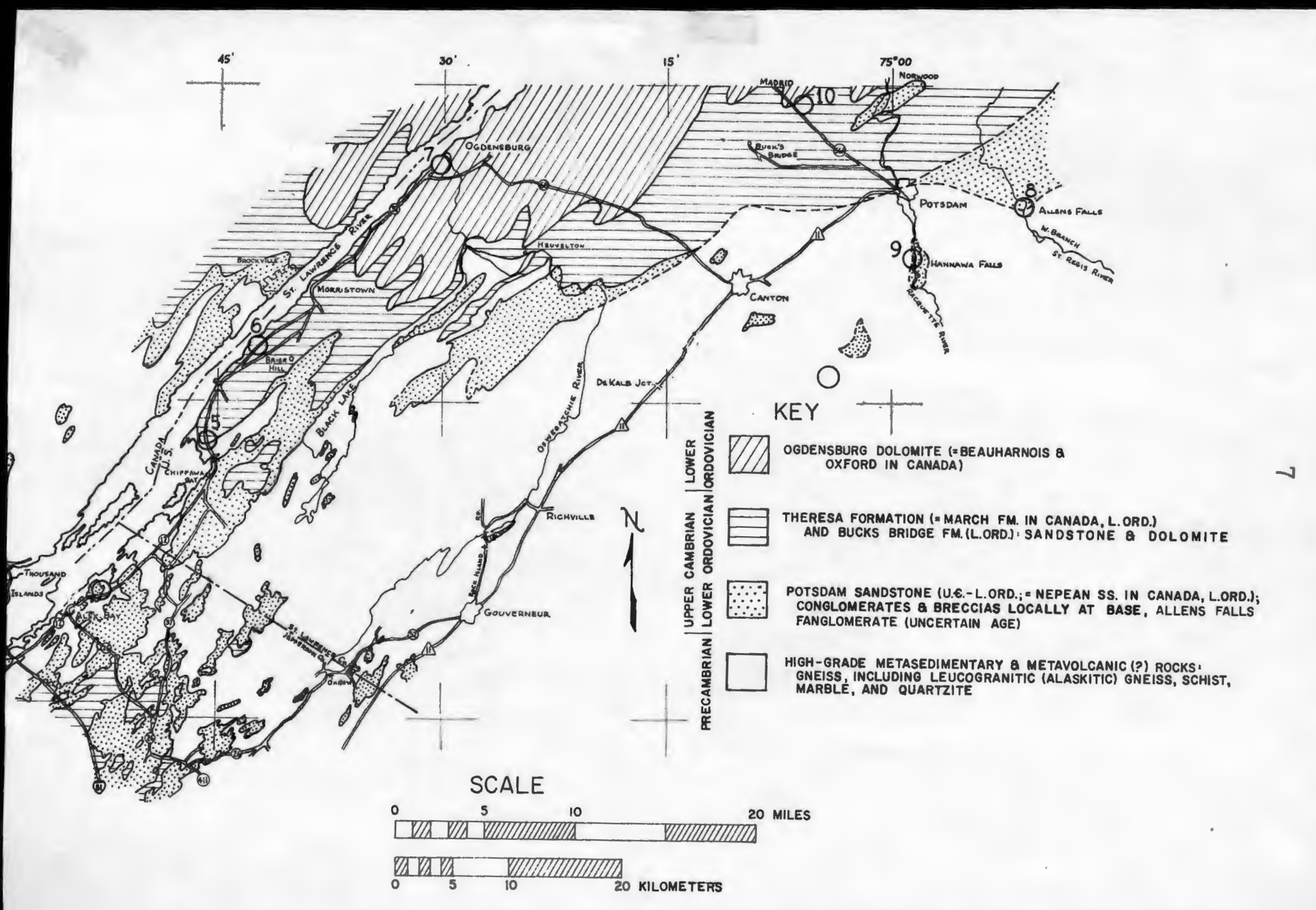


Figure 4

Generalized stratigraphic section of St. Lawrence River Valley.

From: Kirchgasser and Theokritoff (1971) 


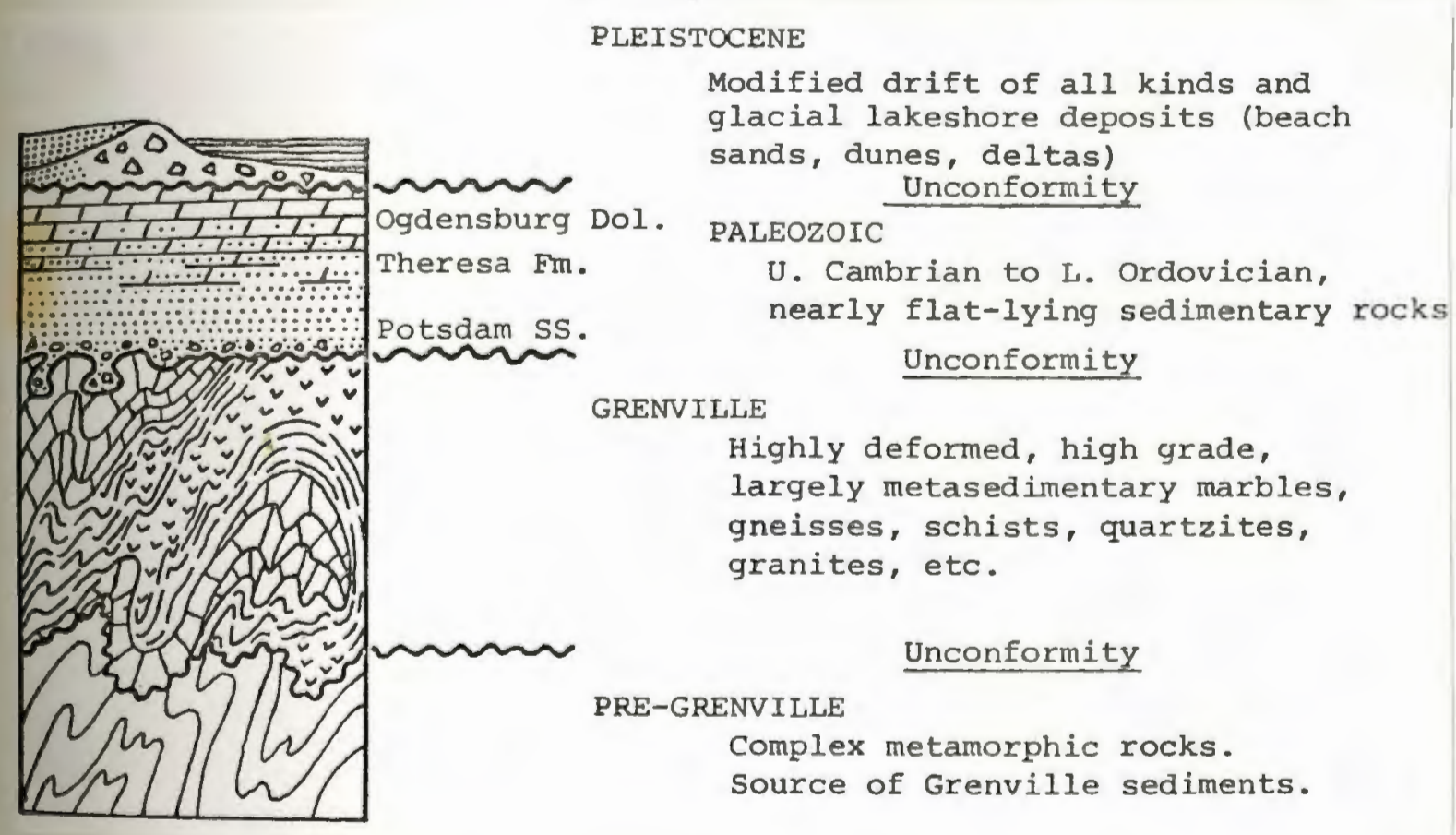


Figure 5

Gravity anomalies and structural features of the northeastern United States.

From: Kane, et. al (1972) 


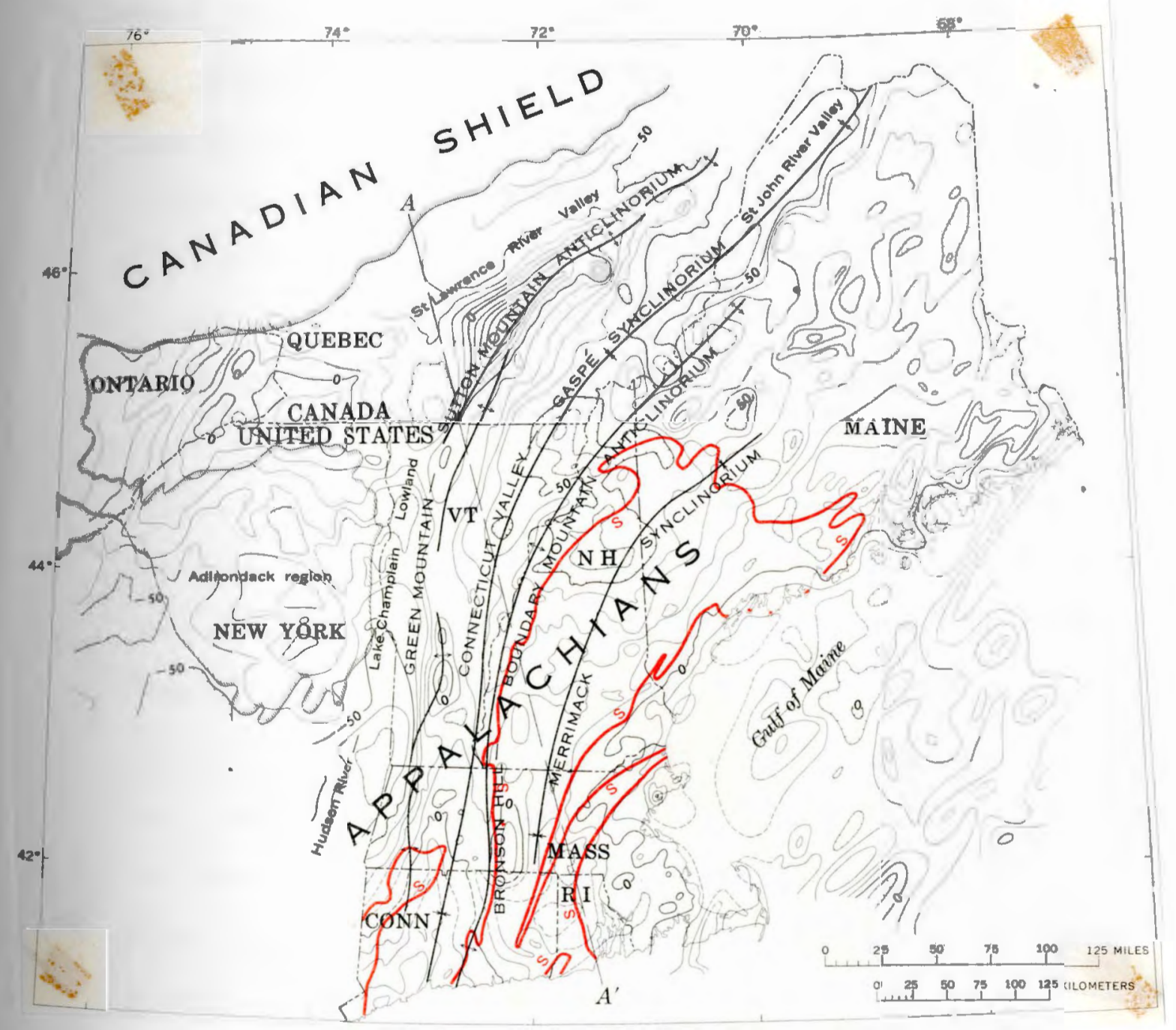


can be observed on the map, both trends are directed in a southwest-northeast fashion.

An extensive fault system has been postulated along; the St. Lawrence River Valley (Kumarapeli and Saul1,1966). As illustrated in figure 5 , the postulated fault system displays two main branches; one extending westward along the Ottawa Graben, and the other extending southward through the Champlain Lowlands. The St. Lawrence Rift system is a supposed tensional graben and includes the Ottawa, Champlain, and St. Lawrence Valleys. This system extends eastward to the Cabot Strait and varies in width from 15 to 30 miles. Major zones of complex faulting, usually gravity or normal faults with the downthrown side towards the center of the rift, bound the system. Displacements on the order of $.5 \mathrm{~km}$ are typical on the major faults. The age of the faulting is believed to be Late Cretaceous or Early Tertiary (Kay, 1942; Dufrensne, 1948). However, glassy pseudotachylite from one of the faults comprising the system has given a K-AR radiometric age of $975+45 \mathrm{~m} \cdot \mathrm{y}$. (Philpotts and Miller,1953). This indicates that some of the faults date well into the Precambrian.

\subsection{Seismicity}

Unlike the west coast, the seismicity of the east coast of the U. S. can not be entirely explained by fault zones displaying a distinct surface morphology 
Figure 6

Location map of St. Lawrence Rift System. From: Kumarapeli and Saull (1966) 


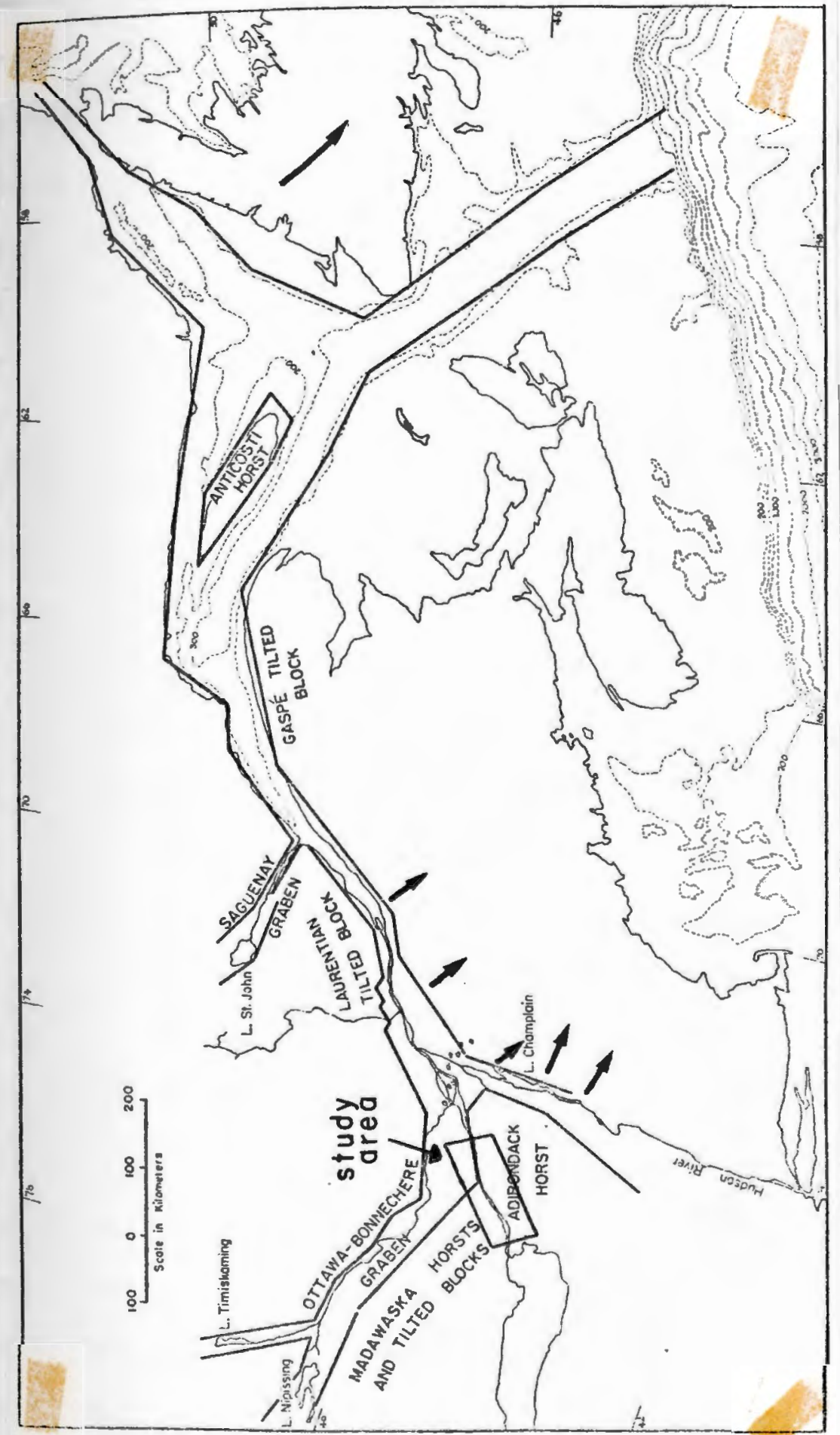


(Woollard,1959). The St. Lawrence Valley is located within the confines of a lithospheric plate and is regarded as stable relative to regions of higher seismiclty such as Alaska, California, and even the Basin and Range Provinces. Historically, the region is one of moderate seismicity with infrequent earthquakes of a destructive nature ( Smith, 1962, 1966). Twenty-five earthquakes of intensity $V$ or greater have been reported since the 1700 's. Eplcenters of earthquakes in the region with intensities of $V$ or more are shown in figure 7. Pertinent information on major shocks has been compiled in table 1 .

The spatial distribution of earthquakes in eastern North America has been commented on by several authors and a number of different trends have been proposed (Smith, 1967: Woollard, 1969; Fox, 1970). One such trend, proposed by Diment, et al. (1972), connects the St. Lawrence River Valley, Blue Mountain Lake, and White Mountain seismic zones to a large lineament joining the Kelvin Seamount chain (figure 3 ). As illustrated in figure 5, the dominant trends of structural surface features and gravity anomalies in the region are directed in a southwest-northeast fashion, cross-cutting the proposed trend of frequent seismicity. This suggests that the proposed seismic trend can not be directly correlated with geologic surface trends. Hence, the foci of earthquakes in the region may lie along structures not visible at the 


\section{Figure 7}

Epicenter location map of Intensity $V+$ earthquakes in New York and adjacent areas.

From: Dames and Moore (1973)

\section{REGIONAL EPICENTER MAP

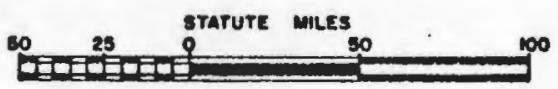

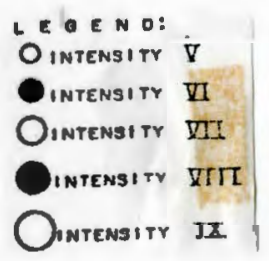

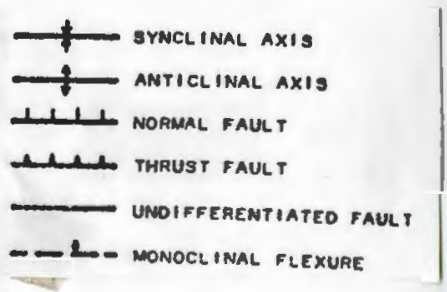




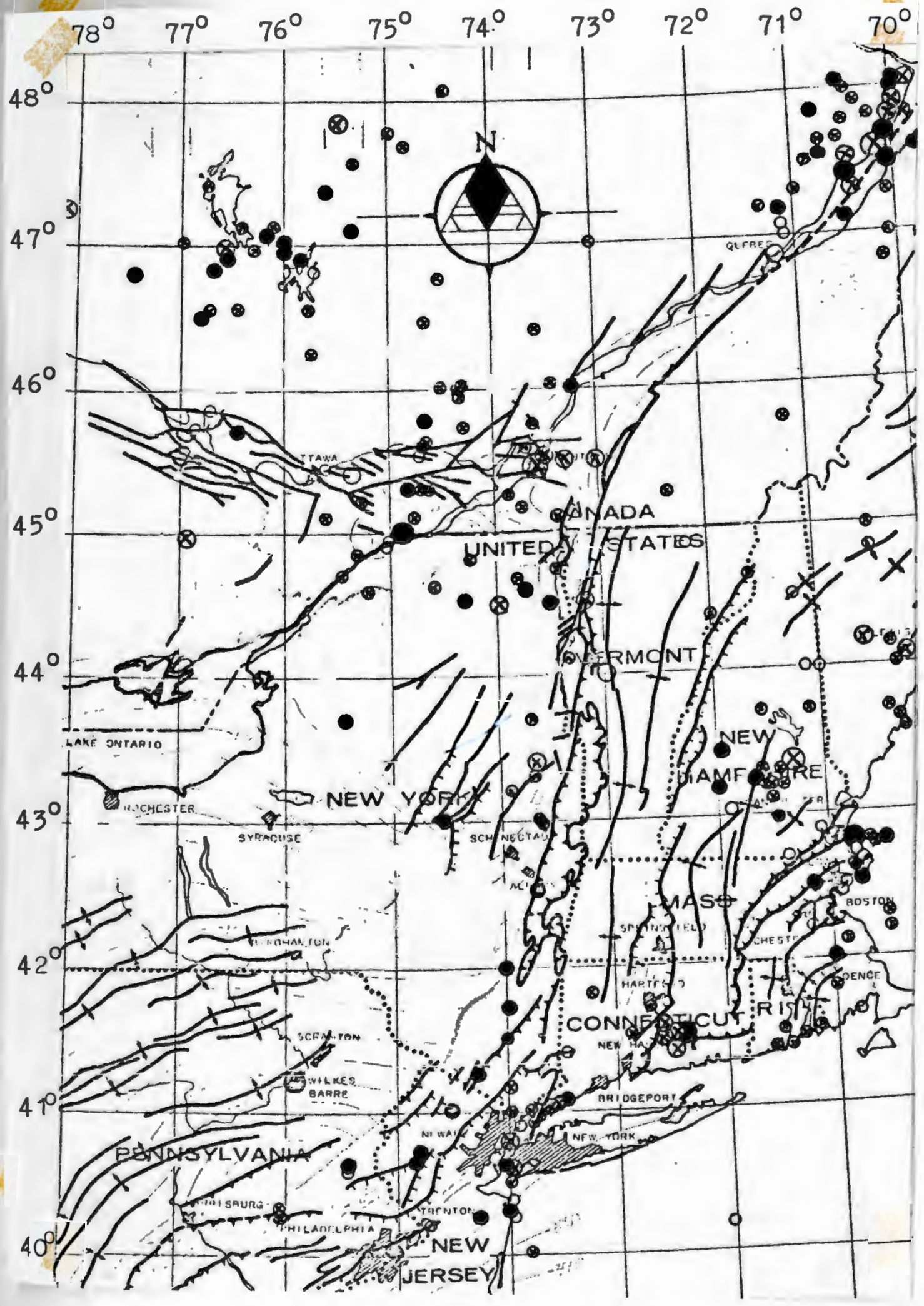


留|总

용.

8
8
0
0

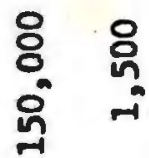

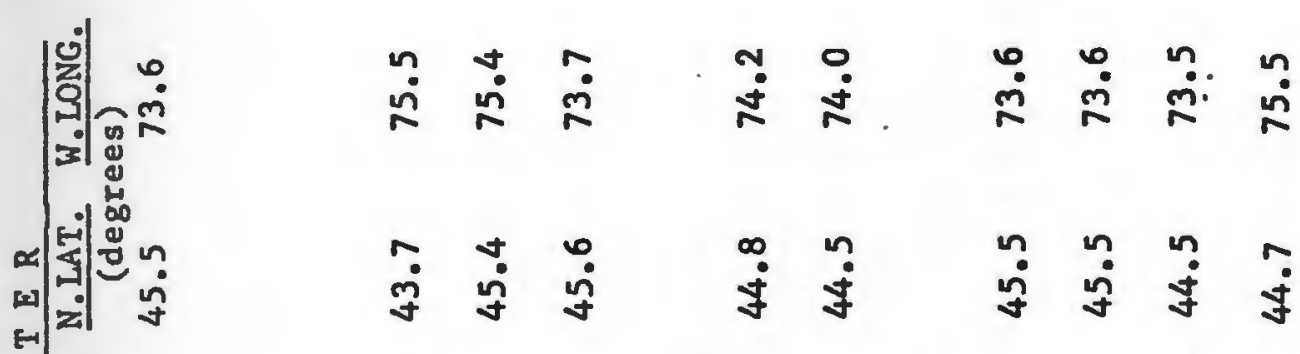

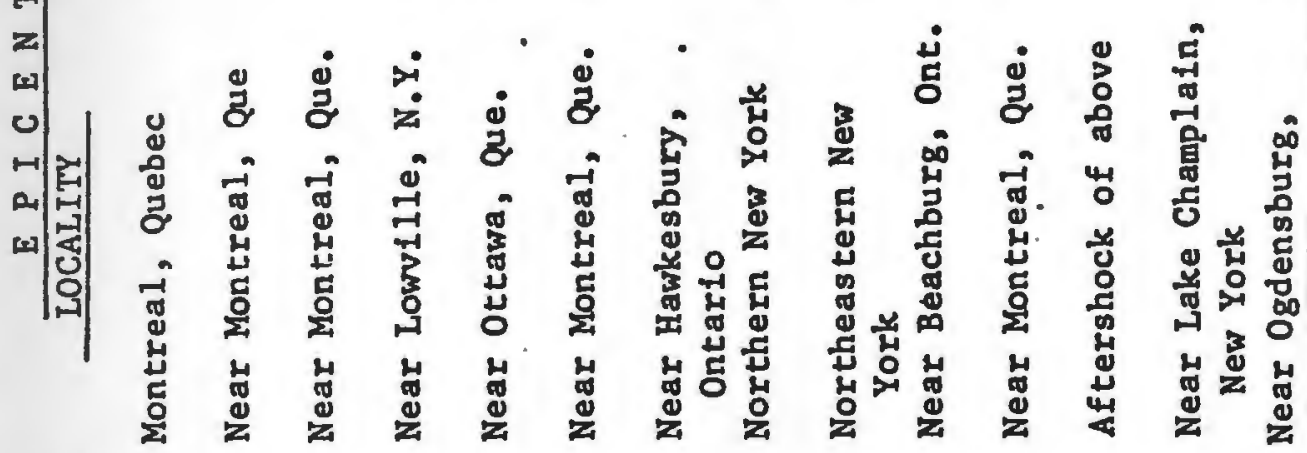

事事

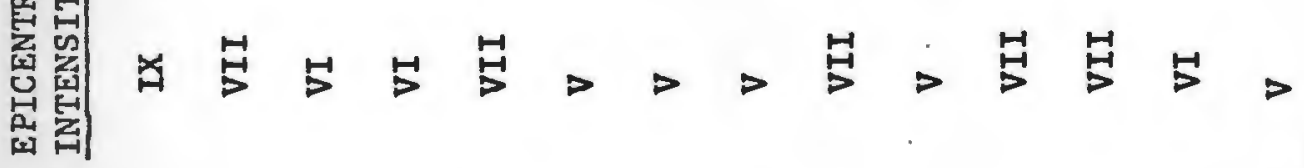

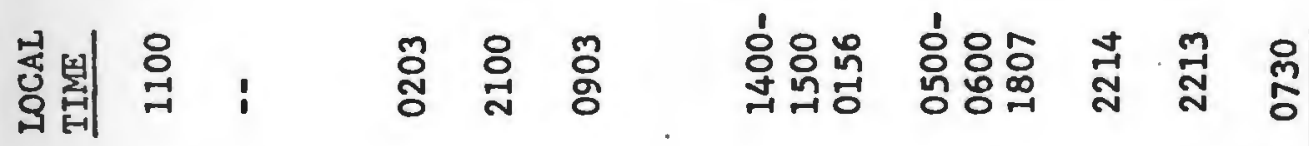
익

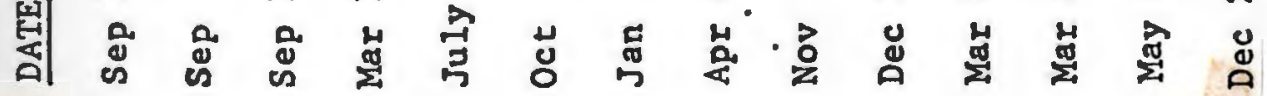

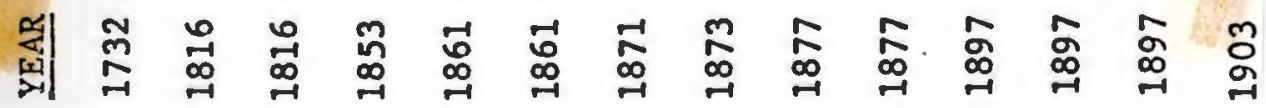


Table 1 cont.

\begin{tabular}{|c|c|c|c|c|c|c|c|c|}
\hline \multirow{3}{*}{$\begin{array}{l}\text { YEAR } \\
1908\end{array}$} & \multirow{2}{*}{\multicolumn{2}{|c|}{ DATE }} & \multirow{3}{*}{$\begin{array}{l}\text { LOCAL } \\
\text { TIME } \\
1542\end{array}$} & \multirow{3}{*}{$\begin{array}{l}\text { EPICENTRAL } \\
\text { INTENS ITY } \\
\\
v\end{array}$} & \multicolumn{3}{|c|}{$E$ P I C E N T E R } & \multirow{2}{*}{$\begin{array}{l}\text { PERCEPTIBLE } \\
\text { (square miles) }\end{array}$} \\
\hline & & & & & LOCALITY & $\frac{\text { N.LAT }}{\text { (d }}$ & $\frac{\text { W. LONG. }}{\text { ees) }}$ & \\
\hline & June & 16 & & & Cornwall, Ontario & 45.1 & 74.8 & \\
\hline 1913 & Apr & 28 & 1929 & $\mathbf{V}$ & $\begin{array}{l}\text { Near Iroquois, } \\
\text { Ontario }\end{array}$ & 44.9 & 75.3 & \\
\hline 1914 & Feb & 10 & 1331 & VII & $\begin{array}{l}\text { West of Lanark, } \\
\text { Ontario }\end{array}$ & 45 & 76.9 & 200,000 \\
\hline 1917 & May & 22 & 0400 & IV-V & $\begin{array}{l}\text { St. Lawrence Valley, } \\
\text { Quebec }\end{array}$ & 45 & 75 & 15,000 \\
\hline 1922 & Dec & 8 & 1624 & $\mathbf{V}$ & Near Canton, New York & & $\cdot$ & \\
\hline 1924 & July & 14 & 1910 & $\nabla-V I$ & $\begin{array}{l}\text { North of Shawville, } \\
\text { Quebec }\end{array}$ & 45.7 & 76.5 & \\
\hline 1928 & Mar & 18 & 1020 & $V-V I$ & Saranac Lake, N.Y. & 44.5 & 74.3 & 12,000 \\
\hline 1934 & Apr & 14 & 2158 & $V-V I$ & $\begin{array}{l}\text { Adirondack Mountains, } \\
\text { New York }\end{array}$ & 44.7 & 73.8 & 8,000 \\
\hline 1942 & May & 20 & 0719 & $\mathbf{V}$ & Near Kilmar, Quebec & 45.8 & 74.7 & \\
\hline 1944 & Jan & 22 & 1655 & $\mathbf{V}$ & $\begin{array}{l}\text { Northwest of Renfrew, } \\
\text { Ontario }\end{array}$ & 45.8 & 76.8 & 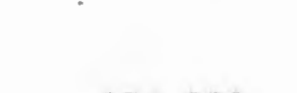 \\
\hline 1944 & Sep & 5 & 0039 & VIII & $\begin{array}{l}\text { Cornwal1, Ontario- } \\
\text { Massena, New York }\end{array}$ & 44.9 & 74.9 & 175,000 \\
\hline 1944 & Sep & 5 & 0351 & $V-V I$ & Aftershock of above & 44.9 & 74.9 & \\
\hline 1944 & Sep & 9 & 1825 & $\begin{array}{l}\text { VII- } \\
\text { VIII }\end{array}$ & Aftershock of above & 44.9 & 74.9 & \\
\hline 1964 & Mar & 29 & 0416 & v & Massena, New York & 44.9 & 74.9 & \\
\hline
\end{tabular}


Figure 8

Seismicity of northeasterm North America 1928-1959 and location of the Kelvin Seamount Trend. From: Smith (1966) 


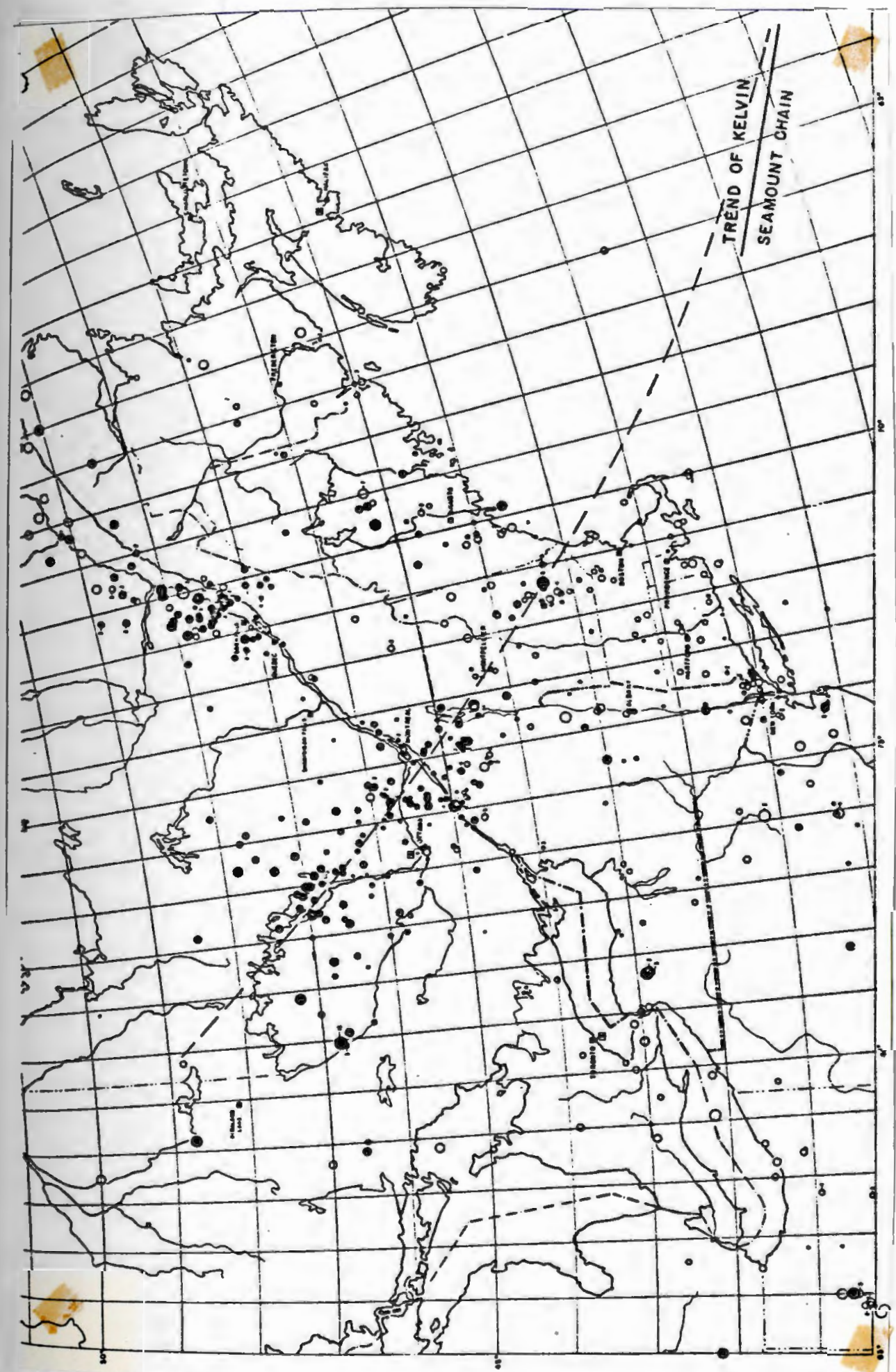


surface.

This is further suggested by a comparison of the known geologic structure with the epicenter distribution (figures 3,10, and 11). The St. Lawrence River Valley lies dominantly within region ' $B$ ' where epicentral concentration lies on unrecognized and/or concealed faults. A comparison of the geologic structure with the earthquake distribution suggests that the earthquake focal zones may: 1) lie along unmapped surface faults, 2) correlate with subsurface fault structures, or 3) not be fault-related.

Sbar and sykes (1973) contend that a contemporary east-west compressive stress predominates along the east coast of North America. This observation is based largely on determinations of the principle stress from in situ measurements by the hydrofracturing and overcoring techniques. In addition, focal mechanism solutions of intraplate earthquakes yield the same east-northeast maximum compressive stress (Sykes and Sbar, 1973). However, the cause of the stress is unknown as it relates to the east coast. This stress, directed along unrecognized surface or subsurface zones of weakness, may explain the moderate seismicity of the region (Albert, et al.,1976).

\section{Gravity Investigation}


Figure 9

Geologic structure of New York and adjacent areas. After: Hadley and Devine (1974) 


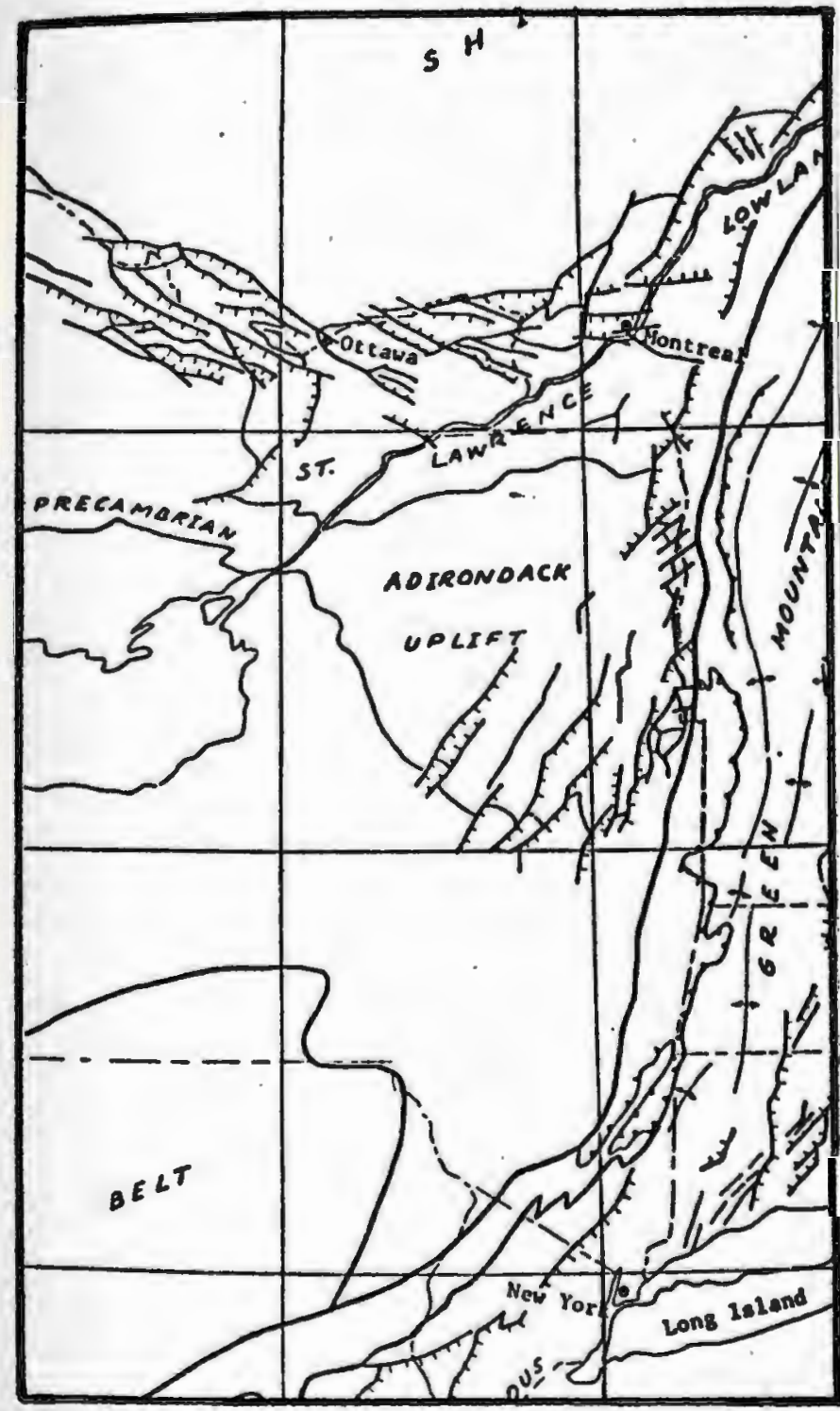

High-angle fault

Hachures on downthrown slde where known; arrows show relative movement. Dashed where approximately located or covered by younger deposits 
Figure 10

Distribution of earthquake epicenters in New York and adjacent areas for the period 1800-1972. After: Hadley and Devine (1974) 


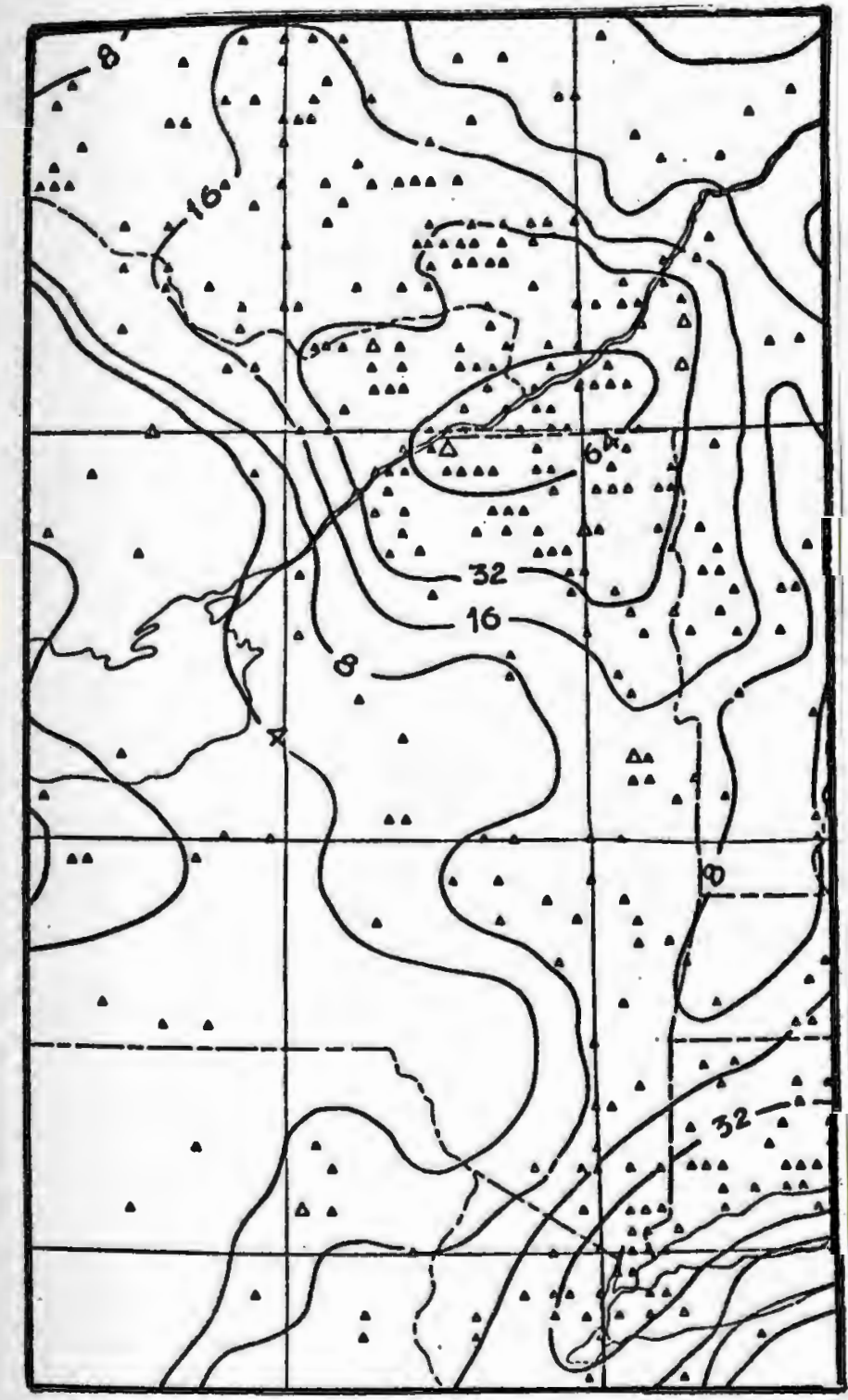

\section{Yodifled Mercalli Intensity}

III to VI

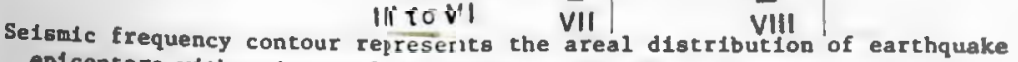
epicenters with epicentral intensity of MM III and greater, as Indicated by the total number per $10^{4} \mathrm{~km}^{2}$ during the period 1800-1972. Contour tntervals are $0-4$, more than 4 but less than 8 , more than 8 but less than 16 , wore than 16 but less than 32 , more than 32 but less than 64, and more than 64. The contours are considerably generalized and are show only as for estimating region of selsmic boundaries. 
Figure 11

Relationship of structural features to epicenter distribu in New York and adjacent areas. After: Hadley and Devine (1974) 


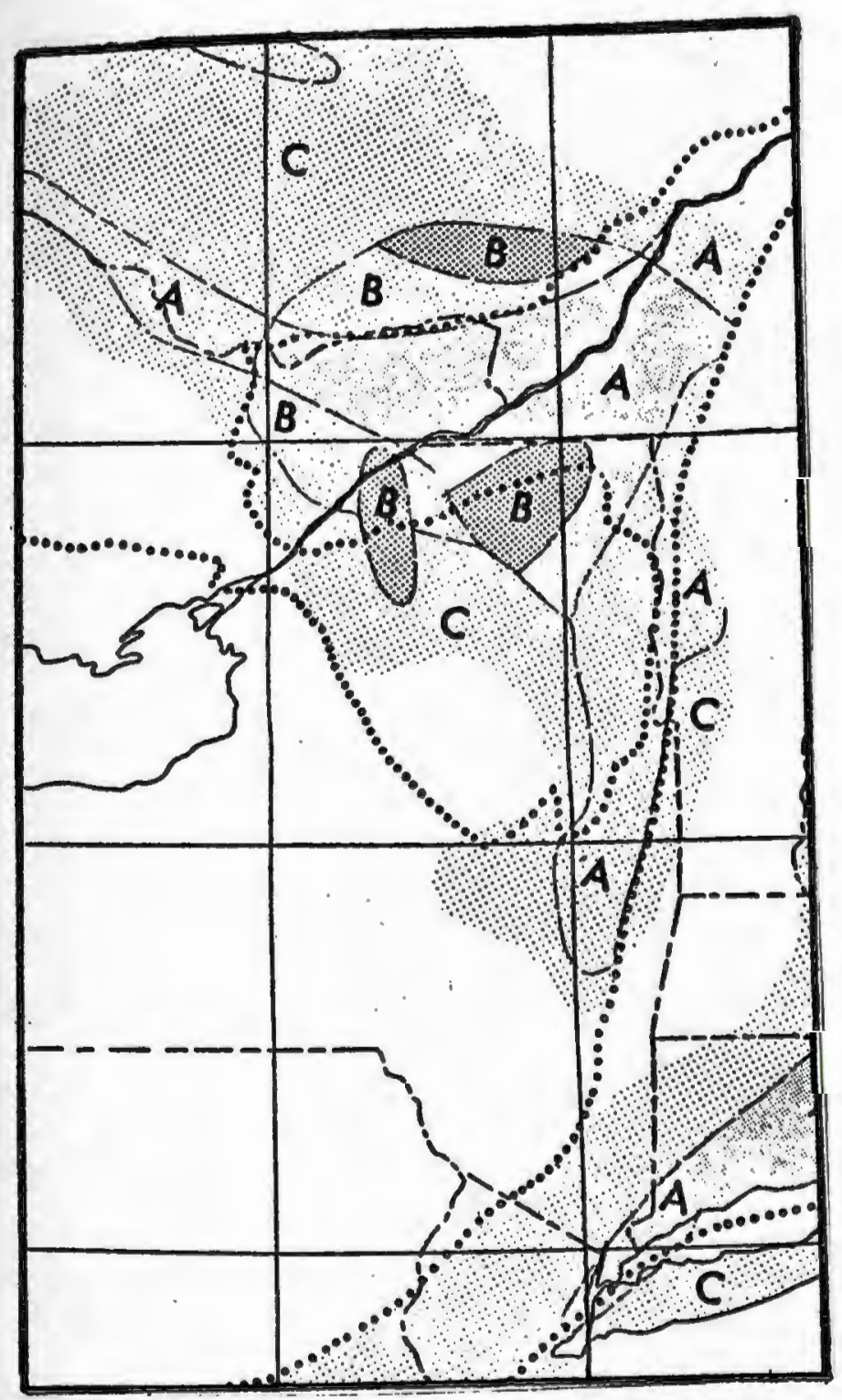

Aiknown faults assoclated with epicentral alignment Biepicentral concentration on unrecognized and/or concealed faults

Cs No relation of epicentere with known faults 
The gravity survey conducted by Albert, et al. (1974) entailed the occupation of over $17 n 0$ gravity stations in the St. Lawrence River Valley within the area shown in figure 1. Gravity stations established during this survey were spaced approximately two miles apart. A field network of ten base stations was established in the survey area through looping, (ilettleton, 1940). This network was tied to the Canadian gravity network in Ottawa (figure 12).

All gravity readings were made with the lorden Gravimeter. The drift of this apparatus was assumed to be linear between successive readings at the hase. Drift curves were plotted and the corrected gravity values were obtained from the resulting curves.

\subsection{Reduction of Gravity Data}

The gravity method allows the user to measure horizontal changes in the Earth's gravitational field produced by variations in rock density. A gravity anomaly is the difference between a corrected gravity value and a theoretical value of gravity on the ellipsoid depending on the latitude of the station. To find this anomaly, several corrections must be applied to the observed gravity value at the station for various influences on the measured value. Three corrections were applied to the data in this survey: 1) the free-air correction, 2) the latitude correction, and 3) the Bouguer correction. A terrain correction 
Figure 12

Location of gleavity base stations in St. Lawrence Ritver Valley. 


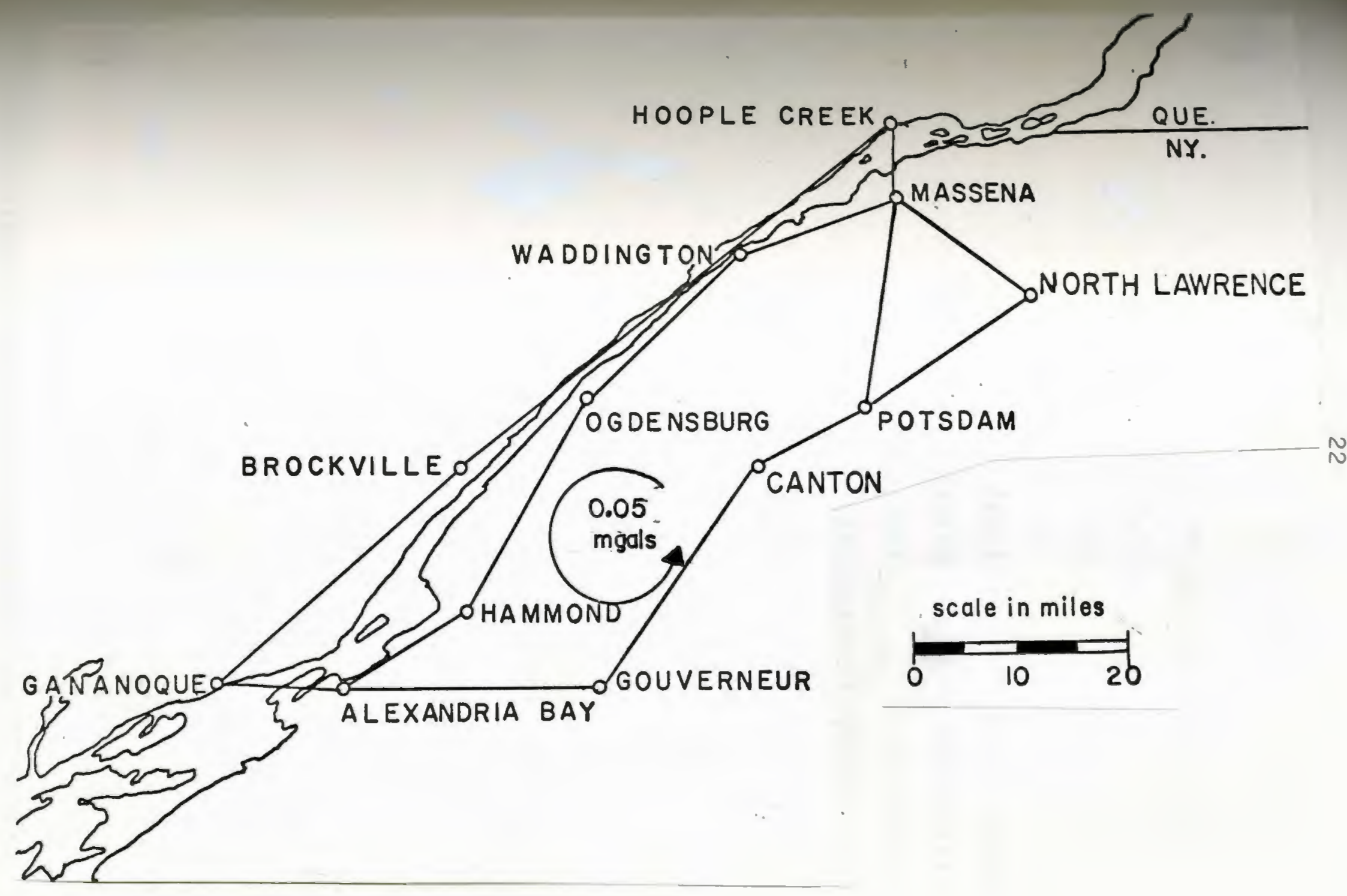


was not calculated due to the small variation in topography.

The following discussion on the types of anomalies and reductions is after Dobrin (1960).

\subsection{Observed Gravity}

The observed gravity $\left(g_{0}\right)$ is measured in scale divisions at each gravity station with the gravimeter. The value obtained at the station is then changed to milligals by multiplying by the callbration factor of the meter. The gravity at each station is determined by the difference in gravity between a base station, where the value of gravity is known, and that station.

\subsection{Theoretical Gravity}

The theoretical gravity $\left(g_{+}\right)$was calculated from latitudes measured to 0.1 minute of arc. The International Gravlty Formula of 1930 was used in calculating the theoretical values, where:

$$
g t=978.049\left(1+0.0052884 \sin ^{2} \theta-0.000059 \sin ^{2} 2 \theta\right)
$$

\subsection{Free-air Correction}

A free-air correction is made to allow for the decrease in the attraction of the Earth with increasing distance of a station from the center of the Earth. A correction of $.09405 \mathrm{milligals}$ per foot is the accepted value for the theoretical vertical gradient of gravity based on the international ellipsold. 


\subsection{Bouguer Correction}

The Bouguer correction is an attempt to account for the attraction of material between sea level and the level of the gravity station. This attraction is approximated by an infinite slab with thickness equal to the elevation of the gravity station and an average density of $2.67 \mathrm{gms} / \mathrm{cc}$. The value 2.67 is in agreement with the average density of outcropping rock in the study area. The formula $.01276 \mathrm{hp}$ represents the attraction of this slab where ' $h$ ' is the thickness in feet and ' $p$ ' is the average density of the slab.

\subsection{Terrain Correction}

The terrain correction is an attempt to take into account the deviance between the Earth's surface and the assumption of the infinite slab used in the Bouguer correction.

Due to the flat-lying nature of the St. Lawrence Valley, the terrain correction was deemed unnecessary.

\subsection{Iypes of Anomalies}

The type of anomaly used depends upon the corrections made on the gravity data. The anomaly is defined as the difference between the calculated value and measured value of gravity at each station.

The free-air anomaly results from correcting for the vertical decrease of gravity with an increase in elevation. The following formula is used in 
calculating the free-air anomaly:

$$
\text { F. } A_{0}=g_{0}-\left(g_{+}-F\right)
$$

where

$g_{0}$ represents the observed gravity

$g_{+}$represents the theoretical gravity

$F$ represents the free-air correction

The Simple Bouguer Anomaly accounts for both the elevation of the station and the attraction of an infinite slab of assigned density between the station and sea level. The following formula is utilized in calculating the Simple Bouguer Anomaly:

$$
S \text { B } A=g_{0}-\left(g_{+}-F+B\right)
$$

where

B represents the Bouguer correction

\subsection{Data Analysis}

\subsection{Introduction}

Due to the non-utilization of the terrain correction, the Simple Bouguer Anomaly was employed in all analyses performed in this study. The simple Bouguer Anomaly represents the combined effects of deep-seated and near-surface geological structures. In an area such as the St. Lawrence River Valley, where earthquake-related structures may occur at varying depths, the simple Bouguer map does not allow for the distinction among anomaly-producing bodies dependent on depth. Anomaly-producing structures, possibly related 
to earthquake focal zones, may be masked by unrelated structures. Hence, a method of separating the structures of interest from overlying. inactive structures must be sought.

Dobrin (1960) has demonstrated the usefulness of different analytical techniques applied to gravity data in areas where the structures of interest are deep-seated. One long-established relationship between the observed gravity and the depth to the center of the structure is the so-called 'half-width'. This relationship is illustrated in figure 13 .

A buried sphere with radius ' $R$ ' and depth to center ' $Z_{C}^{\prime}$ is shown with its corresponding gravity profile. Gmax represents the maximum value of gravity over the sphere. The value of ' $x$ ' where Gz is Gmax/2 is called the half-width and is designated as ' $x y_{2}$ '. The half-width is related to the depth to center of a structure by the formula:

$$
z_{C}=x \frac{1}{2}
$$

This method allows for the delineation of the maximum depth of an anomaly-producing structure and is an important relationship when considering filtering techniques. By varying the level of observation, the depth to the center of a structure will change with a corresponding change in the half-width value. However, the gravity profile produced by a structure is dependent on depth, vertical and horizontal extent, and 
Figure 13

The 'half-width' relationship in interpretation of gravit data. 


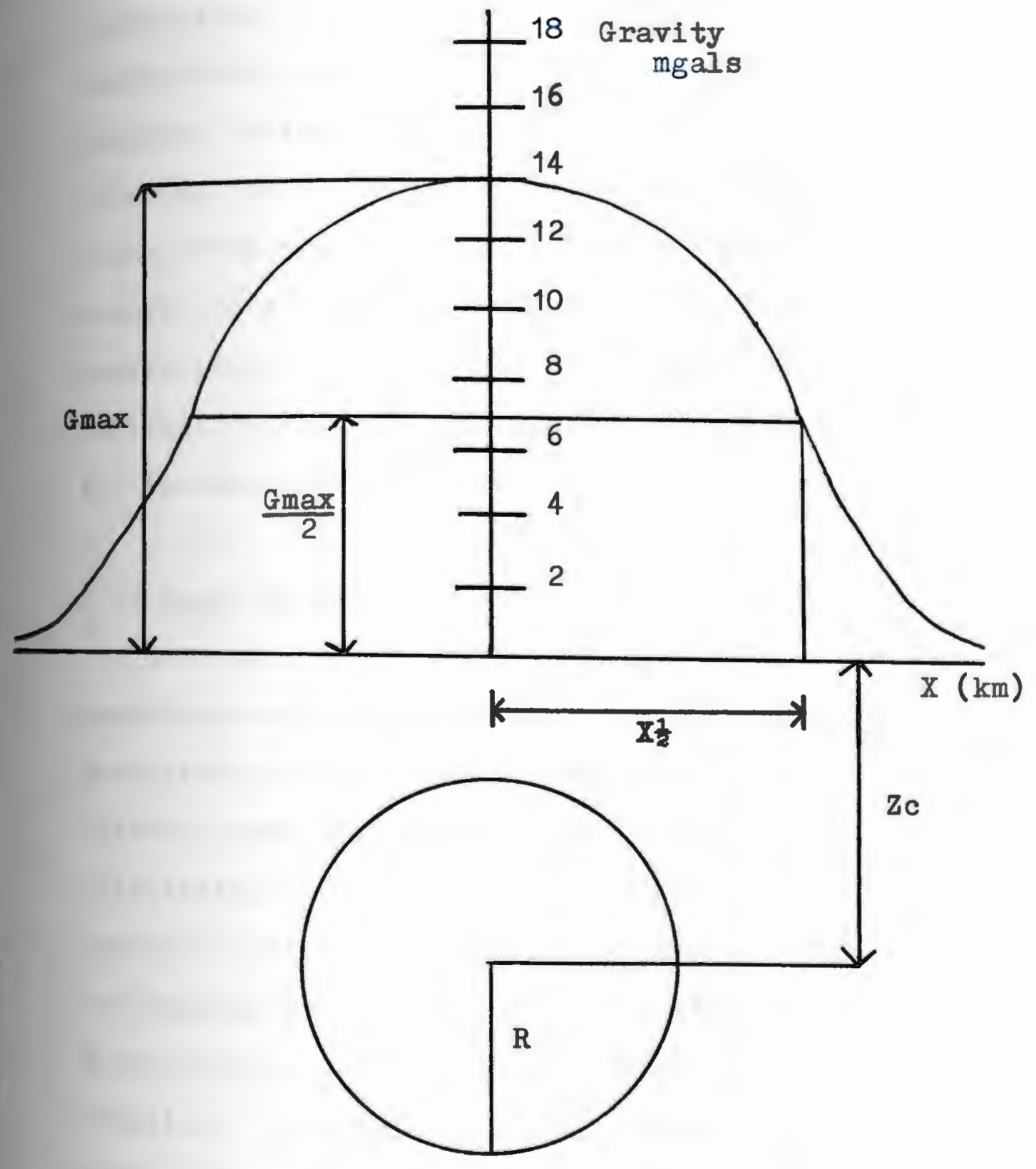


density contrast. In addition, an anomaly may represent a combination of effects produced by different structures. By changing the level of observation and applying density values that are geologically realistic, a three dimensional view of the geologic structure in an area may be obtained, thus allowing for the separation of anomaly-producing bodies from different depths. These methods include the upward continuation, second derivative, and downward continuation of potential fields. Such methods were applied to the Simple Bouguer Gravity data from the St. Lawrence River Valley.

\subsection{Basic Formulae}

Numerous procedures for the calculation of the upward-downward continuation and first-second derivative methods are found in the literature. Peters (1949) developed the first practical approach for calculating the upward and downward continuation of potential fields. Trejo (1954) adapted Peters' method to analyze gravity data. Elkins (1951), Henderson and Zietz (1949), and Rosenbach (1953) have all developed practical approaches to the calculation of the second derivative of potential fields.

Nettleton (1954) has made a comprehensive review of the various analytical procedures applied to gravity and magnetic data. Nettleton points out the merits and disadvantages of each system and concludes that the 
choice of a system for calculation must be based on the particular problem encountered.

Henderson (1060) conducted tests on the various procedures for calculation of the upward-downward continuation and first-second derivative methods by computer analyses of practical and theoretical data. This study confirmed the observations made by Nettieton as to the inadequacies of each available method. As a result of Henderson's study, a method of computation applicable to a wide range of problems was developed. This method was used in the current study.

In essence, the continuation and derivative methods allow for the enhancement of anomalies produced by structures at varying depths. This is accomplished by calculating the gravity field at various intervals above and below the plane of observation through a surface integration applied to the observed field. The following explanation is after the works of Peters (1949) and Henderson (1960).

\subsection{Upward Continuation of Gravity}

Consider a set of gravity data $g\left(x^{\prime}, y^{\prime}\right)$ on the plane $z=0$ (figure 14). In order to calculate the values $g(x, y)$ on a plane above the surface, $z$ being positive dowhwards, the following surface integral is, used:

$$
g_{z}(x, y, z)=\frac{-z}{2 \pi} \int_{-\infty}^{+\infty} \int_{-\infty}^{+\infty} \frac{g_{z}\left(x^{\prime}, y^{\prime}, 0\right) d x^{\prime} d y^{\prime}}{\left[\left(x^{\prime}-x\right)^{2}+\left(y^{\prime}-y\right)^{2}+z^{2}\right]^{3 / 2}}
$$


Figure 14

The upward continuation of gravity. 

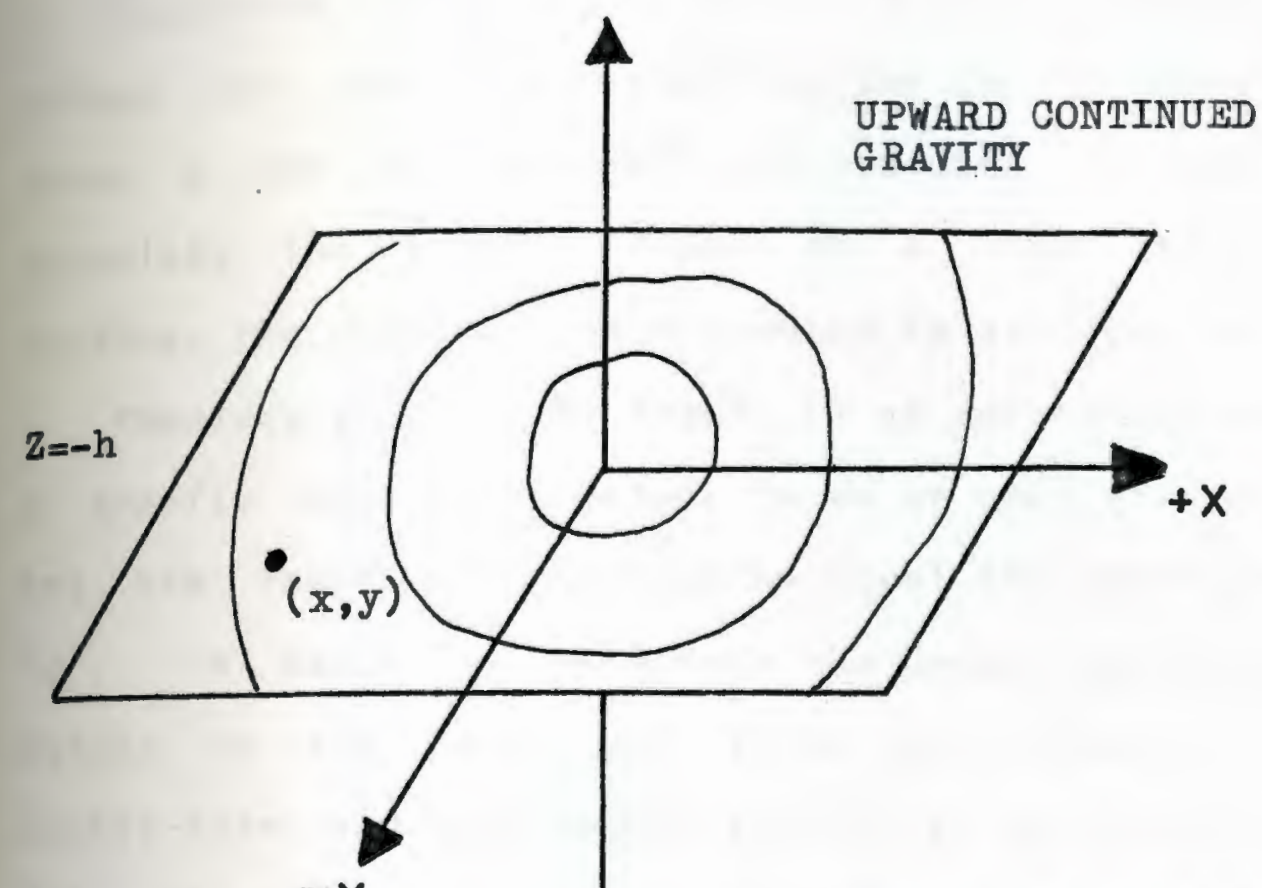

OBSERVED GRAVITY

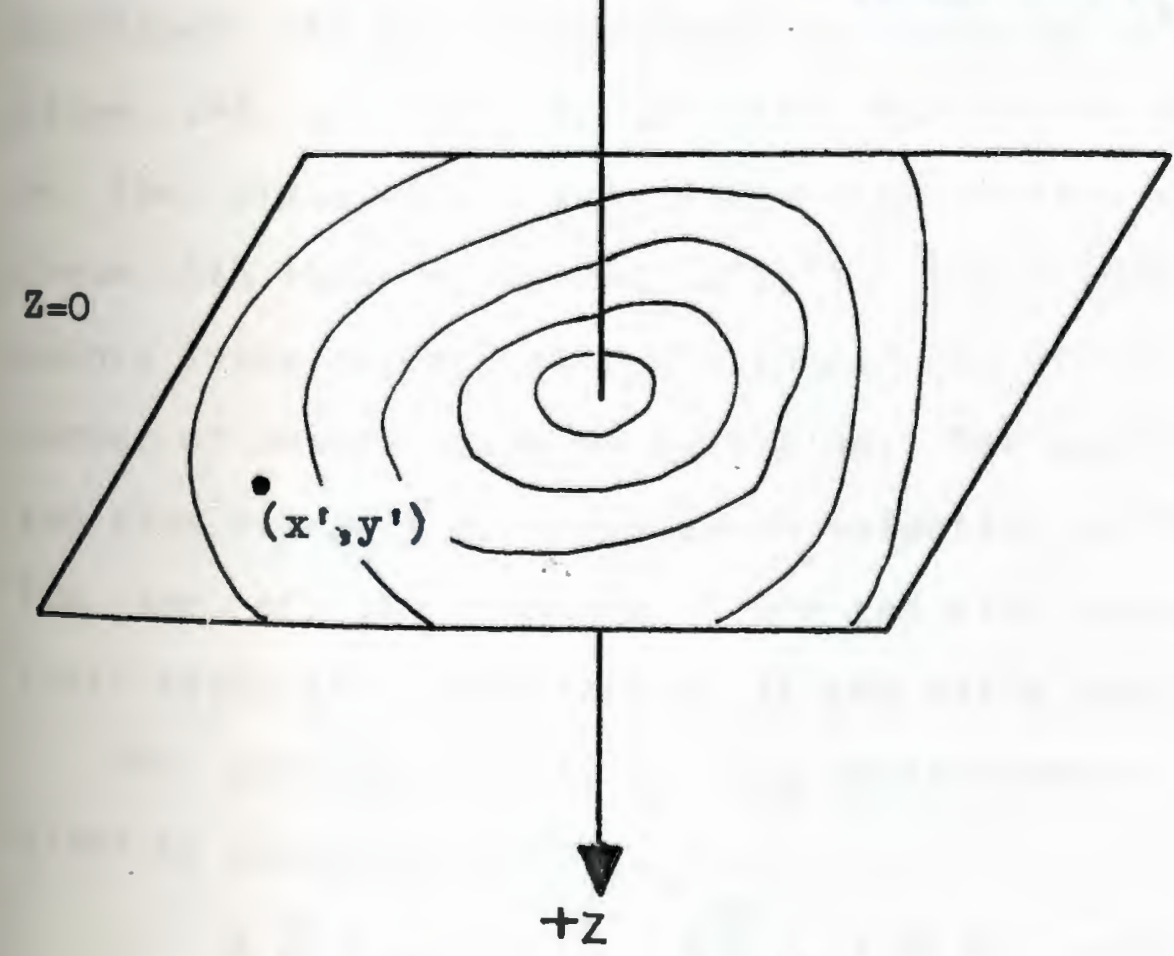


where the left side of the equation is the value of $g_{z}$ at coordinates $(x, y)$ in a plane above the surface.

Henderson (1960) has developed a method whereby the values for the upward continuation can be calculated given a set of observed gravity data. In order to calculate the gravity field on a plane above the surface, the data must be presented in gridded form.

Consider the grid of figure 15 as representative of a gravity map with values known at each grid point. Let the level of continuation equal the grid-spacing ' $m$ '. In order to calculate the upward continuation values on the plane $z=m \quad(z=-h$ in figure 14) a center-point and ring method is applied to the observed data at each grid point $\left(x^{\prime}, y^{\prime}\right)$. Let $g\left(x^{\prime}, y^{\prime}\right)$ represent the gravity measured at point $\left(x^{\prime}, y^{\prime}\right)$ on the plane $z=0$. In order to calculate the values of $g(x, y)$ on the plane $z=-h$ ten rings with varying radi $i$ are drawn with their center at $\left(x^{\prime}, y^{\prime}\right)$. The values for the points lying on each ring are summed and divided by the number of points lying on that ring. For each of these ten ring averages there exists a weighting coefficient. The sum of the products of the ten ring averages and their respective coefficients is the value $g(x, y)$

The working formula for the upward continuation as given by Henderson is: 7

$$
\Delta \Phi(-m) \approx \sum_{i=0}^{10} \Delta \overline{\bar{\Phi}}\left(r_{i}\right) K\left(r_{i}, m\right)
$$




\section{Figure 15}

Center-point and ring method of calculating the continuation of gravity fields.

From: Peters (1949) 

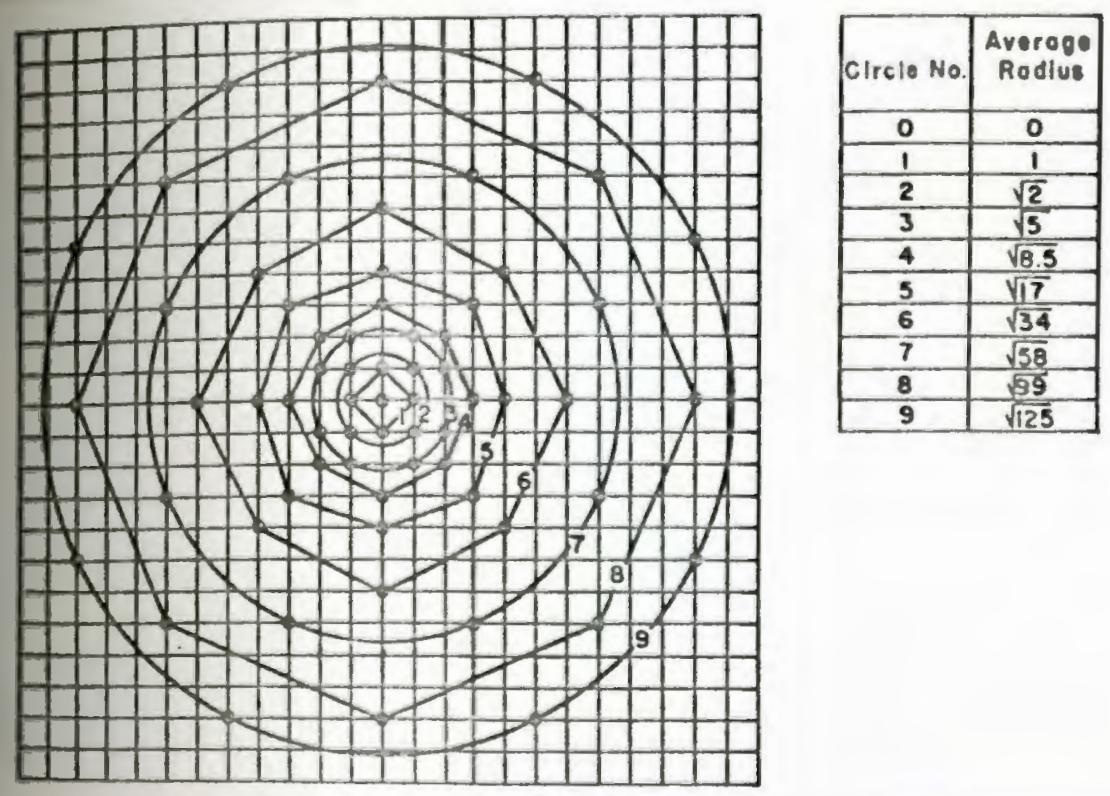
where $K(r i, m)$ is the set of coefficients that operate on the center value 0 and the ten ring averages $\Delta \Phi(r 1), \Delta \Phi(r 2), \ldots \Delta \Phi(r 10)$, in the computation of $\Delta \Phi$ at ' $m$ ' grid spacings above the plane. The continuous double integration has been replaced by a summation of ring averages, each multiplied by a weight function presented by the coefficients. The set of upward continuation coefficients used in this study are presented in figure 2 .

\subsection{Downward Continuation of Gravity}

The problem of the downward continuation of potential flelds was solved by Peters (1949) in a similar manner as that for the upward continuation. Consider a set of gravity data $g(x, y)$ on the plane $z=0$ (figure 16). In order to calculate the values of $f\left(x^{\prime}, y^{\prime}\right)$ on the plane $z=h, z$ being positive downwards, the following expression is used:

$$
g(x, y, 0)=\frac{1}{2 \pi} \int_{-\infty}^{+\infty} \frac{h F\left(x^{\prime}, y^{\prime}\right) d x^{\prime} d y^{\prime}}{\left[\left(x-x^{\prime}\right)^{2}+\left(y-y^{\prime}\right)^{2}+h^{2}\right]^{3 / 2}}
$$




$\begin{array}{lllllll}1 & \Delta^{\Phi}\left(r_{1}\right) & K\left(r_{1}, 1\right) & K\left(r_{1} 2\right) & K\left(r_{1}, 3\right) & K\left(r_{i}, 4\right) & K\left(r_{1}, 5\right) \\ 0 & \Delta^{\Phi}(0) & 0.11193 & 0.04034 & 0.01961 & 0.01141 & 0.00742 \\ 1 & \Delta^{\Phi}(1) & 0.32193 & 0.12988 & 0.06592 & 0.03908 & 0.02566 \\ 2 & \Delta^{\Phi}(\sqrt{2}) & 0.06062 & 0.07588 & 0.05260 & 0.03566 & 0.02509 \\ 3 & \Delta^{\Phi}(\sqrt{5}) & 0.15206 & 0.14559 & 0.10563 & 0.07450 & 0.05377 \\ 4 & \Delta^{\Phi}(\sqrt{8}) & 0.05335 & 0.07651 & 0.07146 & 0.05841 & 0.04611 \\ 5 & \Delta^{\Phi}(\sqrt{13}) & 0.06586 & 0.09902 & 0.10226 & 0.09173 & 0.07784 \\ 6 & \Delta^{\Phi}(\sqrt{25}) & 0.06650 & 0.11100 & 0.12921 & 0.12915 & 0.11986 \\ 7 & \Delta^{\Phi}(\sqrt{50}) & 0.05635 & 0.10351 & 0.13635 & 0.15474 & 0.16159 \\ 8 & \Delta^{\Phi}(\sqrt{136}) & 0.03855 & 0.07379 & 0.10322 & 0.12565 & 0.14106 \\ 9 & \Delta^{\Phi}(\sqrt{274}) & 0.02273 & 0.04464 & 0.06500 & 0.08323 & 0.09897 \\ 10 & \Delta^{\Phi}(\sqrt{625}) & 0.03015 & 0.05998 & 0.08917 & 0.11744 & 0.14458\end{array}$


Pigure 16

The downward continuation of gravity. 

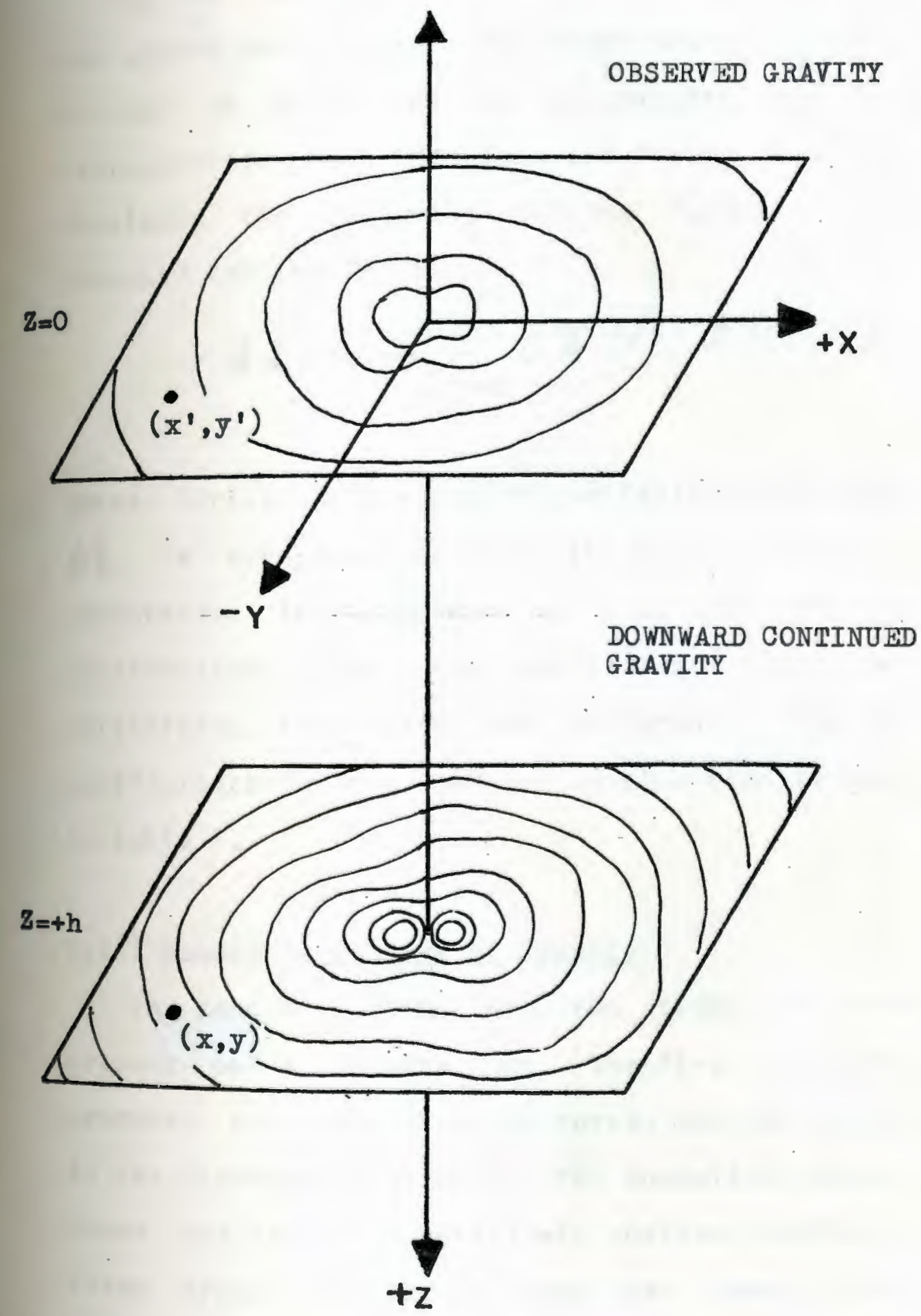
The above expression is similar to that for the upward continuation. Now $g(x, y, 0)$ is known and represents the observed data, while $f\left(x^{\prime}, y^{\prime}\right)$ is unknown.

As is the case for the coefficients and radil for the upward continuation. Henderson has found the values arrived at hy Peters to be insufficient in their representation of the computed field. Henderson has developed the following working formula for the downward continuation:

$$
\Delta \Phi(K) \approx \sum_{i=0}^{10} \Delta I\left(r_{i}\right) D\left(r_{i}, K\right)
$$

where $D(r i, k)$ is the set of coefficients for computing 4I. ' $k$ ' grid-spacings below the plane. The method of computation is identical to that for the upward continuation. Only the coefficients used in multiplying the rings are different. The set of coefficients for the downward continuation is presented in table 3 .

\subsection{Second Derivative of Gravity}

In general, there are two types of anomalies present on a gravity map. The first type are those produced by extensive structures, such as undulations in the basement topography. The anomalies produced are broad and produce a relatively shallow gradient over a large area. The other type are those produced by small, shallow structures. These anomalies are 


\begin{tabular}{rlrrrrr}
1 & $\Delta^{\Phi}\left(r_{i}\right)$ & $D\left(r_{i}, 1\right)$ & $D\left(r_{1}, 2\right)$ & $D\left(r_{i}, 3\right)$ & \multicolumn{1}{c}{$D\left(r_{i}, 4\right)$} & \multicolumn{1}{c}{$D\left(r_{i, 5}\right)$} \\
0 & $\Delta^{\Phi}(0)$ & 4.8948 & 16.1087 & 41.7731 & 92.5362 & 183.2600 \\
1 & $\Delta^{\Phi}(1)$ & -3.0113 & -13.2209 & -38.2716 & -89.7403 & -183.9380 \\
2 & $\Delta^{\Phi}(\sqrt{2})$ & 0.0081 & 0.4027 & 1.7883 & 5.1388 & 11.8804 \\
3 & $\Delta^{\Phi}(\sqrt{5})$ & -0.5604 & -1.9459 & -4.7820 & -9.9452 & -18.6049 \\
4 & $\Delta^{\Phi}(\sqrt{8})$ & -0.0376 & 0.0644 & 0.5367 & 1.7478 & 4.2324 \\
5 & $\Delta^{\Phi}(\sqrt{13})$ & -0.0689 & -0.0596 & 0.1798 & 0.8908 & 2.4237 \\
6 & $\Delta^{\Phi}(\sqrt{25})$ & -0.0605 & -0.0522 & 0.1342 & 0.6656 & 1.7777 \\
7 & $\Delta^{\Phi}(\sqrt{50})$ & -0.0534 & -0.0828 & -0.0560 & 0.0718 & 0.3606 \\
8 & $\Delta^{\Phi}(\sqrt{136})$ & -0.0380 & -0.0703 & -0.0900 & -0.0890 & -0.0571 \\
9 & $\Delta^{\Phi}(\sqrt{274})$ & -0.0227 & -0.0443 & -0.0639 & -0.0802 & -0.0921 \\
10 & $\Delta^{\Phi}(\sqrt{625})$ & -0.0302 & -0.0600 & -0.0891 & -0.1173 & -0.1444
\end{tabular}


characterized by steep gradients with a high curvature to the isanomals.

It is essential that one be able to distinguish between anomalies produced by large and small structures. One method which allows for this distinction is the downward continuation. which has been discussed. Another method is the second derivative.

Smaller structures superimpose their anomalies on broader features and may be identified by a change in curvature along any profile. Curvature evaluations depend largely on the second derivative, hence the second derivative is considerably important.

Peters (1949) has developed a method for calculating the second derivative of the vertical component of gravity involving the same procedure as that used for the upward and downward continuation. Again. Henderson (1960) has found the coefficlents and rings to be inadequate. The working formula for the second derivative is given by Henderson as:

$$
\left[\frac{\partial^{2} \Delta \Phi}{\partial z^{2}}\right]_{z=k}=\sum_{i=0}^{10} \Delta \Phi\left(r_{i}\right) D^{\prime \prime}\left(r_{i}, k\right)
$$

Where $D^{\prime \prime}(r i, k)$ is the set of coefficients for computing $\Delta \Phi, '$ ' $k$ ' grid-spacings on or below the plane. The set of coefficients for the second derivative is presented in table 4. 


\begin{tabular}{rlrrrr}
1 & $\Delta^{\Phi}\left(r_{1}\right)$ & $D^{\prime \prime}\left(r_{1}, 0\right)$ & $D^{\prime \prime}\left(r_{1}, 1\right)$ & $D^{\prime \prime}\left(r_{1}, 2\right)$ & \multicolumn{1}{c}{$D^{\prime \prime}\left(r_{1}, 3\right)$} \\
0 & $\Delta^{\Phi}(0)$ & 2.82994 & 7.08408 & 14.15751 & 24.74755 \\
1 & $\Delta^{\Phi}(1)$ & -2.49489 & -6.93715 & -14.51327 & -26.02351 \\
2 & $\Delta^{\Phi}(\sqrt{2})$ & 0.05173 & 0.36265 & 0.96018 & 1.92719 \\
3 & $\Delta^{\Phi}(\sqrt{5})$ & -0.39446 & -0.80764 & -1.42970 & -2.30269 \\
4 & $\Delta^{\Phi}(\sqrt{8})$ & 0.00932 & 0.13050 & 0.35907 & 0.72474 \\
5 & $\Delta^{\Phi}(\sqrt{13})$ & -0.00732 & 0.07231 & 0.22256 & 0.46253 \\
6 & $\Delta^{\Phi}(\sqrt{25})$ & 0.00304 & 0.06502 & 0.17330 & 0.33920 \\
7 & $\Delta^{\Phi}(\sqrt{50})$ & 0.00219 & 0.02312 & 0.05501 & 0.09985 \\
8 & $\Delta^{\Phi}(\sqrt{136})$ & 0.00040 & 0.00565 & 0.01239 & 0.02070 \\
9 & $\Delta^{\Phi}(\sqrt{274})$ & 0.00004 & 0.00103 & 0.00210 & 0.00322 \\
10 & $\Delta^{\Phi}(\sqrt{625})$ & 0.00000 & 0.00043 & 0.00085 & 0.00122
\end{tabular}


2.224 Comparison of Techniques Used in Dellineating Local Structures

Upon comparing the coefficlents for the second derivative with those for the downward continuation, one notices a resemblance in the coefficients used. This is reflected in the similarity of the results produced by each method in enhancing the gravity field produced by local, near-surface structures. It should also be noted, however, that different degrees of emphasis are placed on different rings with each method.

Upon inspection of the downward continuation coefficients, one notes the high magnitude of welghting placed on the smaller rings in relation to the lower order coefficients for the second derivative. This is reflected in the maps produced by the different methods. The downward continuation produces a larger number of small anomalies of high magnitude. In addition, the high weighting of small circles helps preserve the sign of anomalies produced by the downward continuation. On the other hand, sign reversals are characteristic of the second derivative method due to the low magnitude of weighting placed on the rings near the center point value.

Hence the second derivative should be used with care in the interpretation of gravity data. It may be used in delineating the presence of local, near-surface structures, but can not be used in establishing density 
parameters. In any event, the second derivative should not be the only method used in such interpretation. 
2.3 Computer Analyses

All computations for the upward and downward continuation and second derivative methods were made by computer. The programs employed for this study were obtained from the U.S. Geological Survey Computer Center Division (Buehrer,1968). The programs were extensively revised and rewritten by the author to accomodate the 1 BH 370 Computer at the University of Rhode Island. The revised programs and all data used in this study have been permanently stored at the Department of Geology, UnIversity of Rhode Island. A flowchart of the entire reduction process is presented in figure 17 to illustrate the following text.

The first step in data preparation involved the calculation of the Simple Bouguer anomaly. The program employed in this step uses the formula presented under - Reduction of Gravity Data'. Once the Simple Bouguer anomaly is calculated, manipulation of the gravity station locations is required. This process necessitated the conversion of station latitudes and longitudes to $X-Y$ map coordinates in kllometers using a polyconic map projection. These calculated coordinates were used as input to a grid generation program.

The gridding program computes grid intersection points over a specified area of any given dimension for irregularly-spaced data. The input data set contains any quantity of random data points $X-Y-Z$ which represent, respectively, the $x$ coordinate in kilometers, 
Figure 17

Flowchart of the three-dimensional continuatio process. 


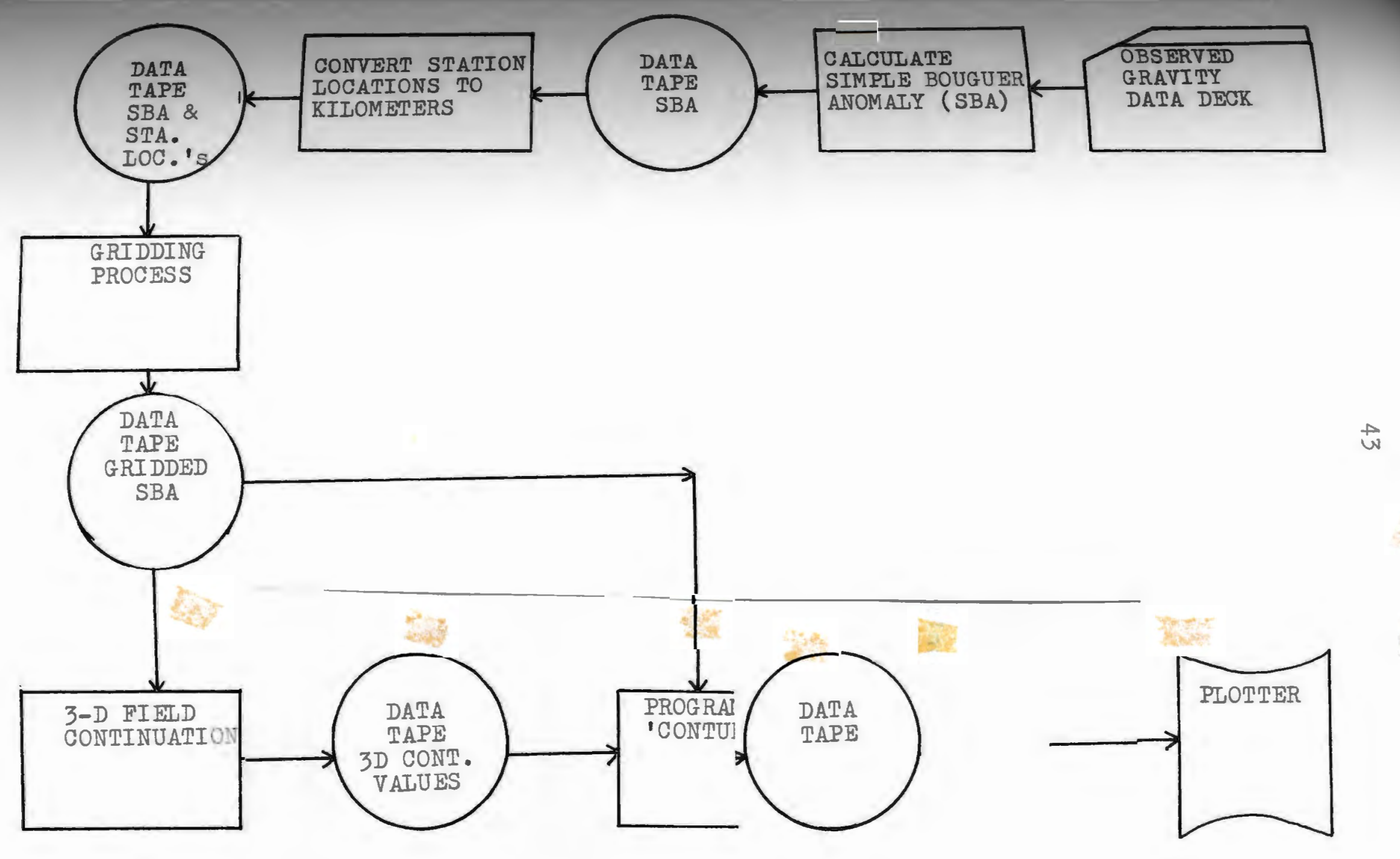


the $Y$ coordinate in kilometers, and the simple Bouguer value within the specified region. The dimension of the grid is restricted to $120 \times 120$ points. The actual process of grid generation has been described in the documentation accompanying U.S.G.S. Program W9322.

Once the Simple Bouguer data have been stored in a gridded form, the three-dimensional field continuation program may be applied. This program has the capability to compute the upward cont continuation, first derivative, and of potential fields as described by $H$ The computation is made in two ba

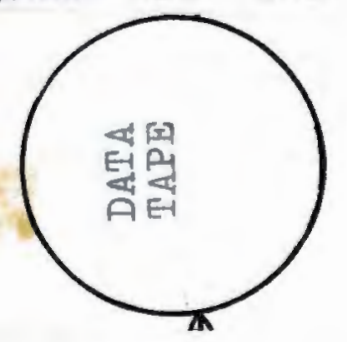
the average values on ten circles about eac, are calculated. The eleven radil chosen $\sqrt{2}, \sqrt{5}, \sqrt{8}, \sqrt{13}, \sqrt{25}, \sqrt{50}, \sqrt{136}, \sqrt{274}$, an previously described. The gravity values at the grid points lying on a circle are sumn divided by the number of such grid points on that This process is carried out for each of the ele rings, producing eleven values for each grid point. These ring averages are stored on a temporary work space for use in calculating the continuation and derivative values.

The second step involves the actual calculation of the values for each analysis. Tables of coefficients for the upward continuation, downward continuation, first derivative, and second derivative are applled to the values derived from the first step. Each of the 
tables contains coefficlents for a maximum of five evaluations above or below the observation plane (tables 2,3 , and 4 ).

The output section of the three-dimensional continuation program was revised by the author to input the calculated values for each analysis to a plotting routine avallable at the University of Rhode Island Computer Center. The program CONTUR takes the gridded values for each analysis and correspondingly draws isanomals of the calculated fields.

\subsection{Programs Test}

In order to test the operation of the gridding and continuation programs, test cases for which the gravity is known were developed. The first test to be made was on the accuracy of the grldding program.

The model employed consisted of two spheres located below a $30 \times 25$ matrix where the grid-spacing 'a' was equal to 3.6 kilometers (figure 18). The data for the two spheres are as follows:

Position

in Matrix

Radius

Depth to

Center

Density

Contrast

\section{Large Sphere}

$$
X=12 a, Y=15 a \quad X=8 a, Y=10 a
$$

$5 a$

$10 a$

$+.5 g / c c$
Small sphere

la

$2 a$

$+2.0 \mathrm{~g} / \mathrm{cc}$ 
Pigure 18

Model developed to test the operation of the threedimensional continuation program sequence. 


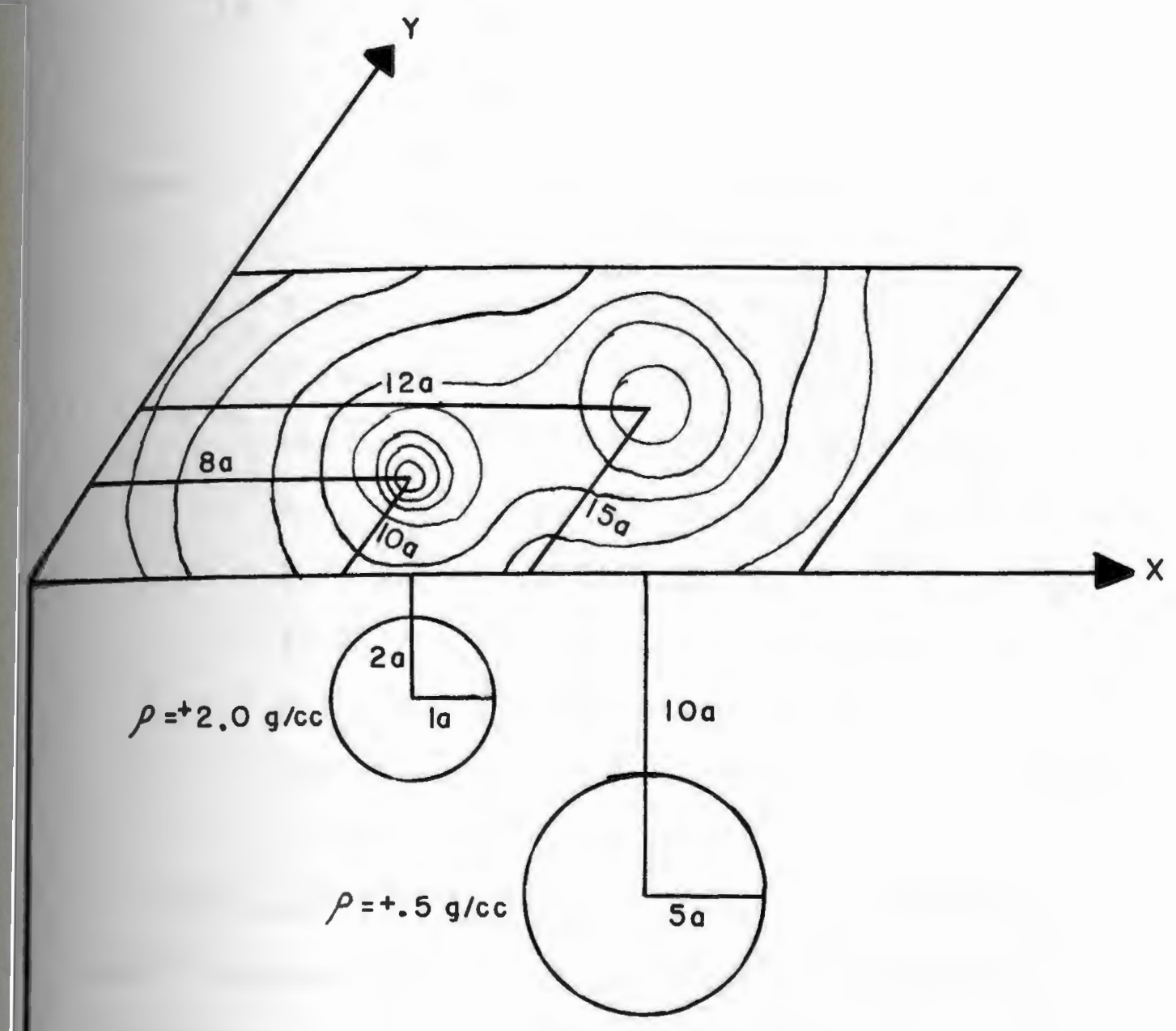


The gravity is calculated on the surface by the

equation:

$$
g_{z}=C \frac{P R^{3}}{z^{2}}\left[1+\left(\frac{x}{2}\right)^{2}\right]^{-3 / 2}
$$

where:

C respresents the gravitational constant

$P$ represents the density contrast between

the sphere and the surrounding medium

$R$ is the radius of the sphere in kilometers

$Z$ is the depth to the center of the sphere

in kilometers

$X$ is the distance of the observation point from a point on the surface directly above the center of the sphere

This calculation was carried out for each sphere at each observation point. The values obtained for the individual spheres were then summed and the total gravity calculated. The resulting gravity map is shown in figure 19.

The resulting data were then used as input to the gridding program. However, a smaller matrix of $27 \times 24$ was generated by the grldding program in order to test the interpolation process. Figure 20 shows the same gravity picture as figure 19. Note the locations of the centers of both spheres in each figure.

In order to test the effectiveness of the 
Figure 19

Observed gravity over model illustrated in figure 18 for $30 \times 25$ matrix.

Contour interval $=5 \mathrm{mgals}$ 


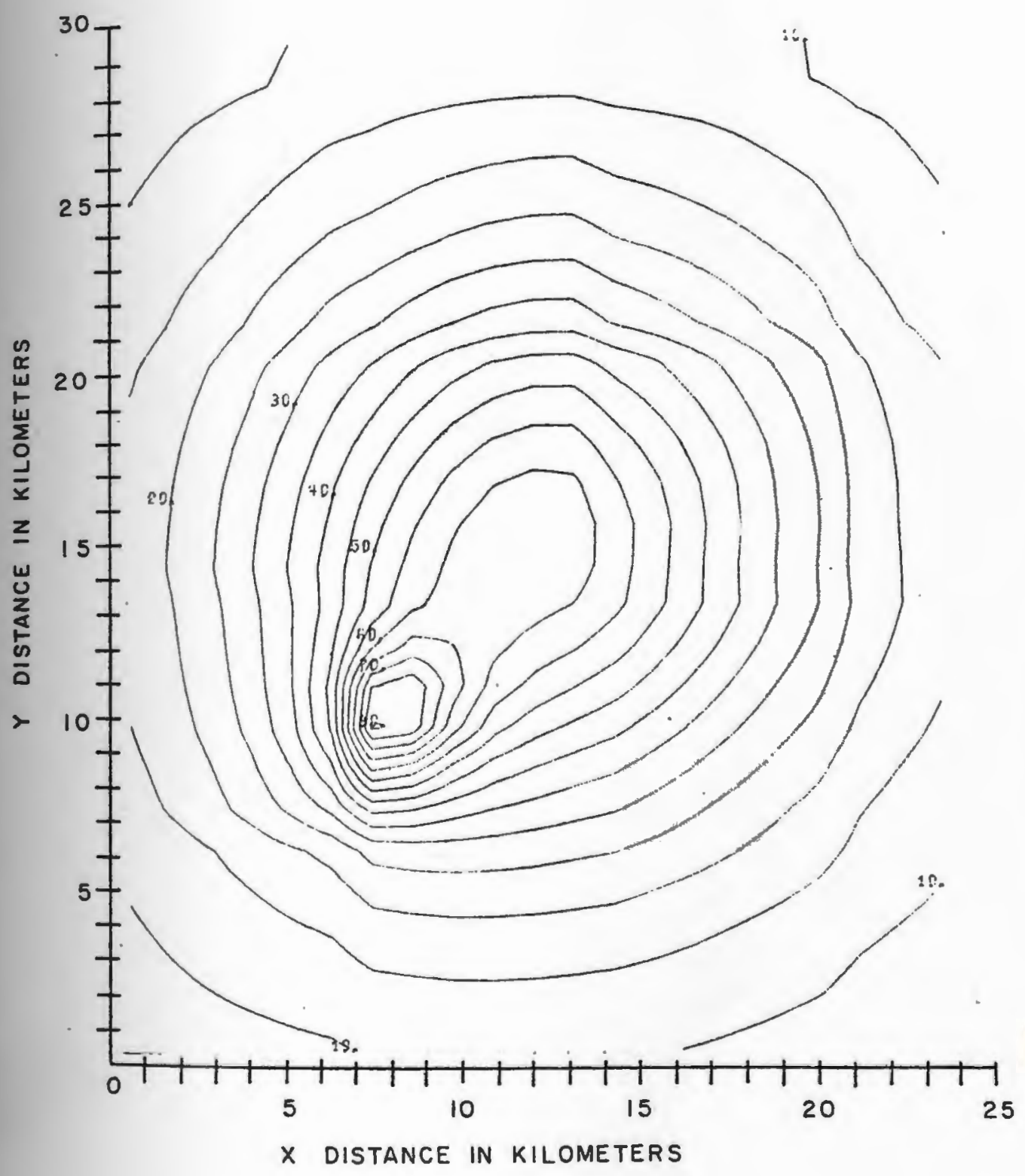




\section{Figure 20}

Observed gravity over model illustrated in figure 18 $27 \times 24$ matrix after analysis by gridding program. Contour interval $=5 \mathrm{mgals}$ 


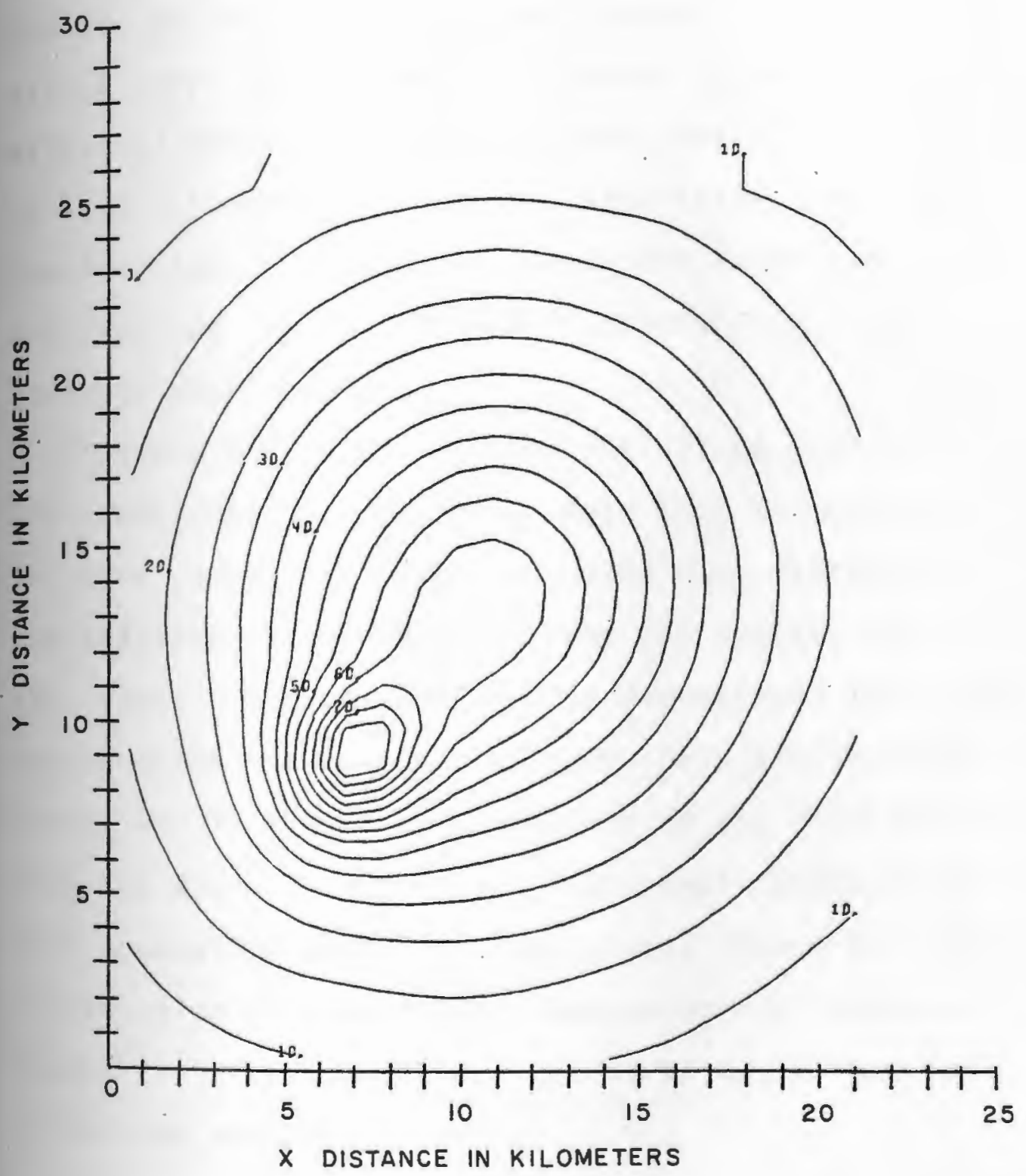


three-dimensional continuation program, test cases utllizing the formula for a sphere were developed in order to simulate the upward-downward continuation process. By varying the depth to the center of the spheres by intervals of the grid spacing 'a', a simllar effect may be produced. Figures 21 and 22 show the effect of successively burying the spheres by intervals of 3.6 kllometers, thereby simulating the upward continuation. Figure 23 shows the result of raising the spheres by 3.6 kilometers, thereby simulating the downward continuation.

Figures 24,25 , and 26 show the values arrived at by the continuation programs. Note that the matrix used In this case was $27 \times 24$ producing some discrepancy in the absolute values obtained, but the overall effect is the same. Figures 24 and 25 demonstrate the upward continuation process. In each case the observation plane was increased by a multiple of the grid spacing. Note the diminishing effect of the small shallow sphere with successive upward continuations. Thus, the upward continuation allows for the enhancement of deep-seated bodies by de-emphasizing the gravity effect of structures near the surface.

Figure 26 demonstrates the effect of the downward continuation. A level of la $(3.6 \mathrm{kllometers})$ below the observation plane produces an enhancement of the small sphere, while masking the effect of the large sphere. A similar effect is arrived at by applying the second 
Figure 21

Simulation of upward continuation process by lowering

level of spheres 3.6 kilometers in $30 \times 25$ matrix.

Contour interval $=5 \mathrm{mgals}$ 


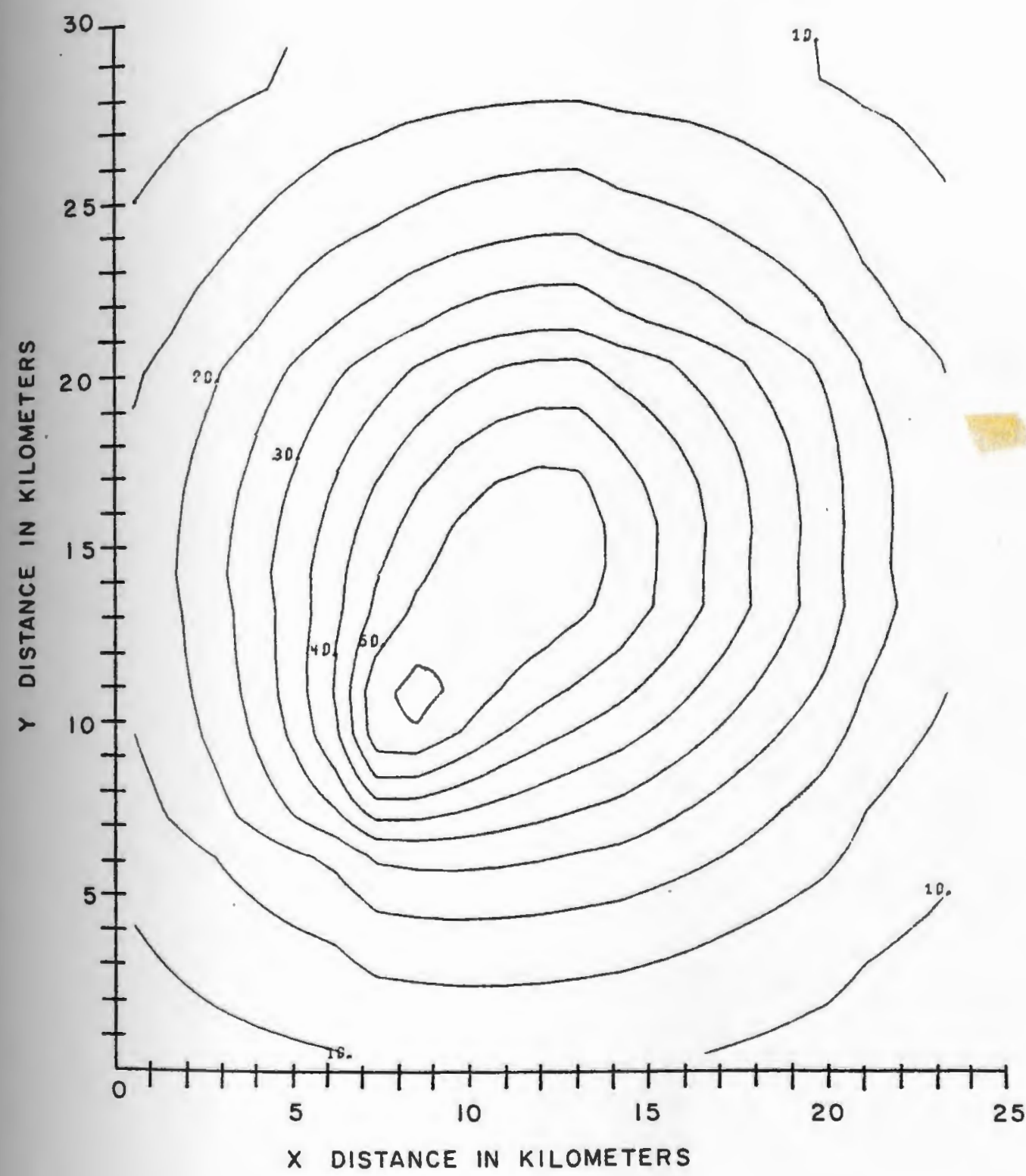


Figure 22

Simulation of upward continuation process by lowering level of spheres 7.2 kilometers in $30 \times 25$ matrix. Contour interval $=5 \mathrm{mgals}$ 


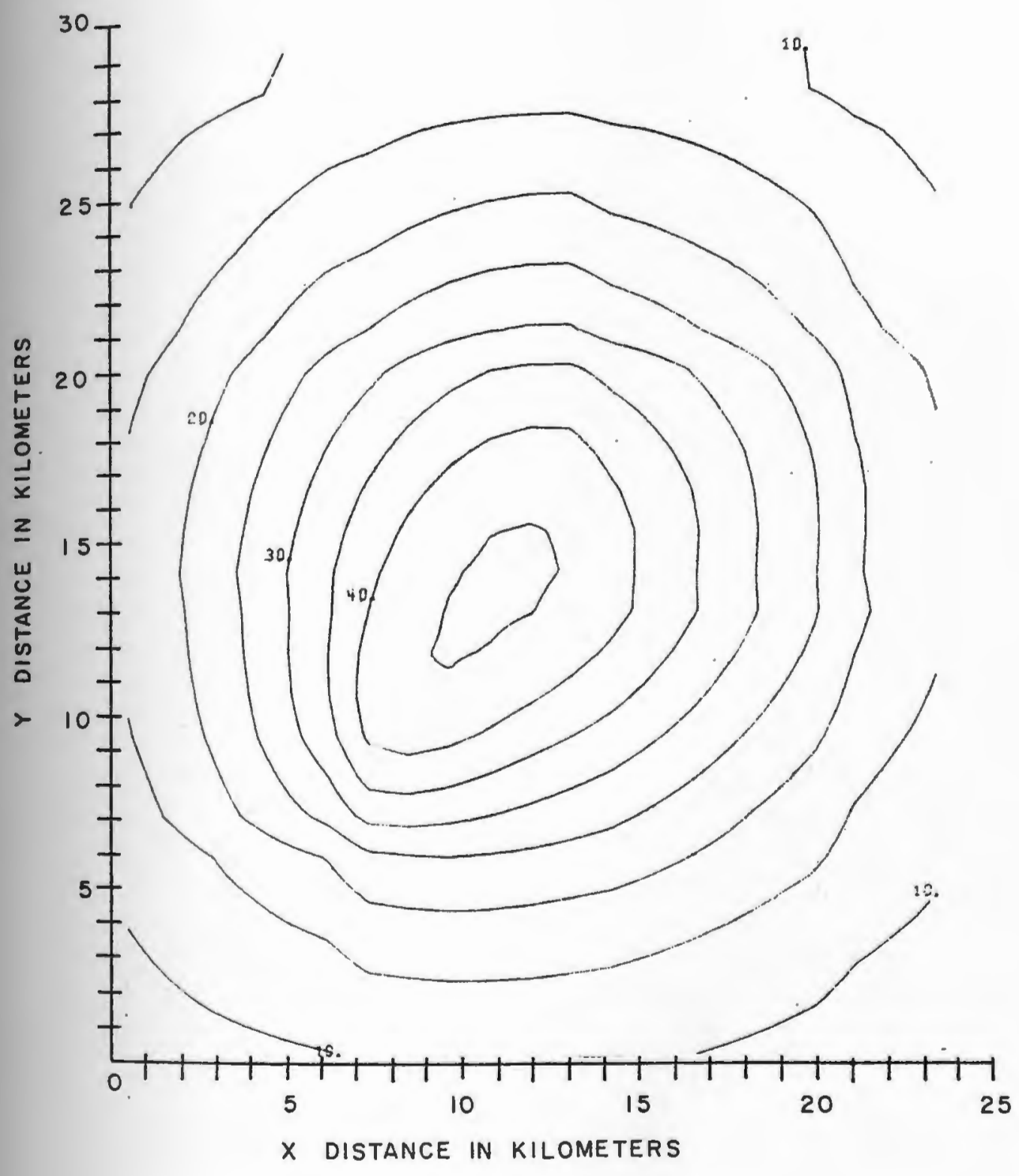


Figure 23

Simulation of downward continuation process by raising level of spheres 3.6 kilometers in $30 \times 25$ matrix. Contour interval $=10 \mathrm{mgals}$ 


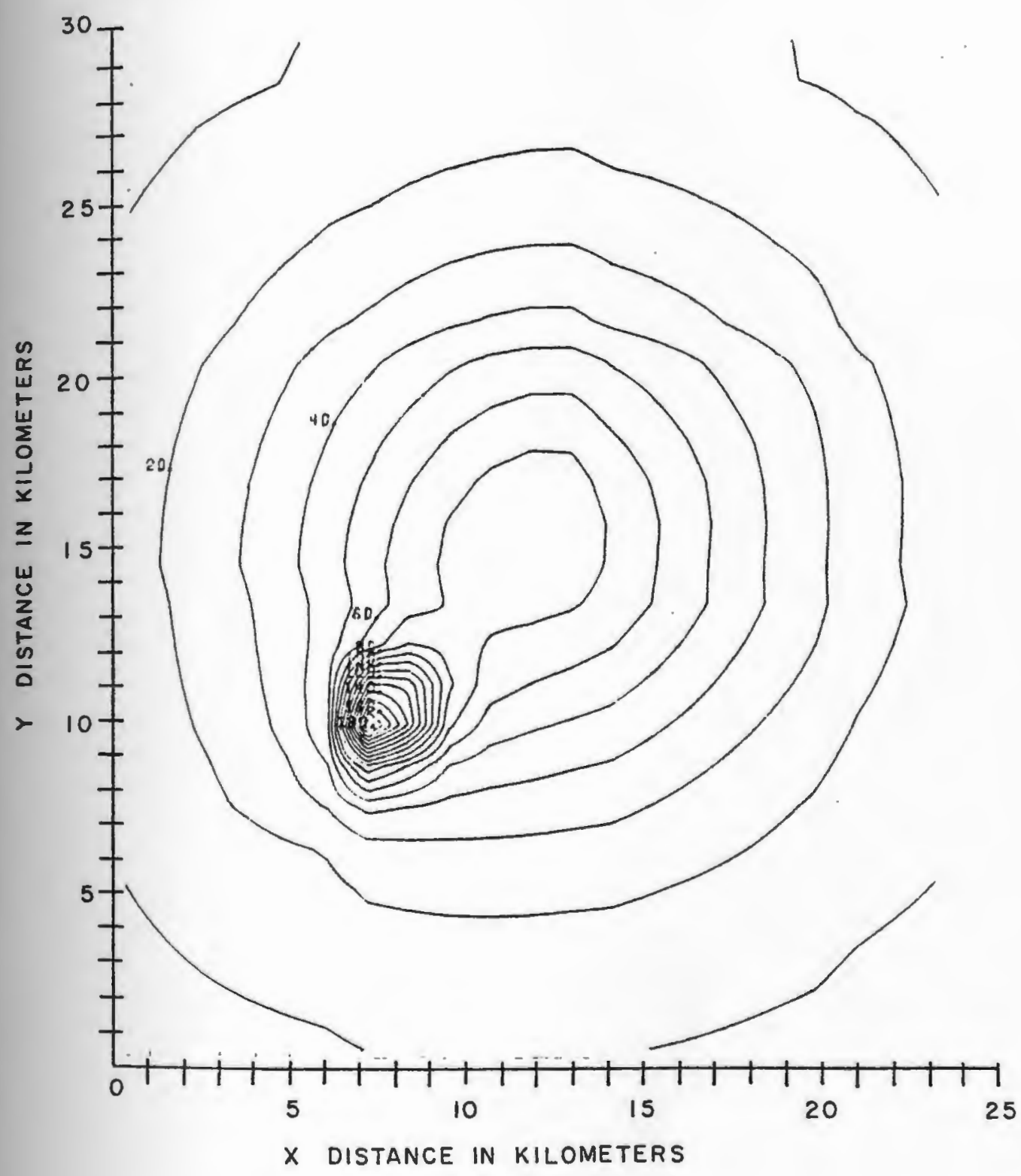


Figure 24

Upward continuation of gravity produced by threes dimensional continuation program in $27 \times 24$ matrix at 3.6 kilometers above surface.

Contour interval $=5 \mathrm{mgals}$ 


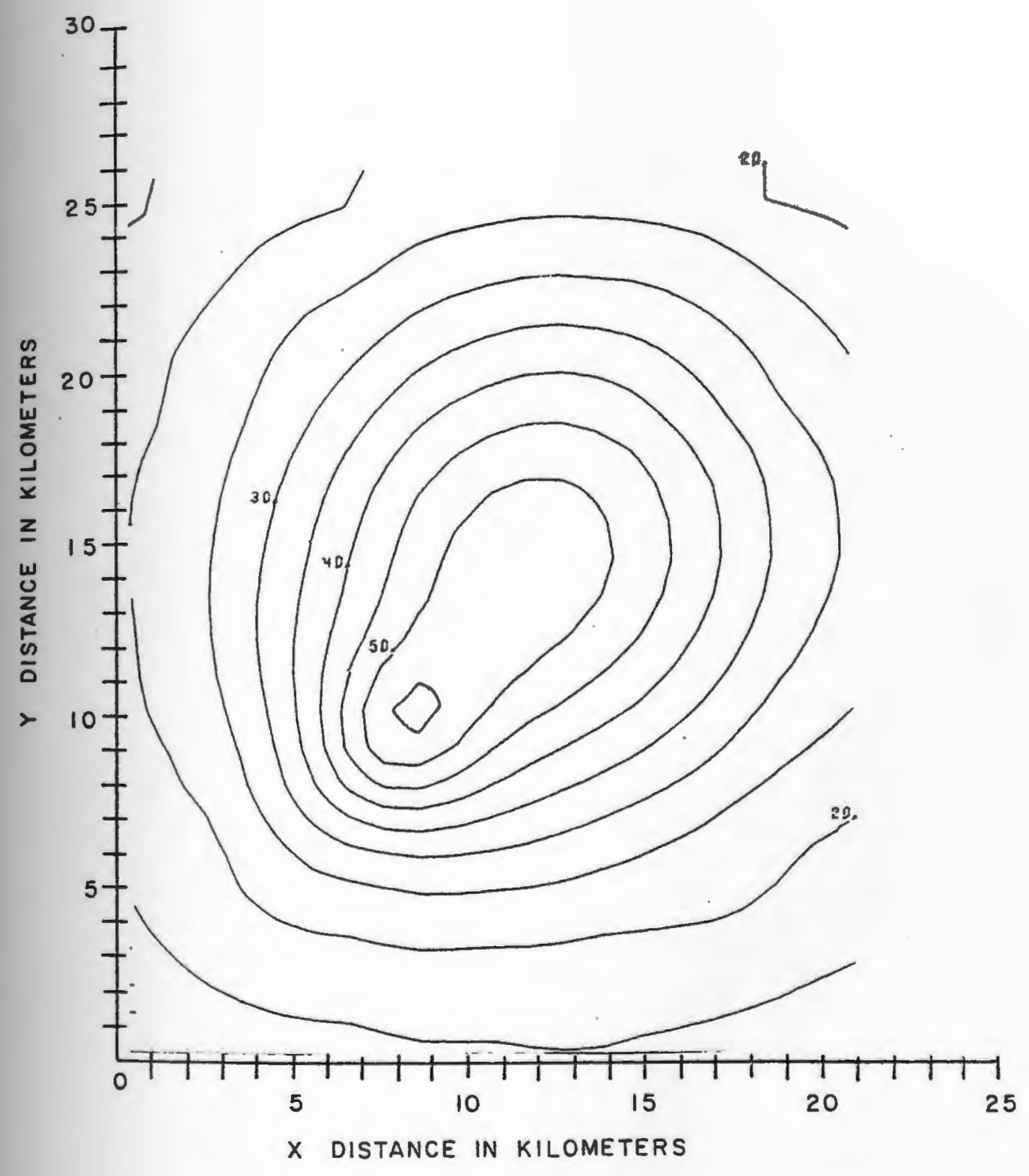


Pigure 25

Upward continuation of gravity produced by threedimensional continuation program in $27 \times 24$ matrix at 7.2 kilometers above surface.

Contour interval $=5 \mathrm{mgals}$ 


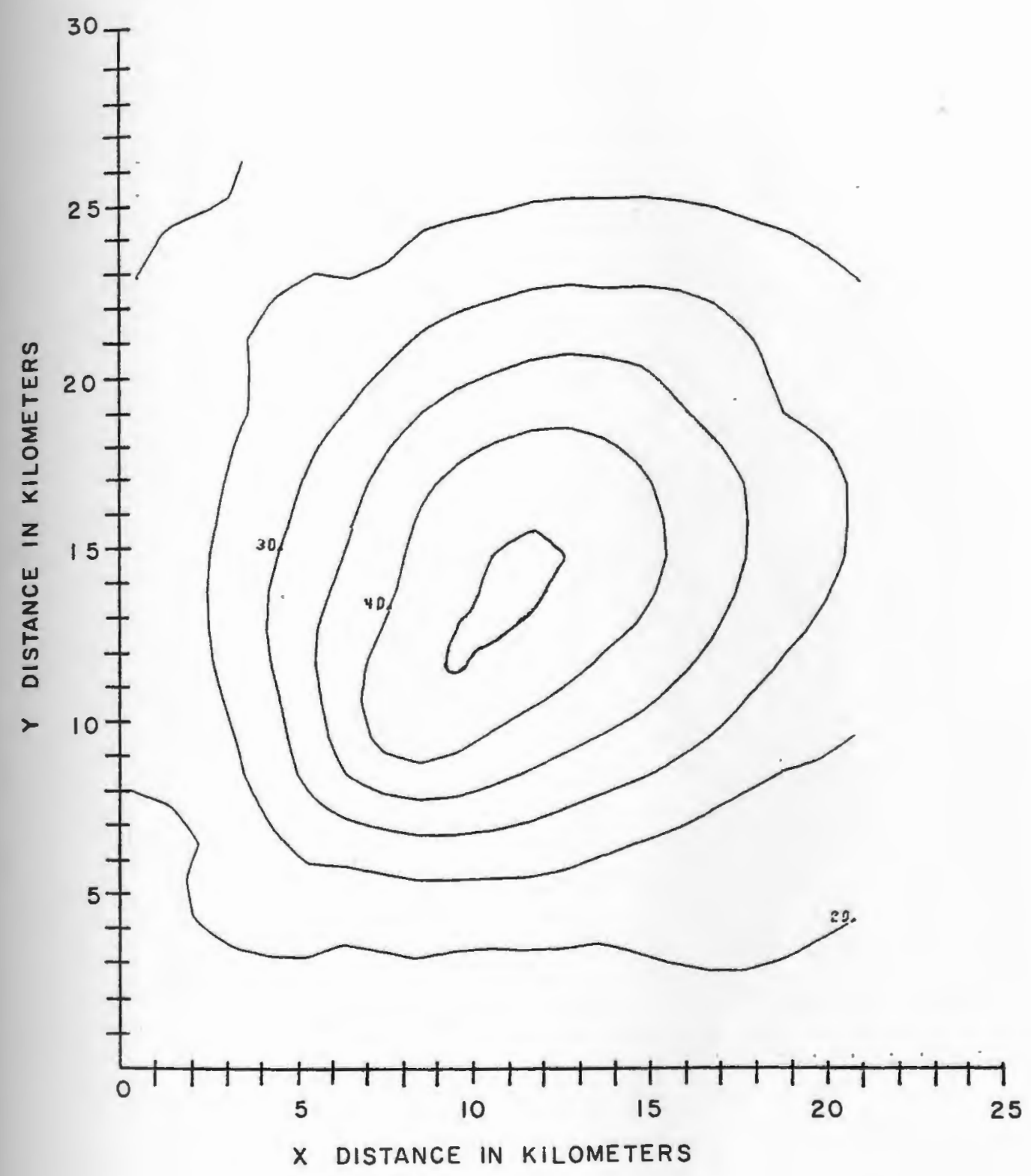


Figure 26

Downward continuation of gravity produced by threedimensional continuation program in $27 \times 24$ matrix at 3.6 kilometers below surface.

Contour interval $=10 \mathrm{mgals}$ 


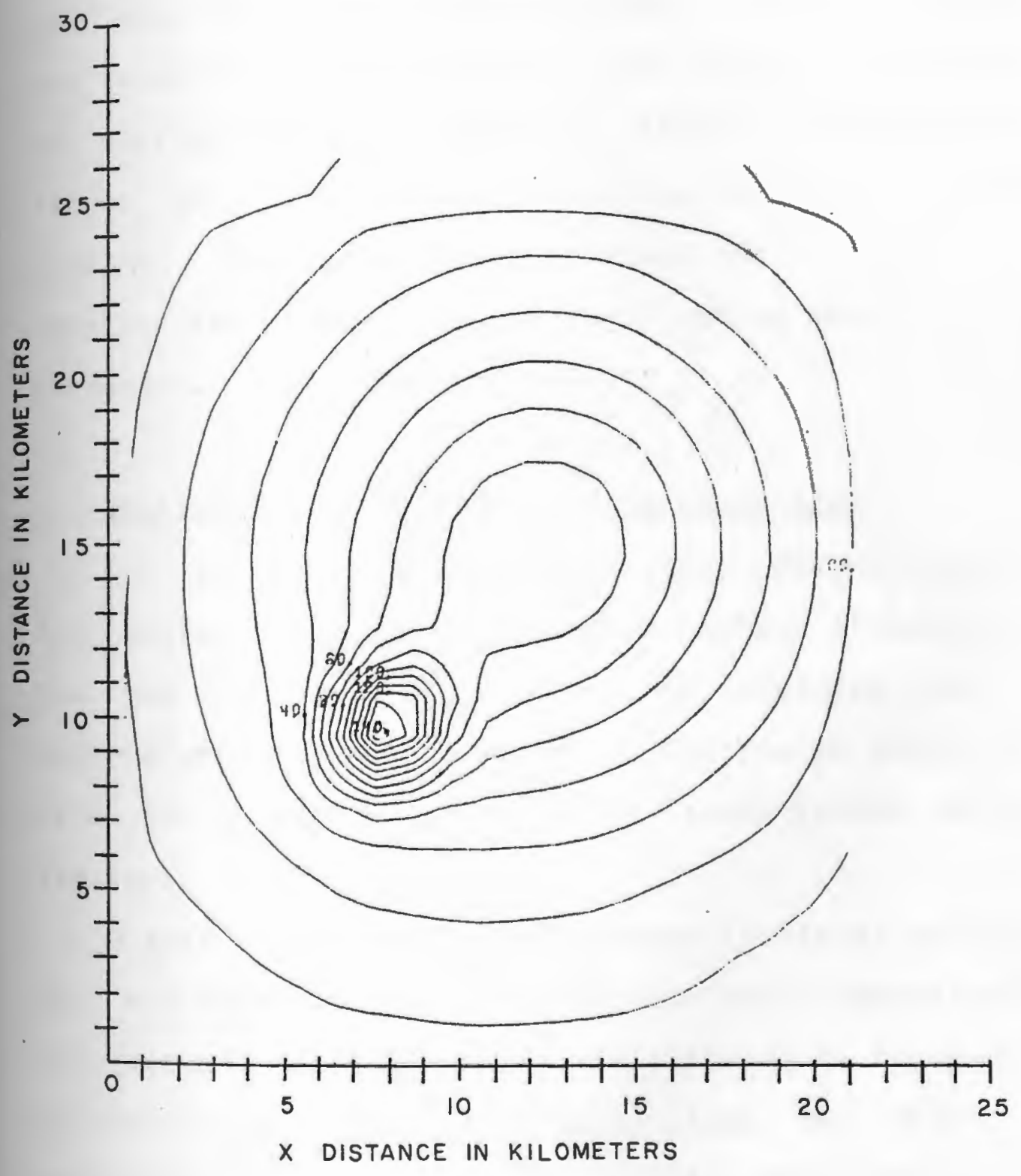


derivative method (figure 27 ).

As is the case with gravity contours, the higher the curvature, the higher the second derivative. Near-surface structures produce a greater curvature to the observed field than do deeper structures. Hence, the second derivative method allows for the enhancement of shallow bodies. This is clearlyillustrated in figure 27. The second derivative was applied at the surface. The steepening gradient of the contours towards the center of the small sphere indicates the presence of a shallow structure.

\subsection{Apolication of Programs to the Study Area}

Two sections of the entire study area were chosen for analysis by the continuation methods (figure 28). The two sections were chosen to minimize any interpolation errors inherent in fitting an equal area grid to a region where large areas lacked gravity stations.

A grid spacing of 3.2 kilometers ( 2 miles) was used for the calculations. This value closely approximates the actual spacing of gravity stations in the survey (plates 1 and 2). For each plane for which calculations were made, a multiple of 3.2 kilometers was used. Hence, upward continuation level 1 translates to the gravity produced at 3.2 kilometers above sea-level.

In this study the upward continuation, downward 


\section{Figure 27}

Second derivative of gravity produced by threedimensional continuation program in $27 \times 24$ matrix at surface.

Contour interval $=10 \mathrm{mgals}$ 


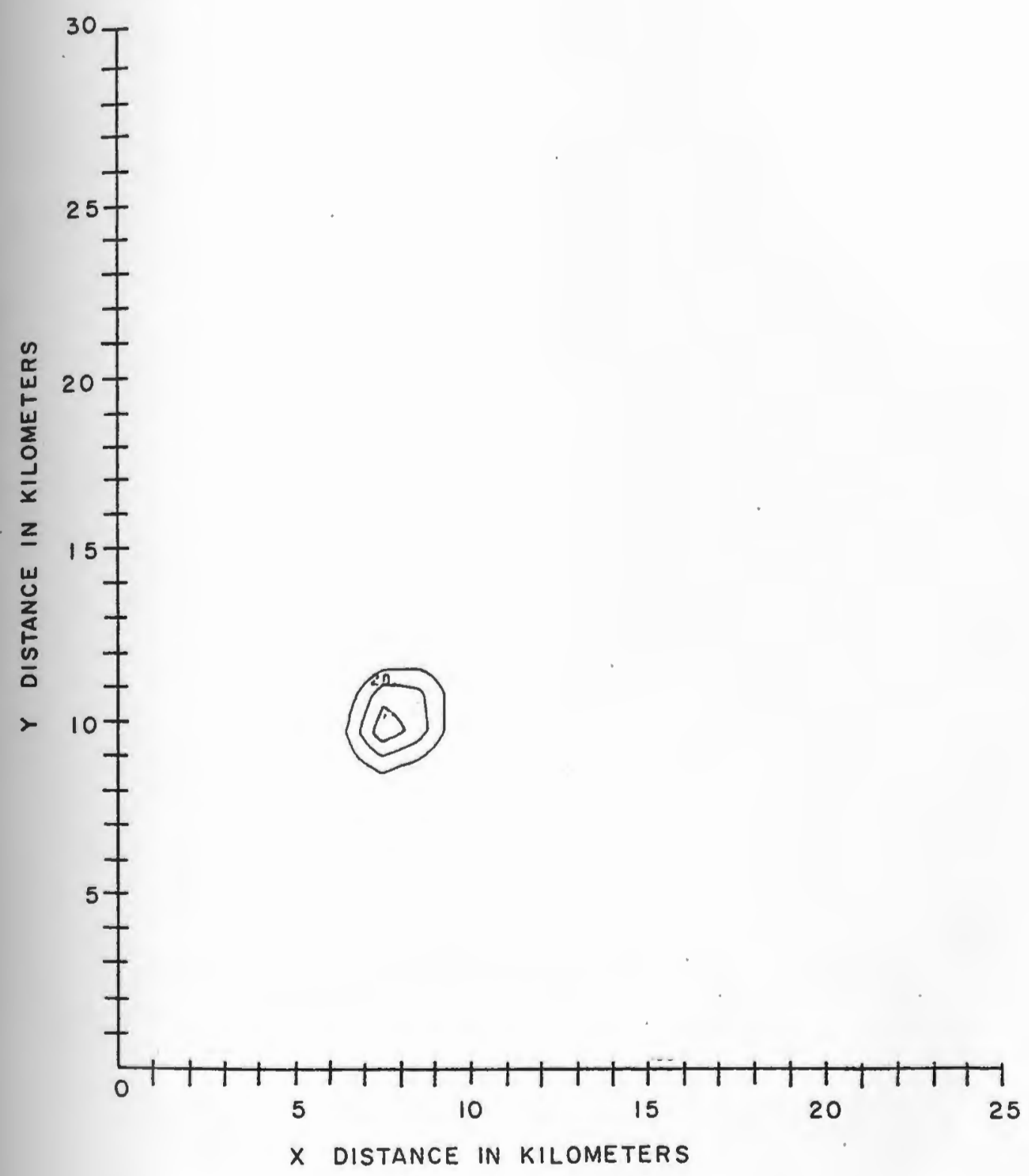


Figure 28

Iocation of regions $A$ and $B$. 


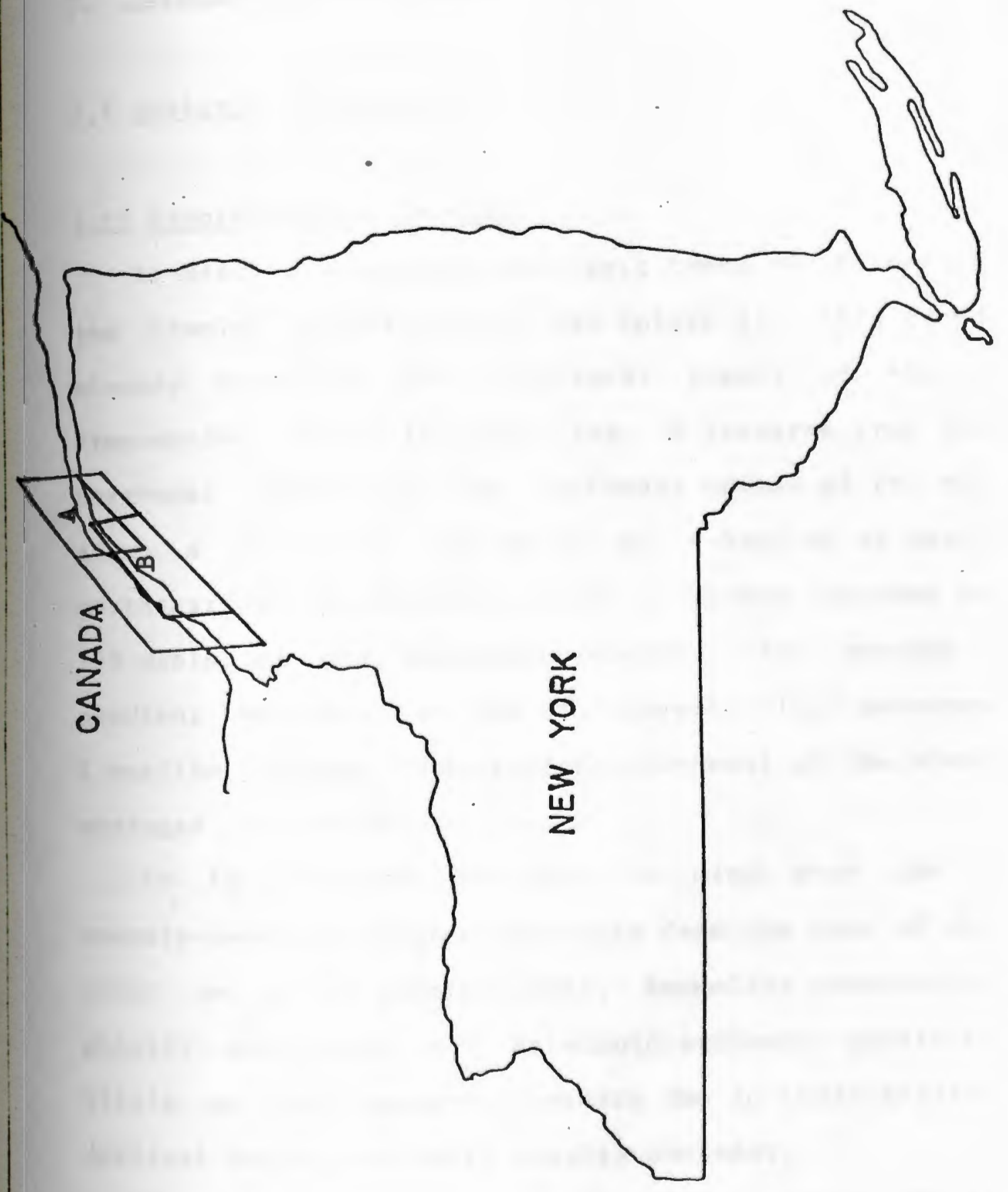


continuation, and second derivative methods were applied to the simple Bouguer gravity data. 3. 3. Interpretation of Data

3.1 Analysis of Region A

\subsection{Simple Bouguer Gravity}

A distinct southivest-northeast trend characterizes the Simple Bouguer gravity map (plate 3 ). This trend closely parallels the structural trends of the Precambrian rocks in the area. A traverse from the northwest corner to the southeast corner of the map shows a rise from -22 mgals to a high of +6 mgals northeast of Waddington, then a steady decrease to $-30 \mathrm{mgals}$ at the southeast corner. The gravity

gradient northwest of the St. Lawrence River averages I mgal/km whereas the gradient southeast of the river averages .5 mgal/ $\mathrm{km}$.

It is important to keep in mind that the anomaly-producing bodles originate from the hase of the crust up to the glaclal cover. Anomalies produced by glacial overburden and Paleozoic sediments contihute little to the measured gravity due to their shallow vertical extent and small density contrast.

The dominant feature of the simple Bouguer map is the Massena gravity high located on the St. Lawrence River between Massena and Waddington. Earlier work by Simmons (1964) uncovered this anomaly with fewer than 
10 readings. The Massena $\mathrm{High}$ is elliptical in shape, displaying a north-south elongation.

\subsection{Upward Continuation}

In order to establish some depth constraints on the anomaly-producing bodies, successive upward continuations were applied to the Simple Bouguer data. As previously demonstrated, this method allows for the enhancement of deep-seated structures. Plate 4 represents the gravity field as it would appear $3.2 \mathrm{~km}$ above sea-level. Note that the contour interval has been reduced to 1 mgal in order to demonstrate that the upward continuation is not merely a method of removing lines. As is readily observed, the Massena High is still a prominent feature on the first upward continuation map.

Upon comparison with the Simple Bouguer map, a number of differences are noted. The northward semiclosure of the $-10 \mathrm{mgal}$ contour directly west of Canton is no longer apparent on the upward continuation map. The southeastward elongation of the -18 moal isanomal southeast of Potsdam on the Simple Bouguer map has also dissipated. The low near Cornwall is no longer present on the upward continuation map. This indicates that the anomalies absent on the upward continuation map may be produced by shallow structures, originating between 0 and $3.2 \mathrm{~km}$ below the surface. 
$6.4 \mathrm{~km}$ above sea-level. Note that the contour interval has been increased again to 2 mgals. Again, the Massena high remains the dominating feature.

Plate 6 represents the gravity fleld at a level of $9.6 \mathrm{~km}$ above sea-level. The llassena High is still present. Further upward continuations, al though not included, reveal no further information.

\subsection{Downward Continuation}

Plate 7 represents the gravity field at $3.2 \mathrm{~km}$ below sea-level. The contour interval has been increased to 10 mgals resulting in a clear delineation between near-surface and deeper structures.

Upon comparison with the Simple Bouguer map, several near-surface structures become more distinct on the downward continuation map. Immediately to the west of Canton, a circular anomaly appears on the $-10 \mathrm{mgal}$ isanomal. This gravity low may be directly correlated to a granitic phacolith on the geologic map (plate 8). The eastward elongation of the isanomals to the southeast of Potsdam reflect a contact between Precambrian amphibolite and granitic gneiss. Other localized anomalles can not be directly correlated with the geologic map of the region due to the sedimentary cover over most of the map. However, some inferences may be made based on the intensity and geometry of the anomalies.

The two closures of $-10 \mathrm{mgals}$ and 
$-40 \mathrm{mgals}$, approximately $20 \mathrm{~km}$ northwest of Waddington, may represent shallow granitic intrusions, similar to the structure west of Canton. This inference may be made based on the shape and intensity of the two anomalies.

The anomaly surrounding Cornwall. Ontario is prominent on both the simple Bouguer and downward continuation maps. This shallow body may bear some relationship to the Gloucester Fault.

The Gloucester Fault trends $\mathrm{N} 35 \mathrm{~W}$ and demarcates the eastern edge of the system of faults comprising the ottawa- Bonnechere Graben (Dames and Moore,1973). The Gloucester Fault is a normal fault with the west block upthrown relative to the east block. The maximum vertical displacement is on the order of $1800 \mathrm{ft}$ near Russe11, Ontario.

No direct evidence of an extension of the Gloucester Fault across the St. Lawrence River has been found. The disappearance of the Cornwall low with the upward continuation, and the subsequent emphasis of this anomaly on the downward continuation map would suggest a near-surface origin for this anomaly. This low may represent a downthrown block of the fault. The low intensity of the anomaly would further support this conclusion. It should be noted, however, that the Cornivall gravity low is a local feature and displays little areal extent. It is more likely that this anomaly could be indicative of a separate fault, 
distinct from the Gloucester Fault.

The Massena High displays a large increase in magnitude with the downward continuation while retaining its characteristic northeast-southwest strike. Further downward continuations produced severe osclllations of the Massena anomaly. This may suggest that the top of the structure lies between 3.2 and $6.4 \mathrm{~km}$ below sea-level.

\subsection{Second Derivative}

Plate 9 represents the second vertical derivative of gravity at the surface. The similarity between the second derivative and downward continuation maps is quite striking. In addition, the correlation between the second derivative and geologic map (plate 8 ) is excellent in the southern map area.

The aforementioned low west of Canton is more distinct on the second derivative map. A second low, roughly of the same size and intensity, occurs southeast of Canton. This anomaly may be directly correlated to a high density amphiholite body surrounded by relatively low density metasediments. The closures southeast of Potsdam may be associated with the contact between Precambrian amphibolite, to the north, and granitic gneiss, to the south.

Interpretation of the area to the north, below the sedimentary cover, is highly speculative. Numerous near-surface structures are indicated by the large 
amount of small closures. The interpretation of these anomalies has been discussed for the downward continuation map.

The emphasis of the Cornwall Low on the second derivative map, further suggests a near-surface origin. In contrast, the de-emphasis of the Massena High suggests a deeper origin.

\subsection{Gravity modeling}

In order to establish density, size and depth parameters on the structure producing the Massena gravity high, the two-dimensional Talwanl modeling technique was applied (Talwani,1965). This technique allows the user to specify the shape and density of the anomaly-producing structure, then calculates the observed gravity at each field point. By varying shape and density parameters, one is able to obtain a best-fit curve between the observed gravity and the gravity produced by the Talwani method.

The Talwani method was applied to the Massena High across a traverse from $A$ to $A^{\prime}$ (plate 3 ). Figure 29 shows the observed gravity over the Massena anomaly as a solid line. The structure producing the best-fit curve is shown in the same figure, with the curve for the calculated gravity produced by the Talwani program represented by the broken line.

Next an attempt was made to reproduce the upward and downward continuation computed after Henderson's 
program by calculating the gravity of the model in figure 29 at the respective distances from sea-level. By successively burying the structure by intervals of $3.2 \mathrm{~km}$, one can simulate the upward continuation, while raising the structure by the same interval simulates the downward continuation. Figure 29 shows the upwards continued gravity taken along $A-A^{\prime}$ (solid line) in comparison with the the calculated gravity at that elevation based on the Talwanl model (broken line). Also shown are comparisons of the curves for the downward cont inuation.

3.16 Geological Interpretation of the Massena Gravity High

The model represents a wedge of material denser than the surrounding rock. The modeled wedge increases in thlckness from west to east, as suggested by the shallower gradient on the east slde of the curve. The shape of the center of the anomaly suggests that the top of the structure terminates in a plateau. The rise on the west along $A-A^{\prime}$ indicates the presence of a smaller, near-surface body. Repeated attempts at

modeling the gravity along the profile did not allow for a physical connection between the smaller and larger body. The effect of this smaller body rapidly decreases with the upward continuation, while it is emphasized with the downward continuation.

Further discussion of the smaller anomaly will be 
Figure 29

Possible model for stmcture producing Massena Gravity High.

Solid line is gravity produced by three-dimenat continuation process.

Dashed line is gravity produced by Talwani modeling program. 


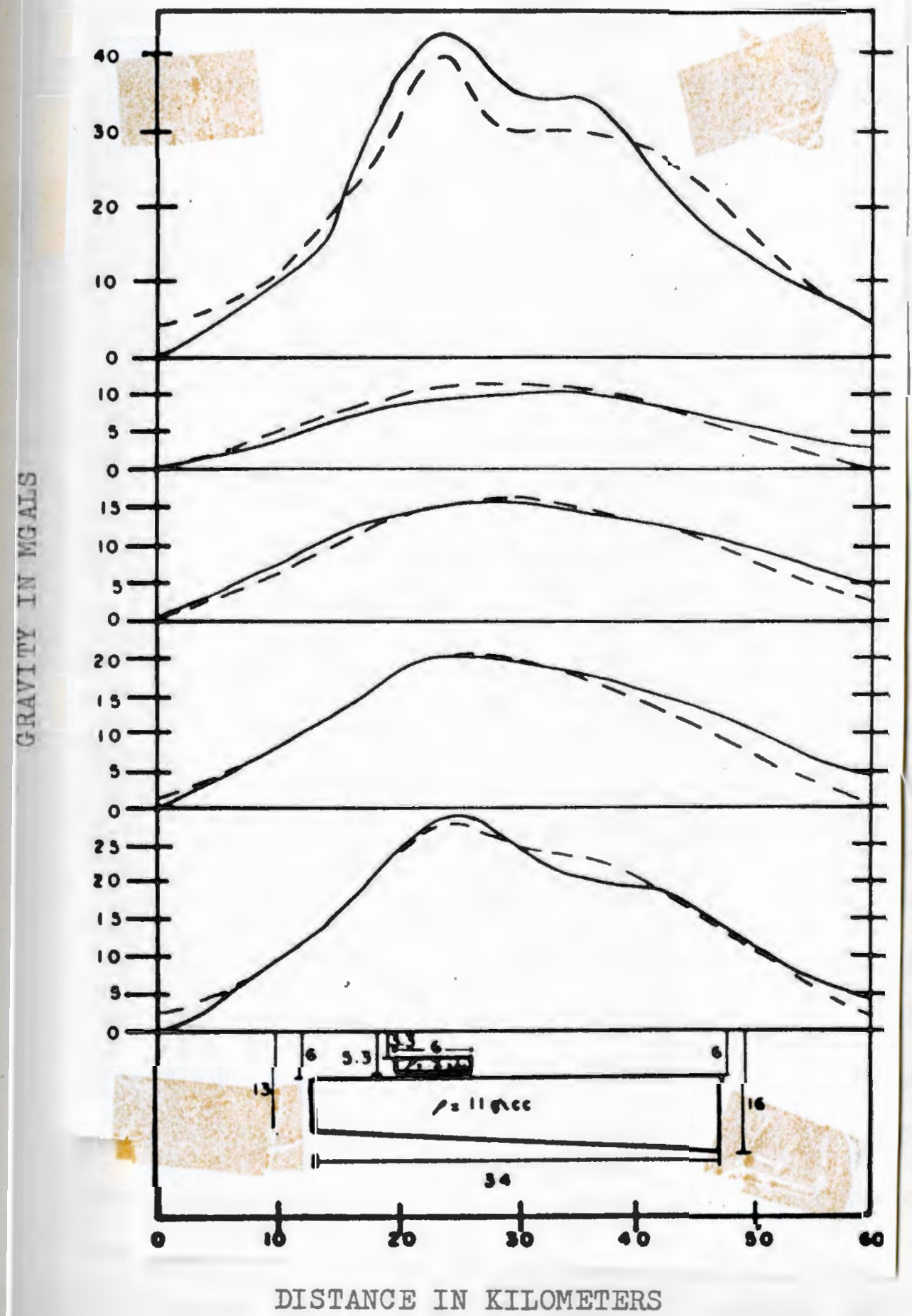


found in section 3.17 .

Simmons (1964) demonstrated that the llassena gravity high could be representative of a density contrast between Grenville metasediments and surrounding granitic rock. The predominant lithologies of the cronping-out Grenville in the study area are calcic and dolomitic marble. Based on the work of Buddington (1934), Engel and Engel (1953), and Simmons (1964) density values for the cropping-out rocks in the study area have been established (table 5) The density of the Grenville metasediments averages from $2.71 \mathrm{~g} / \mathrm{cc}$ to $2.73 \mathrm{~g} / \mathrm{cc}$, while the density of the surrounding granites averages $2.67 \mathrm{~g} / \mathrm{cc}$. This yields a density contrast of $+0.06 \mathrm{~g} / \mathrm{cc}$ used by simmons in modeling the Massena anomaly.

One must keep in mind that Simmons chose to model the residual gravity. The residual gravity is arrived at by removing the regional gravity field, or the gravity effect produced by deeply-seated structures, from the Simple Bouguer anomaly. In utilizing such a procedure, the term "deeply-seated" is not given any depth parameter. Therefore, one is unsure as to the depth of the structures being eliminated from the total gravity field. As a result, only a portion of an anomaly may be left intact using the residual methor. Subsequent modeling of the residual gravity can produce incomplete results.

The cholce of a regional is highly subjective. and 
Table 5

Densities of Cropping-Out Rocks

in the Study Area

(Simmons, 1964)

Rock

granite

syenite

anorthosite

Grenville gneiss

Grenville amphibolite

Grenvilie marble (dolomitic)

Grenville marble (calcitic)

Paleozoic sandstone

Paleozoic dolomite

Paleozoic Iimestone

Paleozoic shale
Average

density

$(\mathrm{gm} / \mathrm{cc})$

$\left\{\begin{array}{l}2.67 \\ 2.77 \\ 2.68\end{array}\right.$

2.72

2.64

3.01

2.78

2.73

2.57

2.78

2.68

2.63
Range

( $\mathrm{gm} / \mathrm{cc}$ )

$2.62-2.76$

$2.61-2.82$

$2.68-2.99$

$2.53-3.16$

$2.86-3.09$

$2.68-2.85$

$2.69-2.83$

$2.43-2.73$

$2.72-2.82$

$2.61-2.71$

$2.60-2.67$ 
much debate has risen as to the various methods used in obtaining the regional gravity. To paraphrase Nettleton (1954), the regional is what you subtract from the observed gravity to make what's left look like the structure.

A station spacing of between five and ten kilometers was used during simmons' survey. Surveys of this type allow for the gross delineation of major structures, however vertical and horizontal extent can not be accurately determined. The application of a trend-surface analysis to calculate the residual gravity from such widely-spaced data results in overlooking structures not revealed by the gravity survey.

The model arrived at by simmons shows an extremely shallow structure, $\langle 1 \mathrm{~km}$ to the top of the structure with a maximum thickness of $5 \mathrm{~km}$. Subsequent gravity model ing produced values much lower than those observed in the current survey. A problem arises when applying the downward continuation to such a model. If the gravity is calculated on a plane which passes through the anomaly source, severe osclllations occur in the calculated data. Based on the downward continuations made in this study, one must assume that the top of the structure must 1 le between $3.2 \mathrm{~km}$ and $6.4 \mathrm{~km}$ below the surface. Hence, the model presented in figure 29 is consistent within these constraints. However, Nettleton (1954) and Dobrin (1960) have cautioned 
against the misuse of such methods in interpretation.

Another method of distinguishing shallow from deep-seated anomalies is the second derivative method. Note the disappearance of the Massena gravity high in plate 9. This further suggests that, although the surface structures do contribute to the overall gravity effect, the major structure producing the Massena High lies at greater depth. Thus, although Simmons' model can account for a portion of the Massena anomaly, it can not account for the entire anomaly.

The model presented in figure 29 indicates a density contrast of $.11 \mathrm{~g} / \mathrm{cc}$. A possible cause for the Massena High could be an increase in the density of the Grenville metasediments with depth. This could result due to a number of factors such as the presence of high-density metavolcanic layers interbedded with metasediments. There are, however, a varlety of lithological models which would explain the density model and the selection of the most probable lithology must be based on what can be inferred from the surface geology.

\subsection{Secondary Massena Anomaly}

As previously mentioned, the entire Massena anomaly could not be accounted for by one anomaly-producing structure. Figure 29 shows the model arrived at to account for the smaller anomaly. The modeled structure is $6 \mathrm{~km}$ in length, has a density contrast of $+.2 \mathrm{~g} / \mathrm{cc}$, 
a depth to the top of the structure of $3.3 \mathrm{~km}$ and a depth to the bottom of the structure of $5.3 \mathrm{~km}$.

The smaller feature may represent an intrusive body of greater density than the larger wedge. Based on the previously mentioned density values for the Grenville, the model suggests a density value of $2.9 \mathrm{~g} / \mathrm{cc}$. This value falls in the range of densities for mafic rocks and suggests a mafic nature for the body. 
3.2 Analysis of Region B

\subsection{Simple Bousuer Gravity}

A more northerly trend of the gravity field is observed on the Simple Bouguer map of reglon $B$ (plate 10). A west-east traverse across the $444^{\prime}$ line shows a steady decrease in gravity due north of Brockville, then a steady increase towards. the eastern edge of the map. The gradient of gravity is fairly constant throughout the region, averaging about $1 \mathrm{mgal} / \mathrm{km}$.

The effect of the llassena High is still dominant over the eastern portion of the map, as indlcated by the strong northeast-southwest trend of the isanomals and steady positive rise towards the east. An elongate gravity low occuring north of Brockville culminates in a closure of -34 mgals. Another gravity low is seen striking northeast near Alexandria Bay.

3.22 Upward Continuation

Plates 11, 12, and 13 represent the gravity field at 3.2, 5.4, and $9.6 \mathrm{kms}$ above the plane of observation, respectively. The dominance of the Massena High is striking. With each successive upward continuation, the Massena anomaly is still a prominent feature, suggesting a very extensive structure.

The gravity low north of Brockville dissipates at two different rates. The southern component of the anomaly rapidly decreases in intensity with successive 
upward continuations, while the nothern portion shows a relatively gradual decrease.

The gravity low near Alexandria Bay, continues to be prominent through each upward continuation.

\subsection{Downward Continuation and Second Derivative}

Plate 14 represents the gravity at a level of $3.2 \mathrm{~km}$ below the observation plane. Plate 15 represents the second derivative of the surface gravity. The correlation between the known geology and each map is excellent in the southern part of the region (plate 16$)$.

The small elliptical gravity lows in the southeast quarter of the downward continuation map may be directly correlated to granitic bodies surrounded by metasediments of higher density. The same anomalies appear on the second derivative map, with some anomalies displaying sign reversals.

Elkins (1951) has shown that some reversals in sign are characteristic of the second derivative method. Hence, only through the application of a number of analytical methods can a geologically realistic picture be produced.

The gravity low near Alexandria Bay, as seen on the downward continuation map, may be related to an extension of the granite body directly north of the anomaly. The presence of this anomaly on each of the upward continuation maps suggests that the origin of 
the anomaly is vertically extensive. A similar interpretation may be applied to the anomaly north of Brockville.

The downward continuation map shows this anomaly as a series of north-south trending lows. The anomaly may represent a density contrast between a low density granite and the surrounding Grenville metasediments. This interpretation would be consistent with the interpretation of region $A$.

\subsection{Summary of Gravity Analyses}

The results produced by the upward continuation, downward continuation, and second derivative methods confirm the geological complexity of the study area and have produced much information as to the vertical extent of anomaly-producing bodies. Numerous small anomalles, previously masked by large deep-seated structures, become quite apparent when the second derivative and downward continuation are applled to the Simple Bouguer data.

The application of the upward continuation to the Simple Bouguer data clearly suggests that the Grenville metasedimentary sequence displays a much greater vertical extent than had originally been thought. The model developed suggests a density-depth relationship with a possible density increase in the Grenville with depth. As mentioned, this may reflect a lithologic change within the Grenville sequence. 
The same gravity picture could be produced if the density values were reduced and the vertical extent of the structure increased. The observed surface rock densities suggest contrasts on the order of .05-.07 g/cc, which produce unrealistic results. If the density contrast of the model developed for the Massena High is reduced to a value of $.06 \mathrm{~g} / \mathrm{cc}$, the thickness of the model must be increased to around $30 \mathrm{~km}$. Katz (1959) has shown that the average crustal thickness in Northern New York is $34.4 \mathrm{~km}$. Selsmic refraction studies are suggested to establish exact density and depth parameters in the Grenville.

The appearance of the gravity low on the simple Bouguer map flanked by the Massena High was suggested by Albert, et al. (1974) as evidence for an extension of the Gloucester Fault across the St. Lawrence River. The existance of a fault is further suggested by the enhancement of the Cornwall Low on the downward continuation and second derivative maps of region 'a'. The low may represent the effect of the downthrown block of the fault, but the localized nature of the low indicates that the anomaly-producing structure is not horizontally extensive. The gravity data suggests that a separate fault, probably related to the ottawaBonnechere Fault system but distinct from the Gloucester Fault may exist between Massena, New York and Cornwal1, ontario.

The Massena- Cornwall Fault has been the site of 
recent earthquake activity including an intensity VIII earthquake in 1944. No surface observation of this fault can be found in the literature, nor did subsequent geological investigations by the author reveal direct evidence of the fault.

Philpotts and Miller (1963) have determined that some faults comprising the system of faults in the St. Lawrence Valley to be Precambrian in age. If the Massena- Cornwall Fault is of Precambrian age, it is overlain by a thin Paleozolc sedimentary cover on the order of 20-40 meters thick showing no expression of the fault (NYSGA Guldebook,1971). Seismic studies are suggested to determine the spatial extent of this fault.

Gravity modeling of the Massena High reveals a second anomaly superimposed on the Massena anomaly. The body producing this anomaly was found to be distinct from the proposed structure causing the larger anomaly and may represent a mafic intrusive.

\section{Discussion}

4.1 St. Lawrence Rift System

Much emphasis has been placed in the literature on the seismicity of the St. Lawrence River Valley. Kumarapeli and Saull (1966) have postulated a rift origin for the St. Lawrence Valley. In support of this they cite the morphological similarity between the 
proposed St. Lawrence Rift System and other recognized rift valleys, the presence of features such as pop-ups and rock bursts which are indicative of stress, and the seismicity of the region, among other factors.

Bullard (1936) was the first to associate negative Bouguer gravity anomalies with rift valleys in a study of the East African Rift System. Girdler (1964) has found the same association of gravity lows with rift valleys in a study of rift valleys of the ivorld. If the St. Lawrence Valley was of a rift origin, the gravity isanomals produced by such a structure should run parallel to the axis of the rift valley. The presence of the Massena High and perpendicular trend of the gravity anomalies relative to the axis of the St. Lawrence Valley suggest the absence of any rift structure.

Earthquake data further suggest the absence of such a structure. Upon comparison of the location of the St. Lawrence Rift System (figure 6) with the epicenters of earthquakes in the region (figure 7 ) one does not notice a continuous trend of seismicity in the region, as should be the case with a rift system. In addition, the series of flanking faults, trending perpendicular to a typical rift valley, is not apparent on the gravity maps. Hence, the results of this study do not support the presence of a major rift system in this portion of the St. Lawrence Valley. 
4.2 Subsurface Faulting and Seismiclty

The gravity data suggest the presence of a fault across the St. Lawrence River between Massena, New York and Cornwall, Ontario. As previously mentioned, an earthquake of intensity VIII occured between Cornwall and Massena in 1944. Milne (1949) reports the epicenter at $7453.9 \mathrm{~W}$ longitude and $4458.5 \mathrm{~N}$ latitude with a focal depth of $25 \mathrm{~km}$. This determination places the epicenter between the Massena High and Cornwall Low on the Simple Bouguer map of region A (plate 3 ). Milne points out the scarcity of seismographs in the area at the time of the shock and that no definite depth of focus could be determined. Hence, the $25 \mathrm{~km}$ figure for the depth of focus should be ignored, although seismograms of the quake do suggest a subsurface focus. Intensity determinations of the shock place the epicenter at $75 \mathrm{~W}$ longitude and $45 \mathrm{~N}$ latitude which is in reasonable agreement with instrumental determinations.

Smith $(1962,1966)$ has shown that numerous quakes lie along the postulated fault. The gravity survey suggests that the fault originates between 0 and $3.2 \mathrm{~km}$ below sea-level. This observation is based on: 1) the disappearance of the Cornwall gravity low with an upward continuation of $3.2 \mathrm{~km}, 2$ ) the emphasis of the anomaly with a downward continuation of $3.2 \mathrm{~km}, 3$ ) the oscillation of the anomaly with downward continuations of $5.4 \mathrm{~km}$ or more, and 4) the emphasis of the Cornwall 
Low on the second derivative map.

sbar and sykes (1973) have suggested that a contemporary east-west compressive stress predominates in eastern North America. This hypothesis is based on stress measurements, the high frequency of earthquakes along with post-glaclal faults, folds, popups, and various rock squeeze features.

Albert,et, al (1976) have suggested that the reactivavion of ancient faults by a contemporary stress may be the cause of some east coast earthquakes. The latter hypothesis is further supported by seismic activity along the Massena- Cornwall Fault.

\subsection{Non-fault Structures and Seismicity}

Close examination of the epicenter map (figure 7) reveals that earthquakes are not confined to the proposed fault. In addition, the gravity survey falled to reveal the existence of other faults within the region. Hence, although some of the earthquakes in this portion of the St. Lawrence River Valley may lie along ancient faults, others show nelther a correlation with recognized surface faulting nor a correlation with surface and subsurface faults revealed by the gravity survey.

Fox (1970), Long and Mc Kee (1973), Long (1975a,b), Mc Keown (1975) and Long (1976) have speculated on the association of epiceneters with mafic intrusions in the southeastern United States. Long (1976) has pointed 
out that the proximity of earthquakes to mafic intrusives is insufficient cause to suggest a distinct physical relationship between intrusives and seismicity. Long has found, however, a distinct correlation between high gradients of gravity (toward positive) and the distribution of epicenters in Georgia and western South Carolina.

In the present study, the Massena anomaly showed a distinct gravity high superimposed on the larger anomaly. The cause of this superimposed high may be a mafic intrusion. It is interesting to note the proximity of the suggested body to earthquake epicenters in the region (figures $7,8,9-11$; plate 3 ).

Revetta (personal comm.) has noticed a similar relationship between positive gravity anomalies believed to be produced by mafic units and epicenters in western New York.

Long (1975a) has suggested that the higher rigidity of mafic crustal units results in a greater resistance to deformation than do the surrounding crustal rocks. Therefore, they favor the amplification of regional stresses. Mc Keown (1975) suggested that local hlgh stress concentrations occur both within the mafic rocks and at their contacts with the host rock. The release of remnant stress from a mafic unit results in the triggering of earthquakes.

If the association of mafic intrusions with selsmicity is a reality, the contemporary compressive 
stress found by Sbar and Sykes (1973) may provide the necessary force to initlate earthquakes along such structures. The current study favors the hypothesis of Long concerning stress amplification. Because the gravity data suggest that the Massena intrusive is located at a depth of $3.3 \mathrm{~km}$, below the PrecambrianPaleozolc unconformity, the intrusive should be of Precambrian age. It is doubtful whether remnant stress from a Precambrian body would be of sufficient intensity to generate contemporary earthquakes.

In order to confirm whether a relationship between mafic units and earthquakes exists in northern New York, a detailed magnetic survey coupled with microearthquake studies should be initiated over the Massena intrusive.

4.4 Relationship of Gravity Data to Selsmic-trend Hypotheses

Numerous seismic trends have been proposed in eastern North America. Woollard (1969) suggested a seismic trend along the entire St. Lawrence Valley into Arkansas. Leblanc, et. al. (1971) and Diment, et. al (1972) postulated a seismic trend from Boston to 0ttawa, whlle the latter suggested that this trend may bear some relationship to the Kelvin Seamount Chain (figure 8).

close examination of each of these trends reveals prominent gaps along the trends. The relatively short 
time of recorded earthquakes in comparison with geologic time can account for some of the gaps, but is unlikely that major gaps should result.

A contemporary feature, such as the San Andreas Fault of the western United States displays a continuous line of seismiclty along its entlre length (Richter, 1958). Based on this observation, it is unlikely that the seismicity of the east coast of the U.S. can be related to a contemporary feature. Also, gravity studies of the east coast do not reveal major continuous structures which can explain a good portion of the seismicity.

The results of this study suggest that a portion of the seismicity of the study area, and perhaps that of a large section of the east coast, may be related to ancient subsurface structures. Ancient features, such as the Kelvin Seamount Chain may have been subsequently reactivated by a contemporary compressive stress. These structures may include surface faulting, subsurface faulting, and mafic intrusives.

Albert,et. al (1976) have shown that the reactivation of ancient faults depends upon their strike direction relative to the present principal stress and their strength. As a result, a range of fault angles exist for which reactivation occurs. Some faults will not display reactivation resulting in gaps along any of the proposed trends. In addition, since stress is released at an angle to the princlpal stress, 
and not parallel to it, as is the case for contemporary structures, earthquakes of a low magnitude result.

A similar arguement can be made for the association of mafic intrusives with eplcenters. Because intrusives are spatially localized, any seismic trend associated with mafic units should display prominent gaps. The host rock and its rigidity in relation to the intrusion must also be considered. If the intrusion and its host are of simllar rigidity, stress amplification should be at a minimum and the resultant seismicity should be at a minimum.

These hypotheses may explain the absence of a continuous line of seismicity along the proposed trends.

\section{Conclusion}

The application of the upward continuation, downward continuation, and second derivative methods to gravity data from a geologically complex region such as the St. Lawrence River Valley has demonstrated their effectiveness in producing a three-dimensional view of anomaly-producing structures originating at varying, depths. The analyses mentioned allow for the separation of anomalies that are depth-related, providing the investigator with the opportunity to develop models for individual structures and observe the behavior of the gravity produced at different levels. This practice, coupled with sound geological 
reasoning, allows for a better delineation of depth, density, and geometrical parameters of a structure.

The gravity and seismic evidence supporting the existence of the Massena- Cornwall Fault and the Massena intrusive suggest possible origins for some east-coast earthquakes. Ancient, subsurface faults which have been reactivated by a contemporary compressive stress is suggested as a possible origin for some unexplained east-coast selsmicity. The association of mafic intrusives with earthquakes, although not conclusive, is also suggested as a possible origin for other east-coast earthquakes. It is recommended that similar gravity surveys be conducted in areas of high seismicity along the east coast in order to determine if identical relationships between gravity and seismic activity exist.

In the case of areas in which surface faulting and earthquake activity show either positive or negative correlations, extensive studies involving fault plane solutions and the orientations of faults relative to the principal stress should be made. In addition, detailed gravity, magnetic, and seismic investigations are recommended in seismically -active areas to determine whether relationships among subsurface faulting, mafic intrusives, and earthquakes exist. 


\section{REFERENCES}

Albert, R.I., J.E. Moore, and I.W. Rom, Supervised By F.A. Revetta, 1974. A Gravity and Magnetic Survey of the St. Lawrence River Valley. On Open File At N.Y.S. Mus. and sci. Service, Geol. Survey, Albany, N.Y., 19 p. Albert, R.I., E.F. Chiburis, and R.K. Frohlich, 1976.

Intensity and Magnitude Determination of March 11, 1976 Portsmouth, Rhode Island Earthquake. Earthquake Notes,

Easterm Sec. Seis. Soc. Amer., vol. 47, no. 3, p. 21-28. Guddington, A.F., 1934. Geology and Mineral Resources of the Hammond, Antwerp, and Iowville Quadrangles. N.Y. State Mus. Bull. 296, 251 p.

puddington, A.F., 1939. Adirondack Igneous Rocks and Their

Metamorphism. Geol. Soc. Amer. Memoir 7, 354 p. Bullard, Sir Edward, 1936. Gravity Measurements in East Africa. Phil. Trans. Roy. Soc. Iondon, Ser. A, no. 235, 445 p.

Dames and Moore, 1973. Regional Geologic and Tectonic Study, St. Iawrence River Valley. Private Report to N.Y.S. Atomic and Space Development Authority. Diment, W.H., T.C. Urban, and F.A. Revetta, 1972. Some Geophysical Anomalies in the Eastern United States. In: Robertson, E.C. Ed; The Nature of the Solid Earth, McGraw-Hill, New York, p. 544-574. Dobrin, M.B., 1960. Introduction to Geophysical Prospecting. 2nd Edition, McGraw-Hill, New York, 446 p. 
Frensne, C., 1948. Faulting in the St. Lawrence Plain. Unpubl. M. Sc. Thesis, McGill University, Montreal. Blkins, T.A., 1951. The Second Derivative Method of Gravity Interpretation. Geophysics, vol. 16, p. 29-50. Fngel, A.E.J., and C.G. Engel, 1953. Grenville Series in the Northwest Adirondack Mountains, New York, Parts.I and II. Geol. Soc. Amer. Bull., vol. 64, p. 1013-1097. Fox, F.I., 1970. Seismic Geology of the Eastern United States. Assoc. Fing. Geologists Bull., vol. 7, p. 2l-43. Girdler, R.W., 1964. Geophysical Studies of Rift Valleys.

In: Physics and Chemistry of the Earth, vol. 5. Edited by Ahrens, Press, and Runcerm, Progress Ser., Pergamon Press, p. 122.

Hadley, J.B., and J.F. Devine, 1974. Seismotectonic Map of the Easterm United States, Series A, B, and C. Miscellaneous Field Studies MF 620, U.S.G.S. Menderson, R.G., 1960. A Comprehensive System of Automatic Computation in Magnetic and Gravity Interpretation. Geophysics, vol. 25, p. 569-585. lenderson, R.G., and I. Zietz, 1949. The Computation of Second Vertical Derivatives of Geomagnetic Fields. Geophysics, vol. 14, p. 508-516. Kane, M.F., G. Simmons, W.H. Diment, M.M. Fitzpatrick, W.B. Joyner, and R.W. Bromery, 1972. Bouguer Gravity and Generalized Geologic Map of New England and Adjoining States. Geophysical Investigations no. GP 839, U.S.G.S., Washington, D.C., 5.p. 
Katz, S., 1955. Seismic Study of Crustal Structure in Pennsylvania and New York. Bull. Seismol. Soc. Amer., rol. 45, p. 303-325.

Kay, G.M., 1942. Ottawa-Bonnechere Graben and the Lake Ontario Homocline. Bull. Geol. Soc. Amer., vol. 53, p. 585 .

Lirchgasser, W., and G. Theokritoff, 1971. Precambrian and Lower Paleozoic Stratigraphy, Northwest St. Lawrence and North Jefferson Counties, New York. In: Geological Studies of the Northwest Adirondacks Region, B.B. VanDiver Editor, N.Y.S.G.A. Field Trip Guidebook, 43rd Meeting, p. BI-B24.

Ermarapeli, P.S., and V.A. Saull, 1966. The St. Lawrence Valley and System: A North American Equivalent of the East African Rift Valley System.Canadian Jour. Earth Sci., vol. 3, p. 639-658.

IeBlanc, G., R.J. Wetmillen, A.E. Stevens, and R. DuBerger, 1971. Microseismic Survey of the St. Lawrence Valley Near LaMalbaie, Quebec. (abs.): Earthquake Notes, vol. $42, \mathrm{p} .16$.

Iong, I.T., and J.H. McKee, 1973. A Microearthquake Survey Near Bowman, South Carolina. (abs.): Earthquake Notes, vol. 44, p. 65 .

Iong, I.T., 1974. Bouguer Gravity Anomalies of Georgia. In: Symposium on the Petroleum Geology of the Georgia Coastal Plain. Georgia Geological Survey Bull., vol. 87, p. 141166. 
Iong, I.T., 1975a. A Model For the Earthquake Tectonics of the Bowman and Summerville, South Carolina Epicentral Zones. (abs.): Bull. Geol. Soc. Amer., S.E. Section Abstracts with Programs, vol. 7, p. 511. Iong, I.T., 1975b. The 1886 Charleston, S.C. Farthquake and Its Relation to the Seismicity of the Southeastern United States. (abs.): Barthquake Notes, vol. 46, p. 50. Iong, I.T., 1976. Speculations Concerning Southeasterm

Barthquakes, Mafic Intrusions, Gravity Anomalies, and Stress Amplification. Earthquake Notes, Eastern Sec. Seis. Soc. Amer., vol. 47, no. 3, p. 29-35. McKeown, F.A., 1975. Hypothesis: Mafic Intrusives and Their Contact Zones Are Source Zones of Many Earthquakes in Central and Southeastern United States. (abs.):

Earthquake Notes, vol. 46, p. 53.

Milne, W.G., 1949. The Location of the Cormwall-Massena

Earthquake, September 5, 1944. Publ. of the Dominion Observ., vol. 7, no. 9, p. 345-362.

Nettleton, I.I., 1940. Geophysical Prospecting For 0il, McGraw-Hill, New York, 444 p. Nettleton, I.I., 1954. Regionals, Residuals, and Structures. Geophysics, vol. 19, p. 1-22. Peters, I.J., 1949. The Direct Approach to Magnetic Interpretation and Its Practical Application. Geophysics, vol. 14, p. 290-320. 
Philpotts, A.R., and J.A. Miller, 1963. A Precambrian Glass From Alexis Des-Monts, Quebec. Geol. Mas., vol. 100, no. 4, p. 337 .

Richter, C.F., 1958. Elementary Seismology. W.H. Freeman and Co., San Francisco, 768 p.

Rosenbach, Otto, 1953. A Contribution to the Computation of the "Second Derivative" From Gravity Data. Geophysics, rol. 18, no. 48, p. 894-912.

Sbar, M.I., and I.R. Sykes, 1973. Contemporary Stress and Seismicity in Eastern North America: An Example of Intra-Plate Tectonics. Geol. Soc. Amer. Bull., vol.84, p. 1861-1882.

Simmons, Gene, 1964. Gravity Survey and Geological

Interpretation, Northern New York. Geol, Soc. Amer. Bull., vol. 75, p. 81-98.

Simmons, G., and W.H. Diment, 1972. Simple Bouguer Gravity Anomaly Map of Northerm New York. Publ. New York State Mus. and Sci. Service, Geol. Survey Map and Chart Series no. $17 \mathrm{~A}$.

Smith, W.E.T., 1962. Earthquakes of Eastern Canada and Adjacent Areas, 1534-1927. Dominion Observatory Ottawa Pubs., vol. 26, p. 271-301.

Smith, W.E.T., 1966. Earthquakes of Easterm Canada and Adjacent Areas, 1928-1959. Dominion Observatory Ottawa Pubs., vol. 32, p. 87-121. Smith, W.E.T., 1967. Basic Seismology and Seismicity of Fasterm Canada. Dominion Observatory Ser. 1966-Z, 43 p. 
sykes, I.R., and M.I. Sbar, 1973. Intraplate Earthquakes, Iithospheric Stresses and the Driving Mechanism of Plate Tectonics. Nature, vol. 245, p. 298-302. Talwani, M., 1965. Computation With the Help of a Digital Computer of Magnetic Anomalies Caused By Bodies of Arbitrary Shape. Geophysics, vol. 30, no. 5, p. 797-817. Trejo, C.A., 1954. A Note On Downward Continuation of Gravity. Geophysics, vol. 19, p. 71-75. U.S.G.S., 1969. Documentation For Grid Generation Program no. W9322. U.S.G.S. Computer Center Division, Washington, D.C., $11 \mathrm{p}$. VanDiver, B.B., 1971. Preface to Geological Studies of the Northwest Adirondacks Region, N.Y.S.G.A. Field Trip Guidebook, 43rd Meeting, p. i-iif, SUNY Potsdam, N.Y. Woollard, G.P., 1969. Tectonic Activity in North America As

Indicated By Earthquakes. In: The Earth's Crust and Upper Mantle, Geophysical Monograph 13, Edited By P.J. Hart. Amer. Geophys. Union, Washington, D.C., p. 125-133. 
PLATES

$1-16$ 
Plate 1

Gravity station density of Region A.

Station spacing $=3.2 \mathrm{~km}$ 


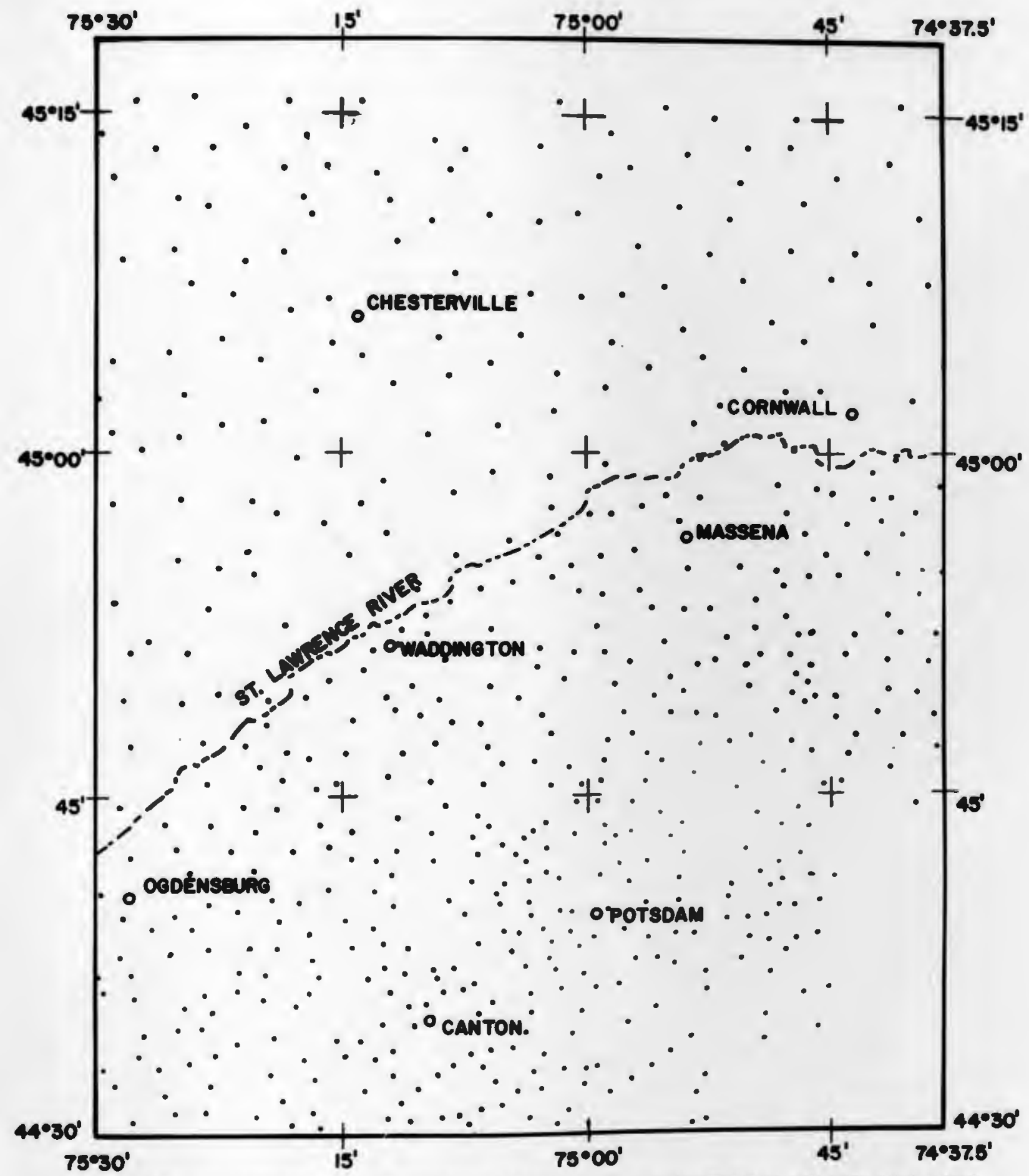

GRAVITY STATION DENSITY MAP ST. LAWRENCE RIVER VALLEY REGION A

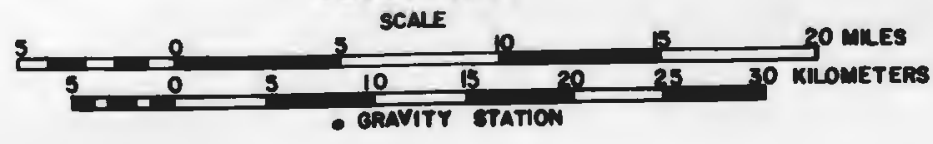




\section{Plate 2}

Gravity station density of Region $B$.

Station spacing $=3.2 \mathrm{~km}$ 

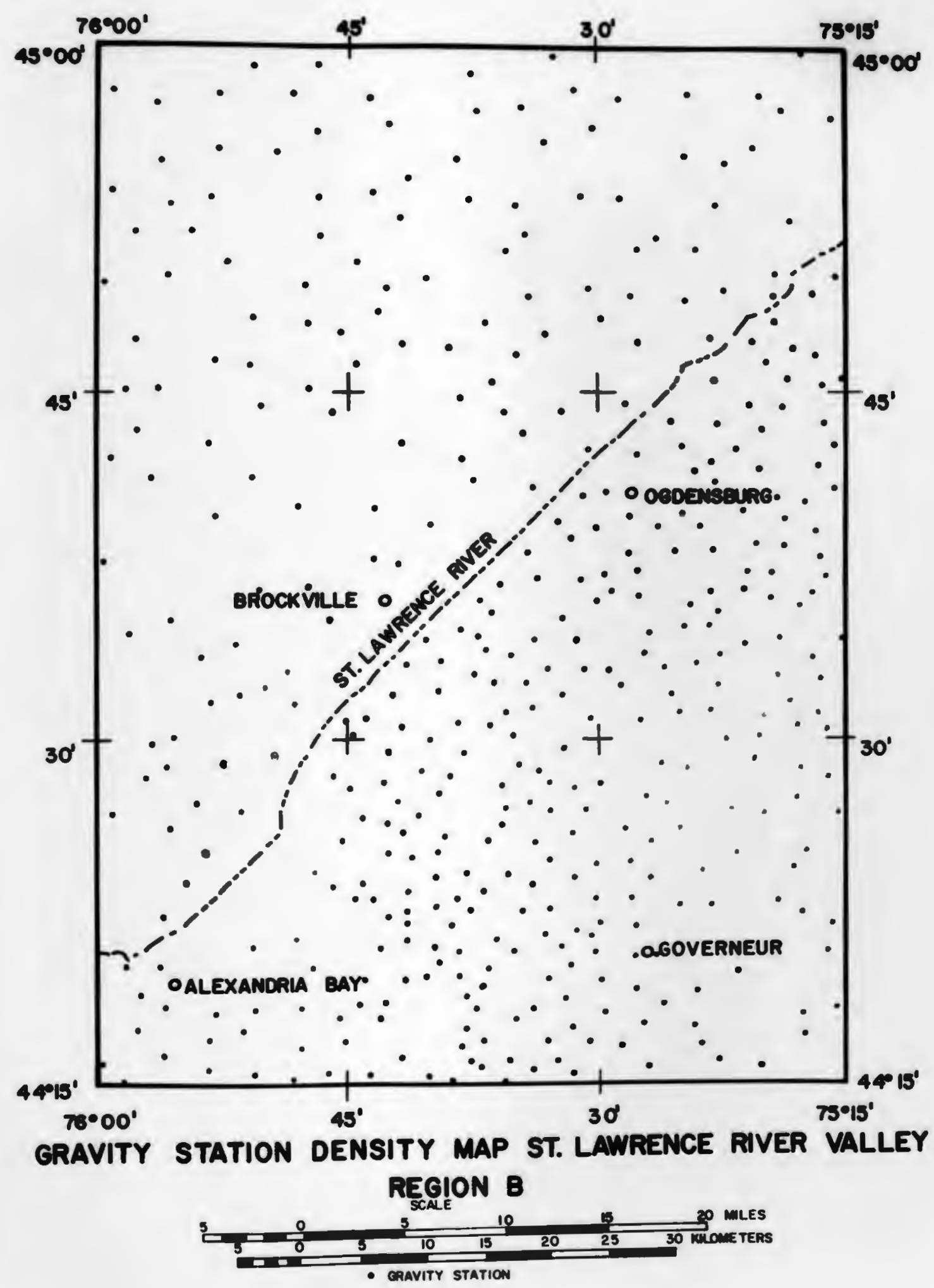


\section{Plate 3}

Simple Bouguer gravity map of Region A. Contour interval $=2 \mathrm{mgals}$ 


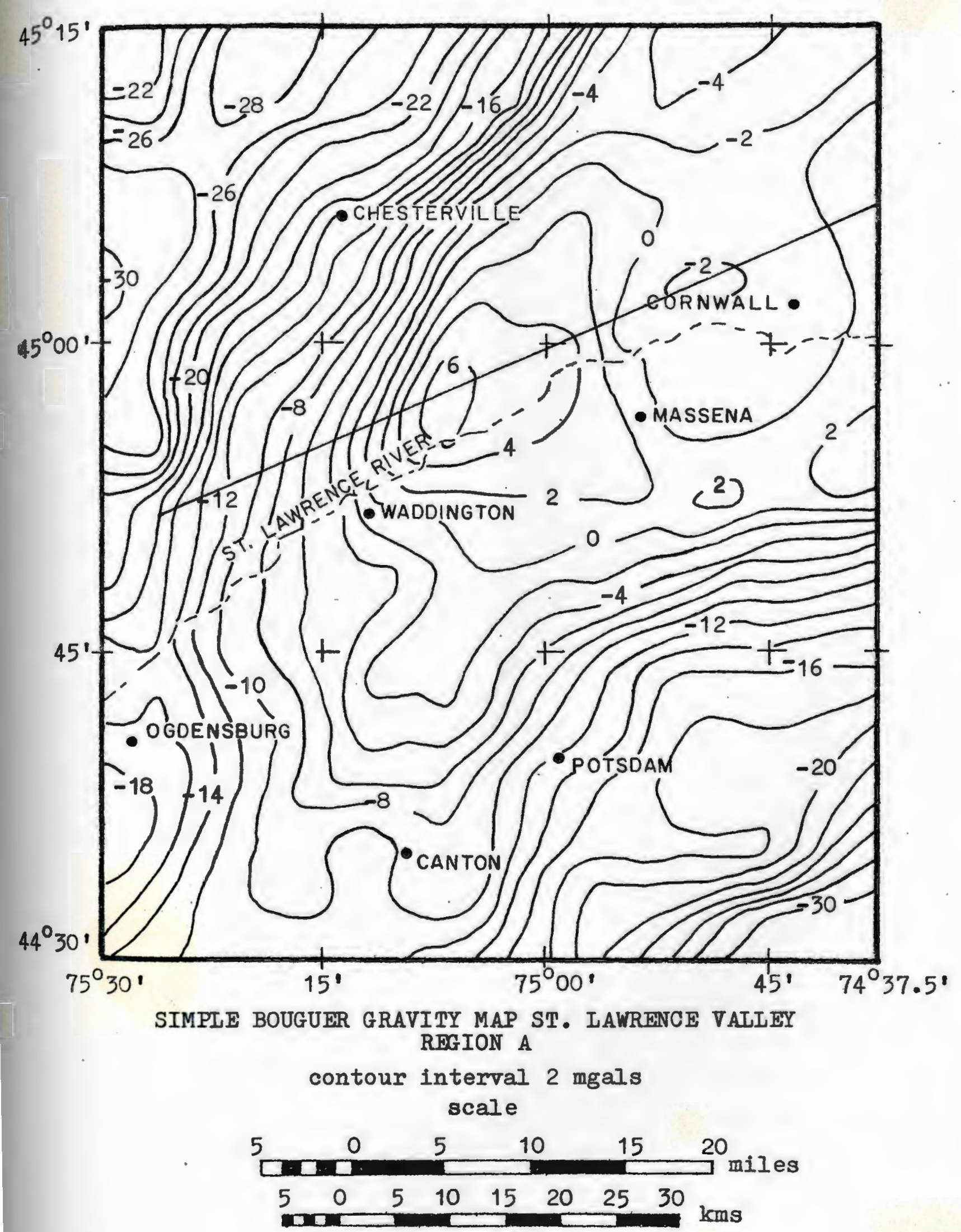




\section{Plate 4}

Upward continuation level $1(3.2 \mathrm{~km})$ of Region A. Contour interval $=1 \mathrm{mgal}$ 


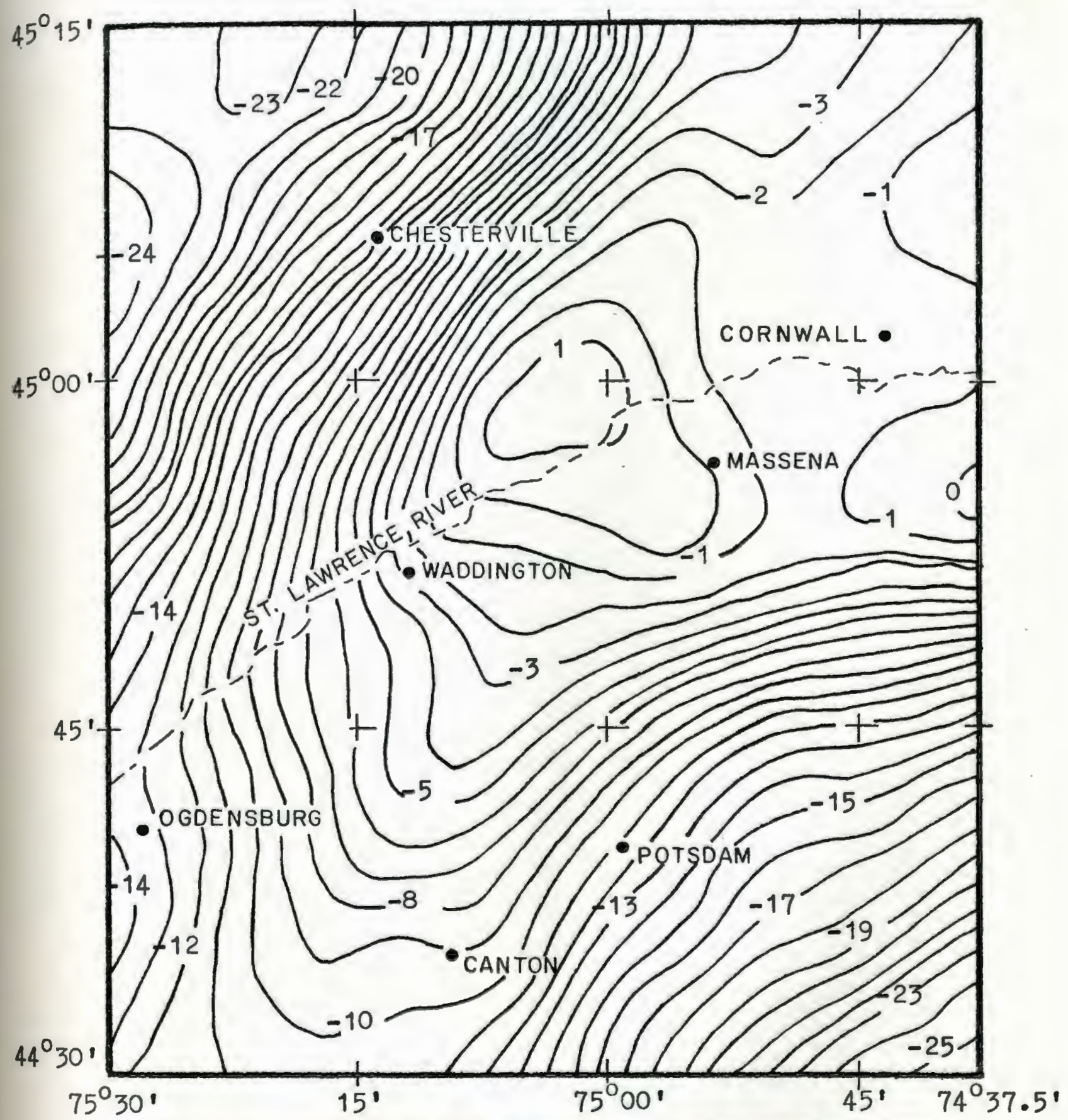

UPWARD CONTINUATION GRAVITY MAP ST. IAWRENCE VAILEY IIVEH 1 REGION A

contour interval $1 \mathrm{mgal}$

scale

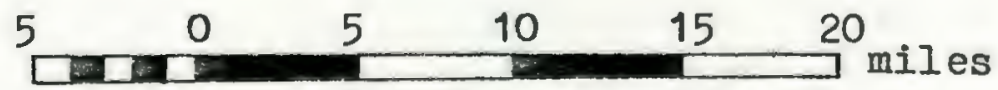

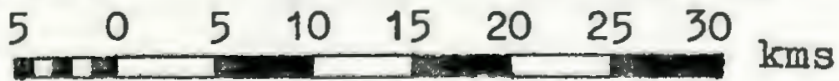


Plate 5

Upward continuation level $2(6.4 \mathrm{~km})$ of Region A. Contour interval $=2 \mathrm{mgals}$ 


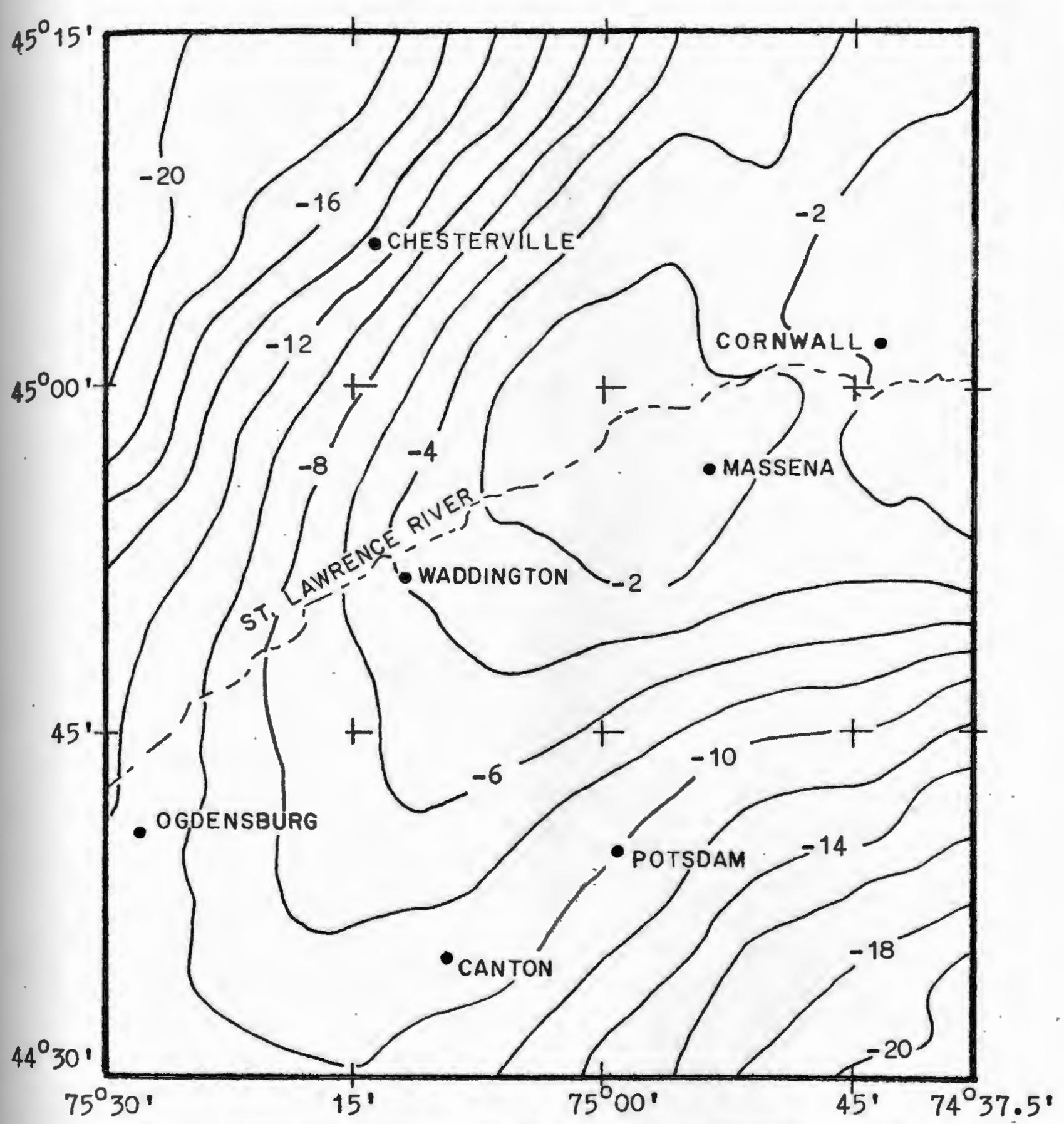

UPWARD CONTINUATION GRAVITY MAP ST. IAWRENCE VALLEY LEVEL 2 REGION A

contour interval 2 mgals scale

\begin{tabular}{llllll}
5 & 0 & 5 & 10 & 15 & 20 \\
\hline & 0 & & & &
\end{tabular}

\begin{tabular}{llllllll}
5 & 0 & 5 & 10 & 15 & 20 & 25 & 30 \\
\hline
\end{tabular} 
Plate 6

Upward continuation level $3(9.6 \mathrm{~km})$ of Region A. Contour interval $=2 \mathrm{mgals}$ 


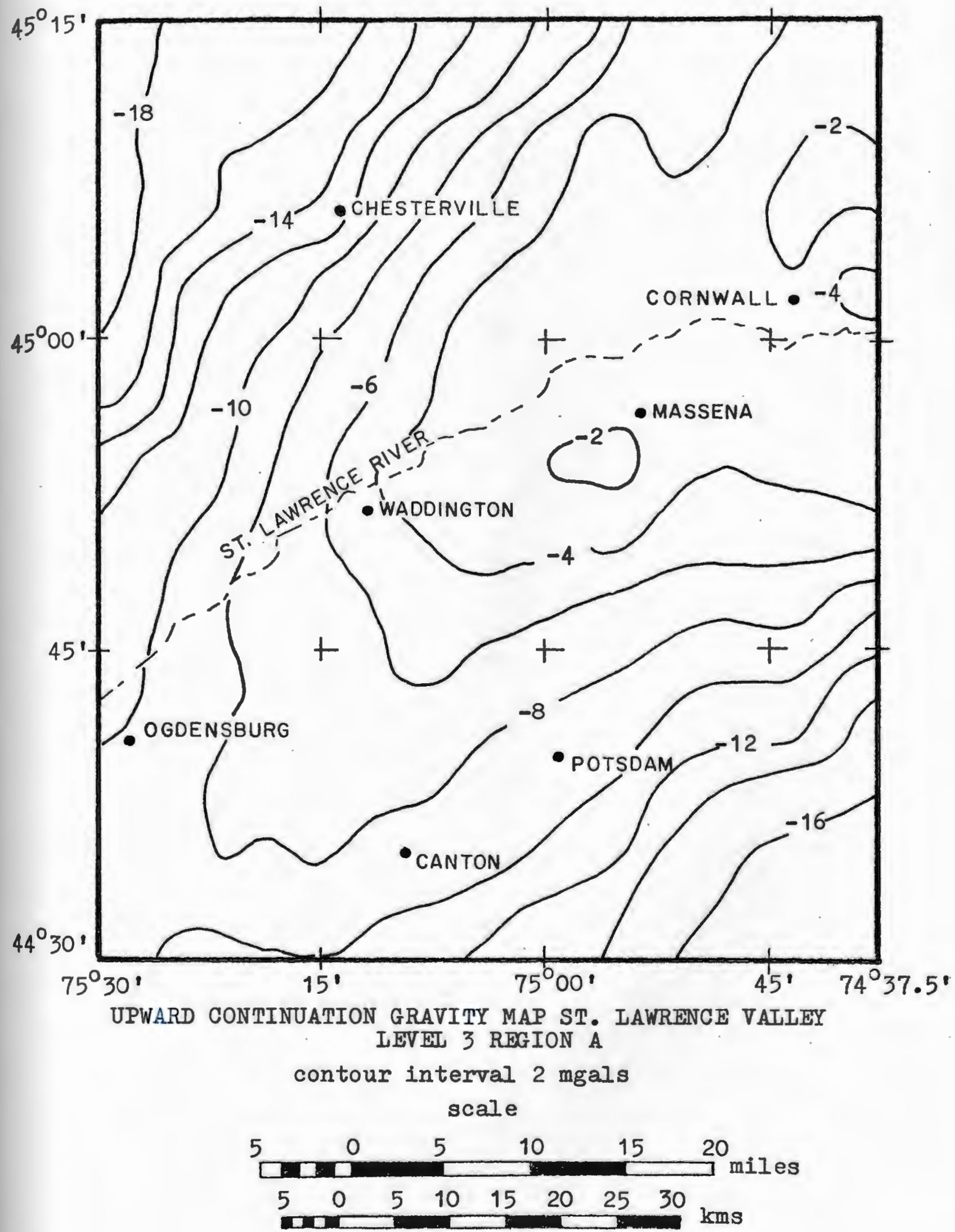




\section{Plate 7}

Downward continuation level I $(-3.2 \mathrm{~km})$ of Region $A$. Contour interval $=10 \mathrm{mgals}$ 


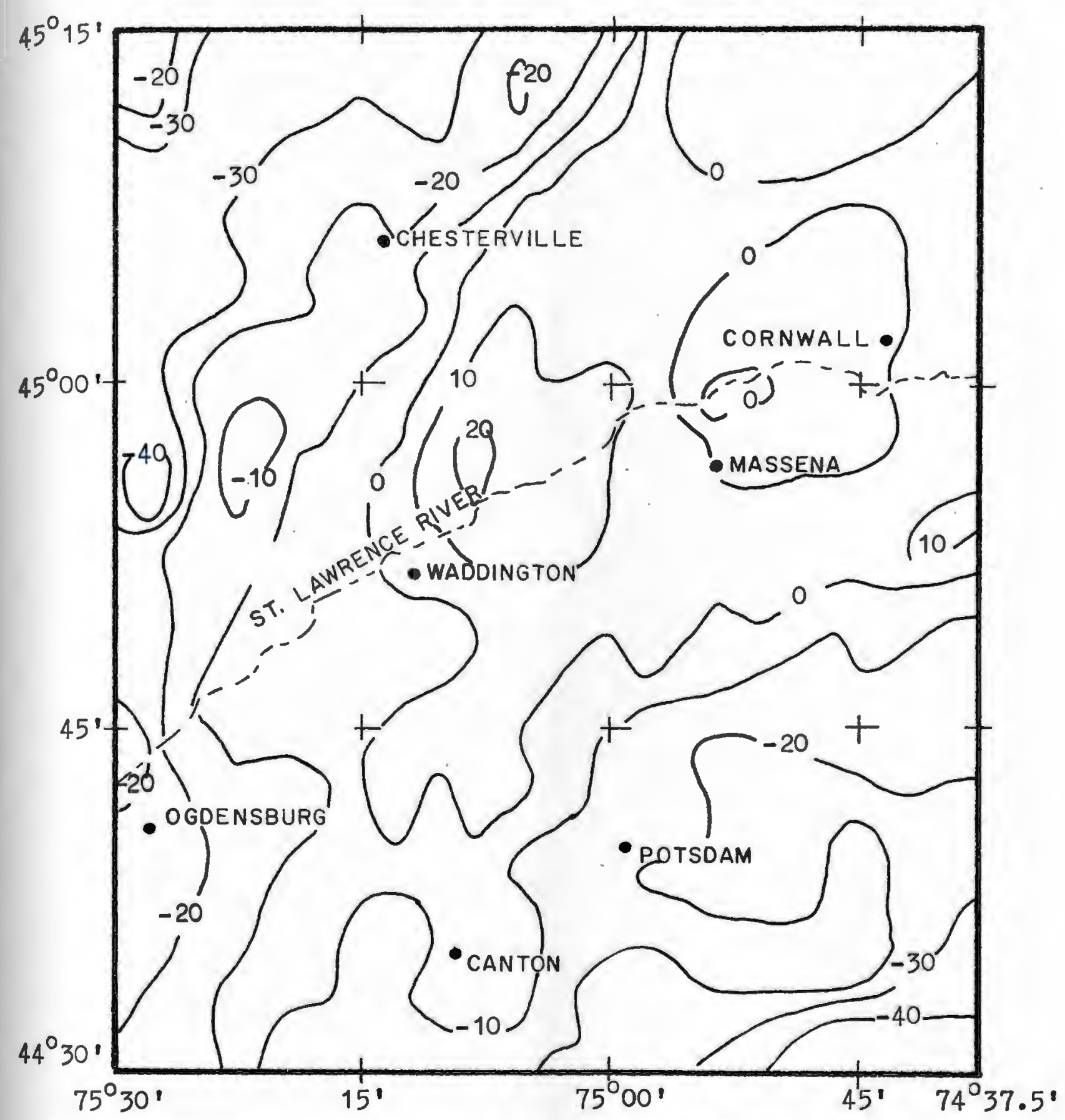

DOWNWARD CONTINUATION GRAVITY MAP ST. IAWRENCE VALLEY LEVEL 1 REGION A

$$
\begin{gathered}
\text { contour interval } 10 \text { mgals } \\
\text { scale }
\end{gathered}
$$

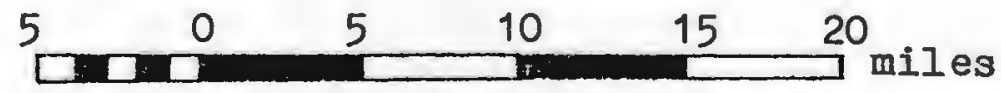

\begin{tabular}{lllllllll}
5 & 0 & 5 & 10 & 15 & 20 & 25 & 30 & \\
\hline
\end{tabular} 


\section{Plate 8}

Generalized geologic map of Region A.

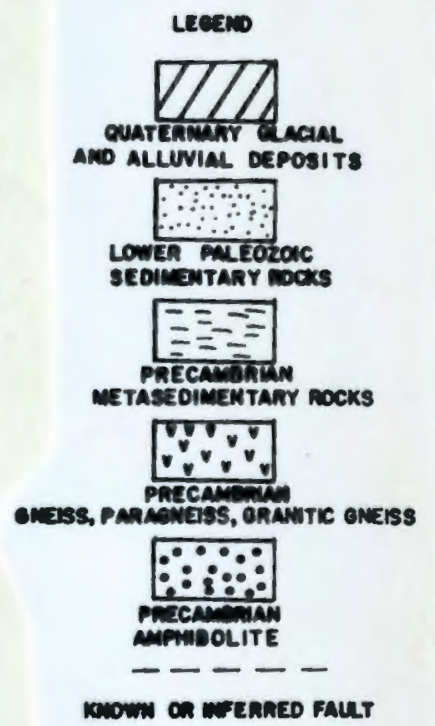




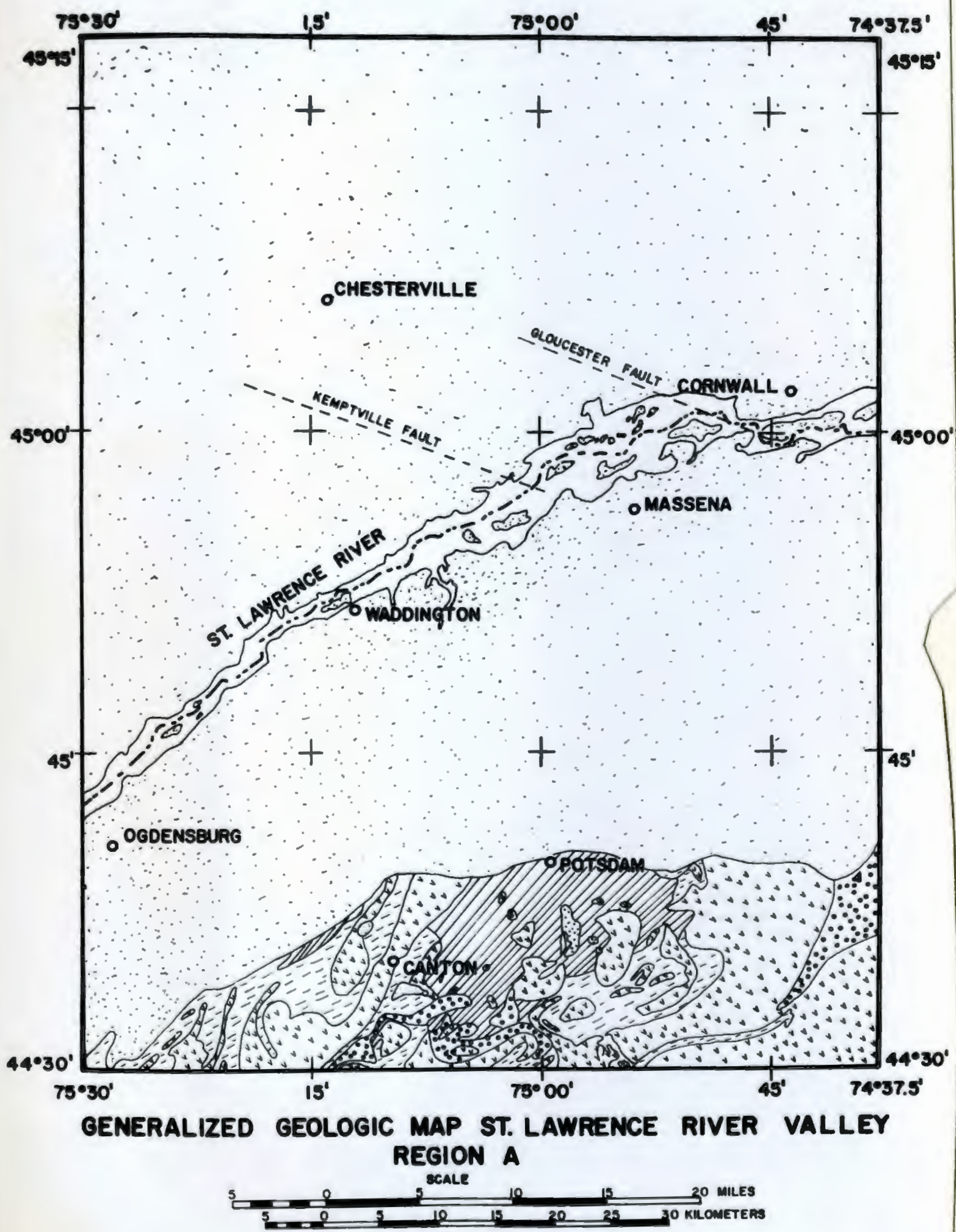




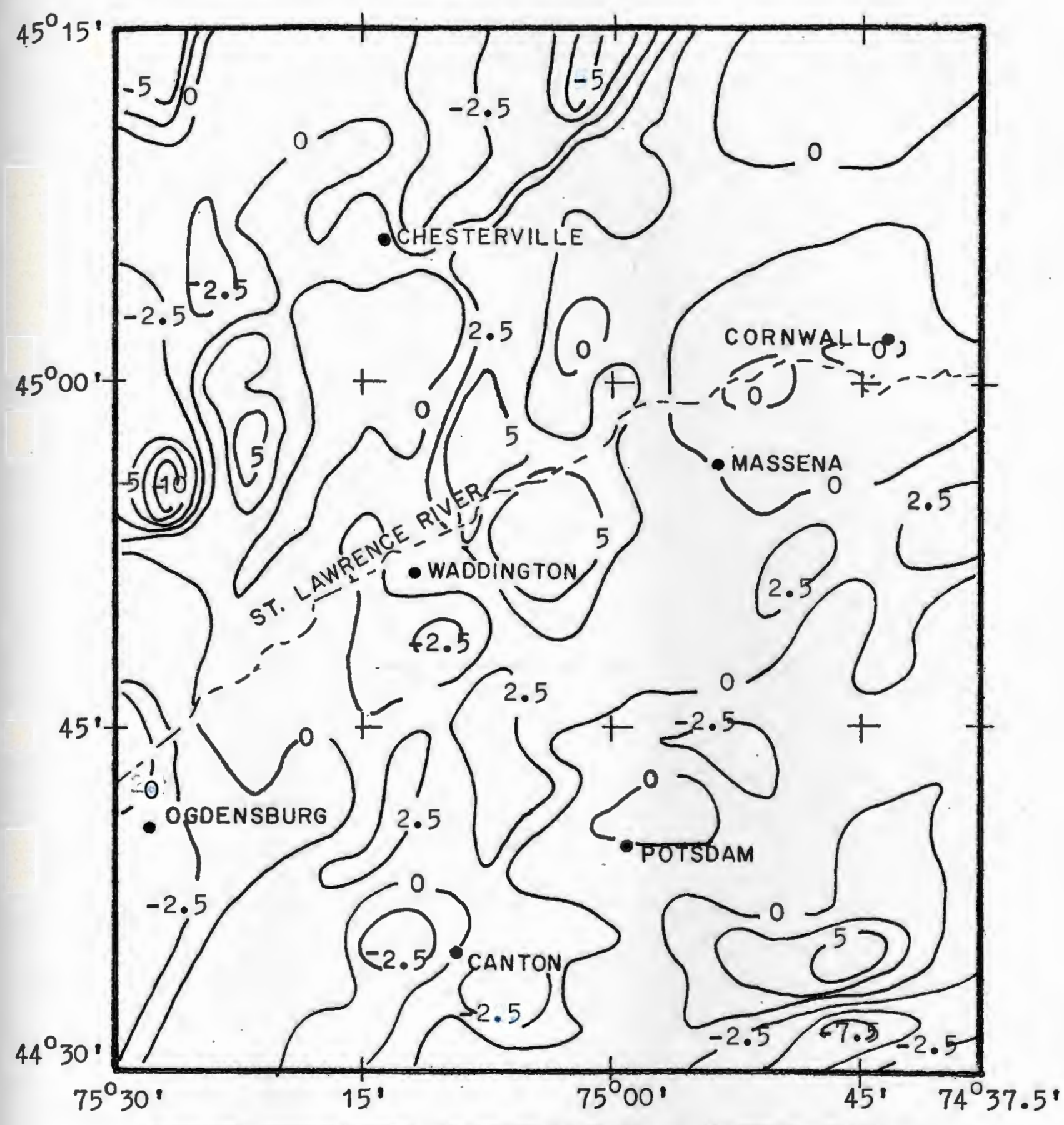

SECOND DERIVATIVE GRAVITY MAP ST. LAWRENCE VALLEY SURFACE REGION A

contour interval 2.5 mgals

scale

\begin{tabular}{llllll}
5 & 0 & 5 & 10 & 15 & 20 \\
\hline
\end{tabular}

$\begin{array}{lllllllll}5 & 0 & 5 & 10 & 15 & 20 & 25 & 30 & \mathrm{kms}\end{array}$ 
Plate 10

Simple Bouguer gravity map of Region B. Contour interval = $2 \mathrm{mgals}$ 


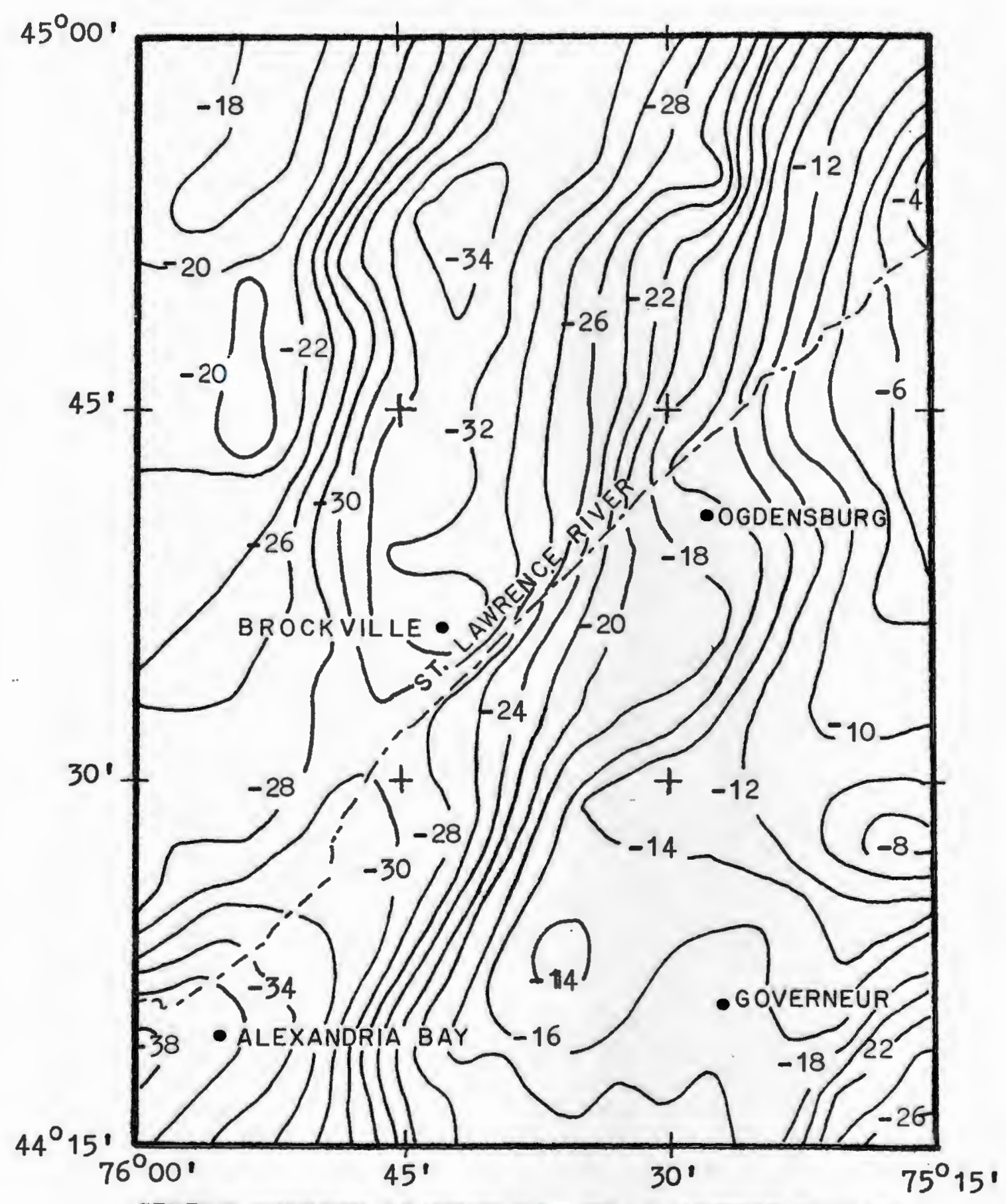

SIMPLE BOUGUER GRAVITY MAP ST. LAWRENCE VALLEY REGION B

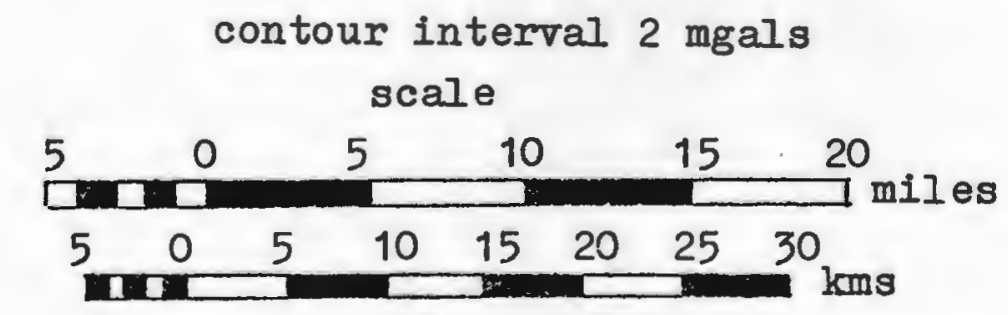


Plate 11

Upward continuation map level $1(3.2 \mathrm{~km})$ of Region B. Contour interval $=2 \mathrm{mgals}$ 


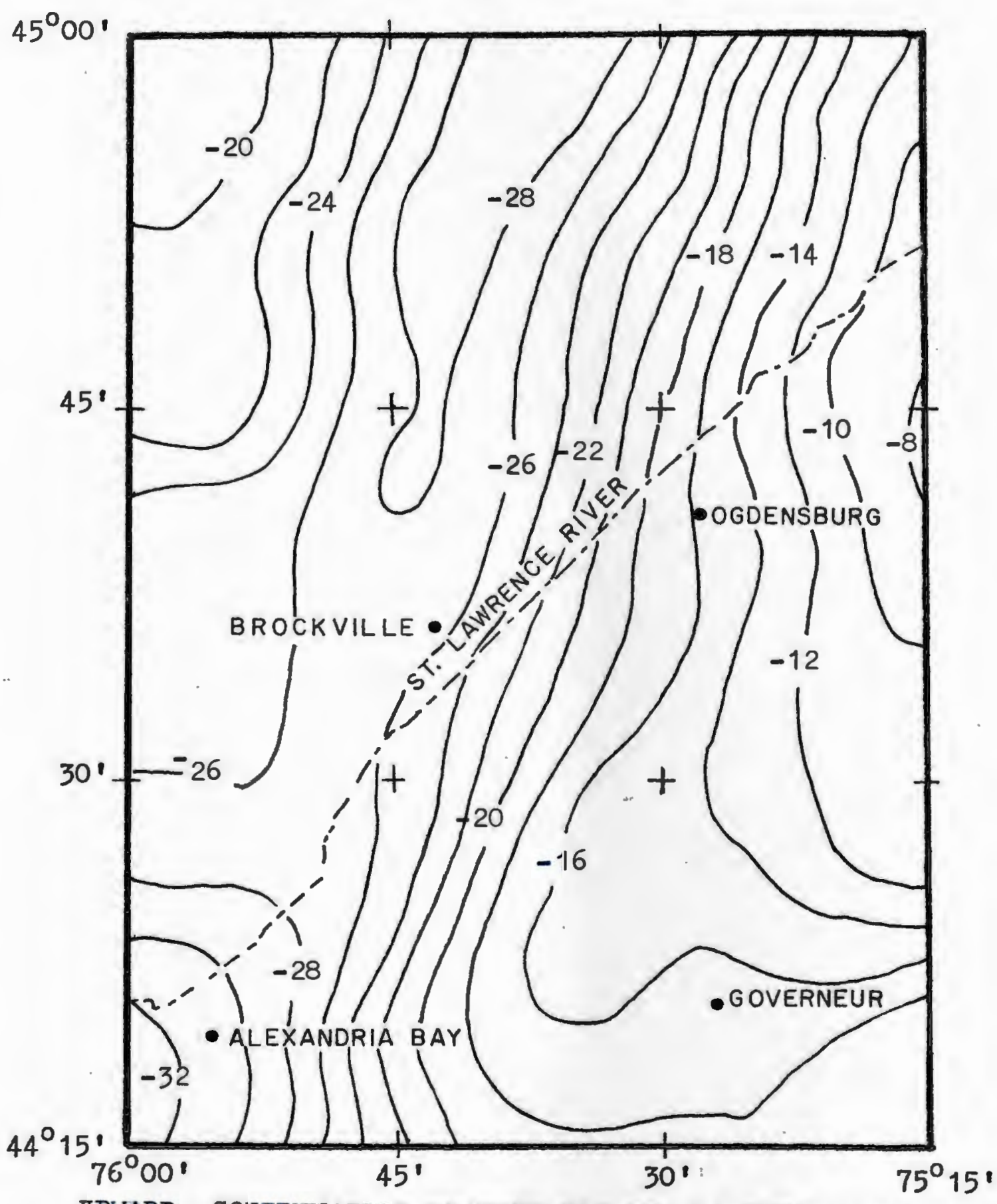

UPWARD CONTINUATION GRAVITY MAP ST. IAWRENCE VALLEY LEVES 1 REGION B

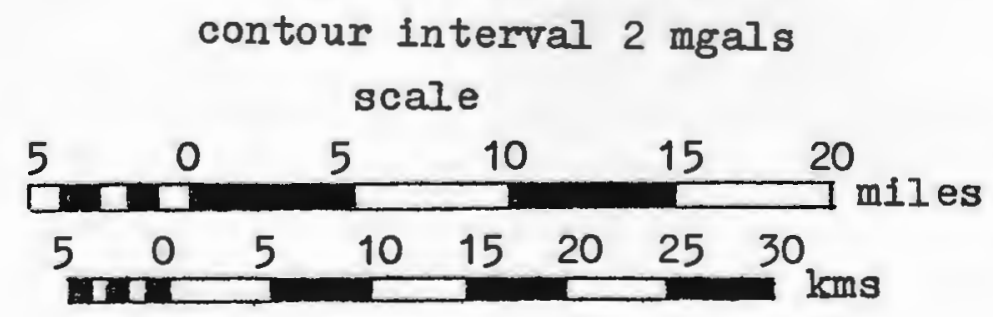


Plate 12

Upward continuation level $2(6.4 \mathrm{~km})$ of Region $B$. Contour interval $=2 \mathrm{mgals}$ 


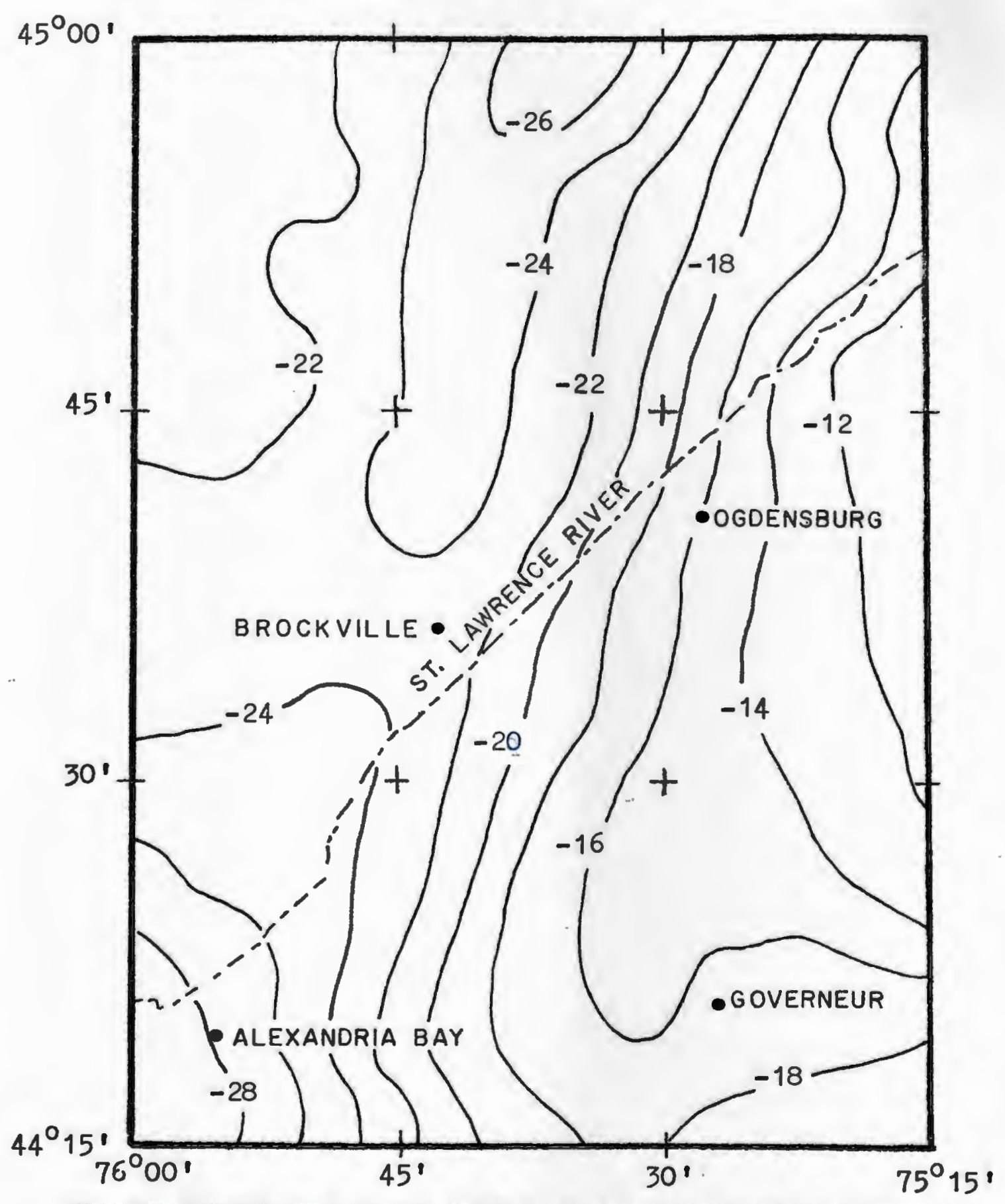

UPWARD CONTINUATION GRAVITY MAP ST. IAWRENCE VALLEY LEV HES 2 REGION B

contour interval 2 mgals scale

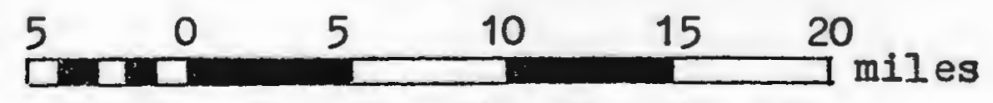

$\begin{array}{llllllll}5 & 0 & 5 & 10 & 15 & 20 & 25 & 30 \\ \mathbf{m a n} & & & & & & \end{array}$ 
Plate 13

Upward continuation level $3(9.6 \mathrm{~km})$ of Region B. Contour interval $=2$ mgals 


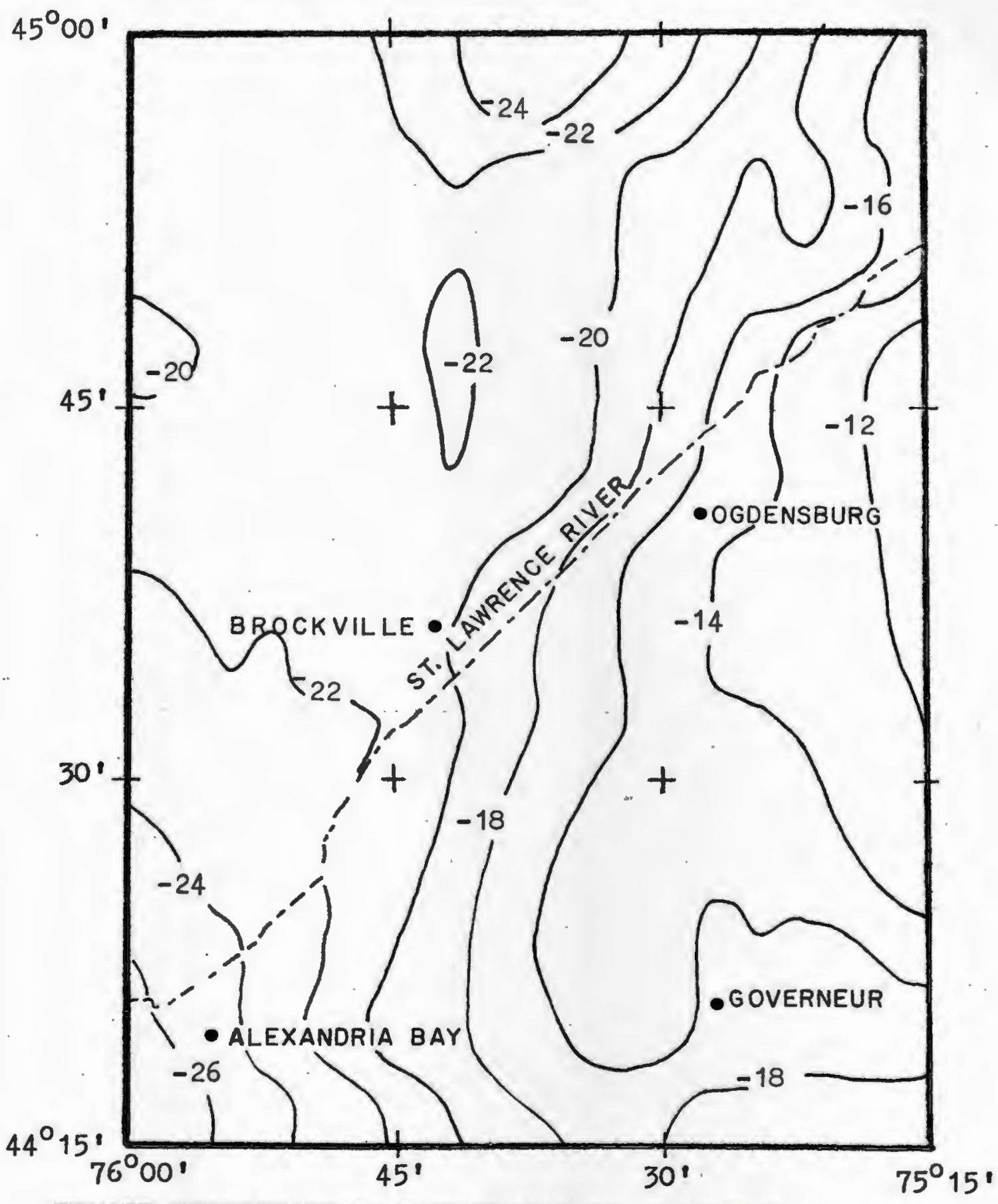

UPWARD CONTINUATION GRAVITY MAP ST. LAWRENCE VALLEY LEV EH 3 RFGION $B$

$$
\begin{gathered}
\text { contour interval } 2 \text { mgals } \\
\text { scale }
\end{gathered}
$$

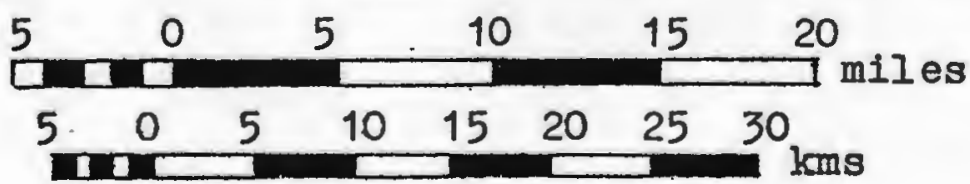




\section{Plate 14}

Downward continuation level I (- $3.2 \mathrm{~km})$ of Region B. Contour interval $=10 \mathrm{mgals}$ 


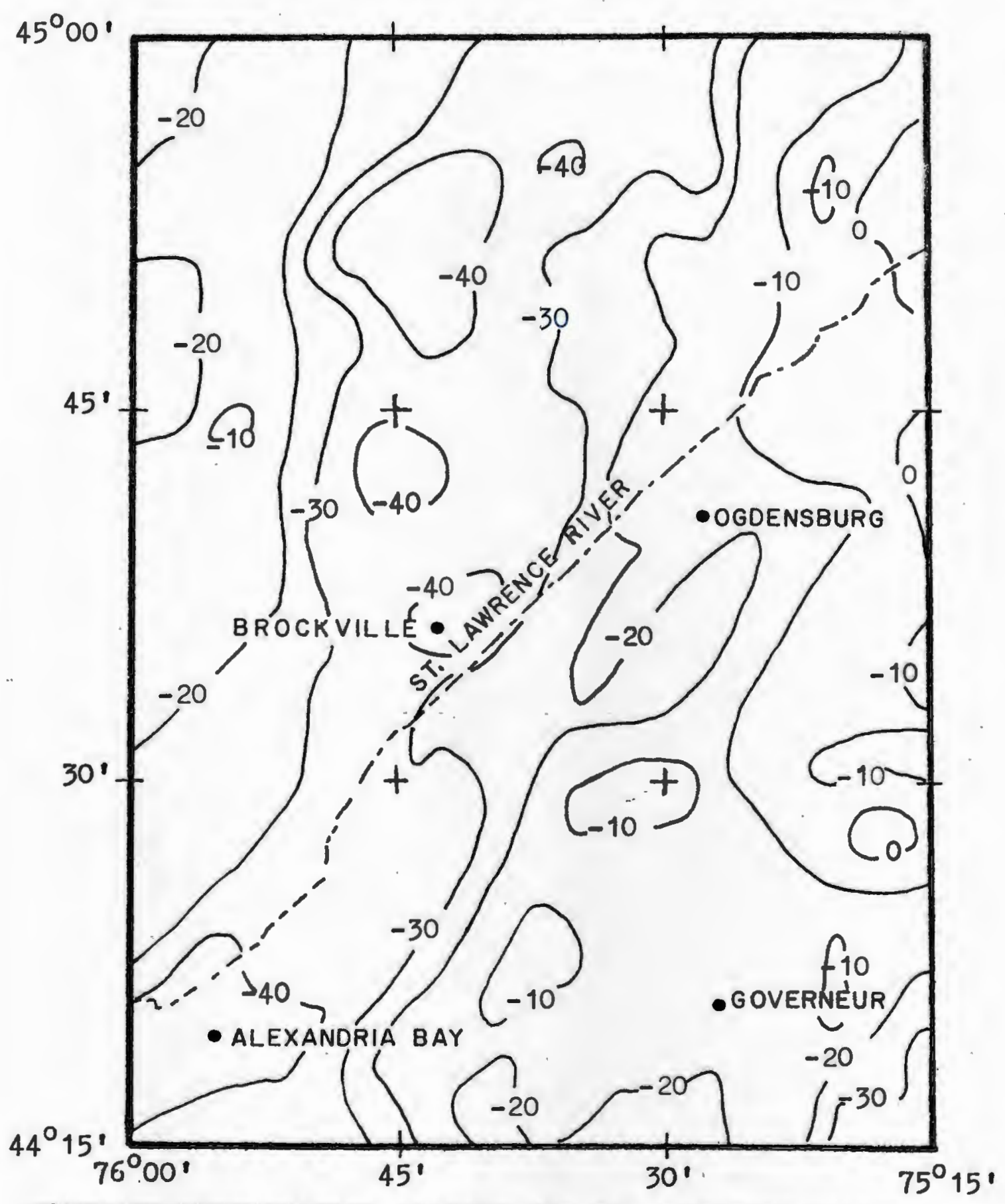

DOWNWARD CONTINUATION GRAVITY MAP ST. LAWRENCE VALLEY LEVEL 1 REGION B

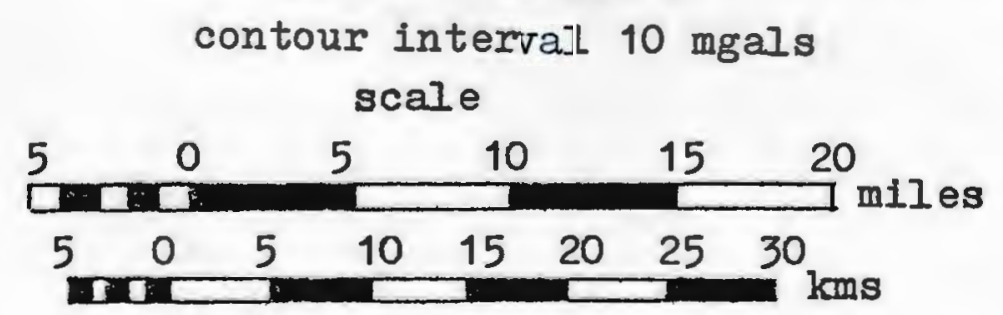


Plate 15

Second derivative at surface for Region $B$. Contour interval $=2.5 \mathrm{mgals}$ 


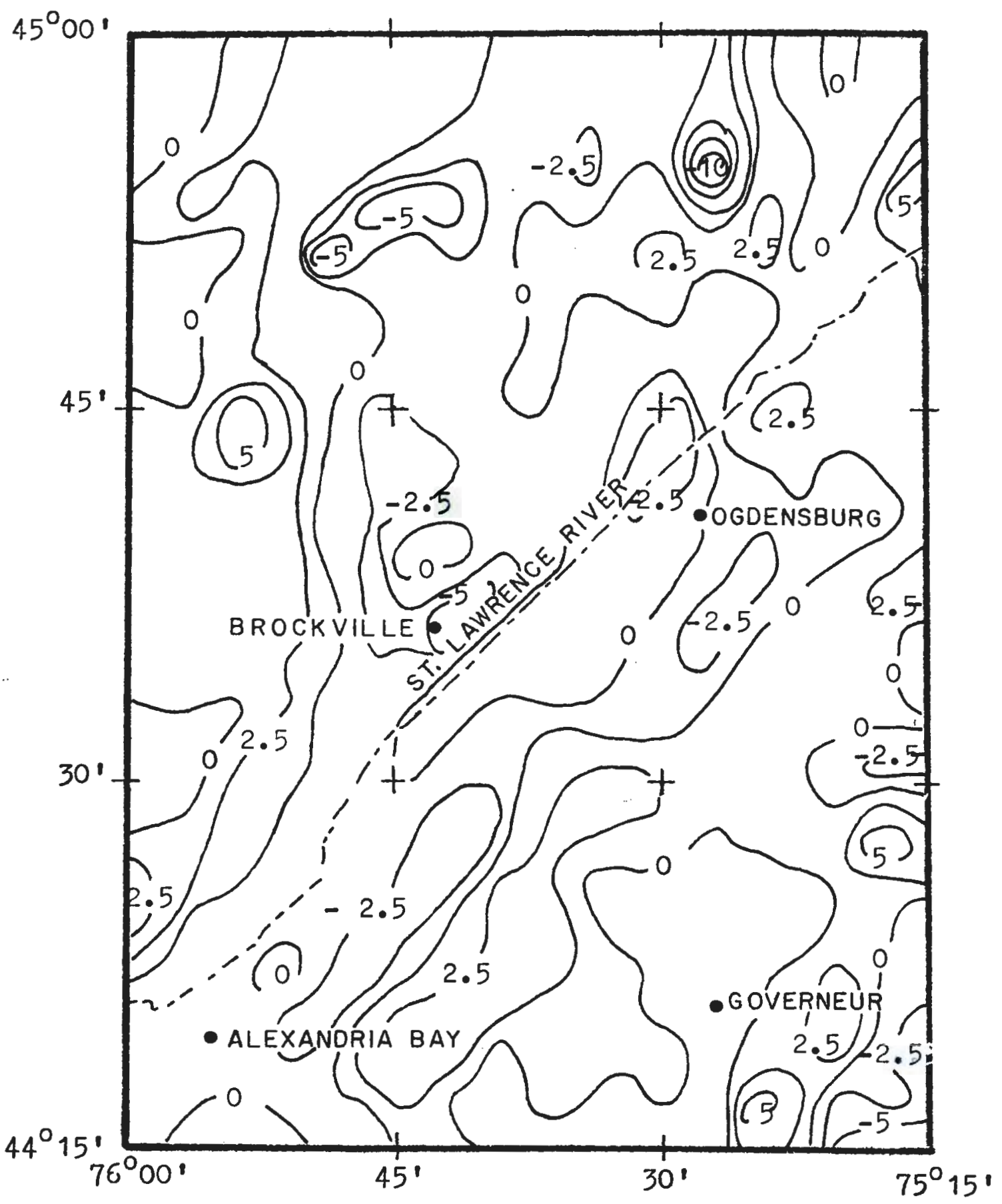

SECOND DERIVATIVE GRAVITY MAP ST. IAWRENCE VALLEY SURFACE REGION B

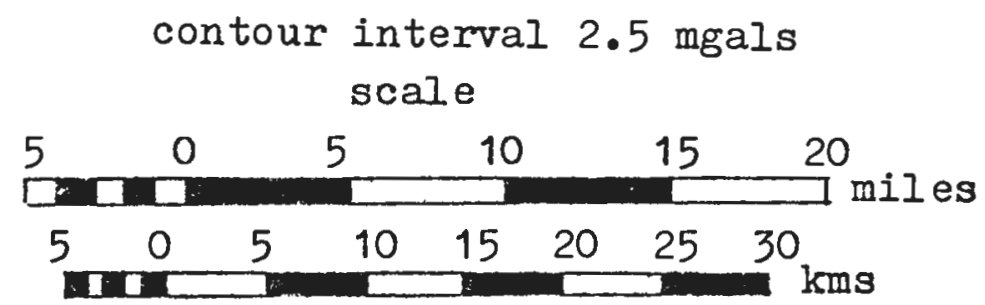




$$
\begin{gathered}
\text { Plate } 16 \\
\text { Generalized geologic map of Region } B \text {. }
\end{gathered}
$$

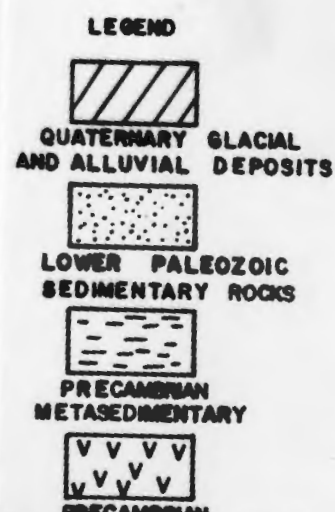



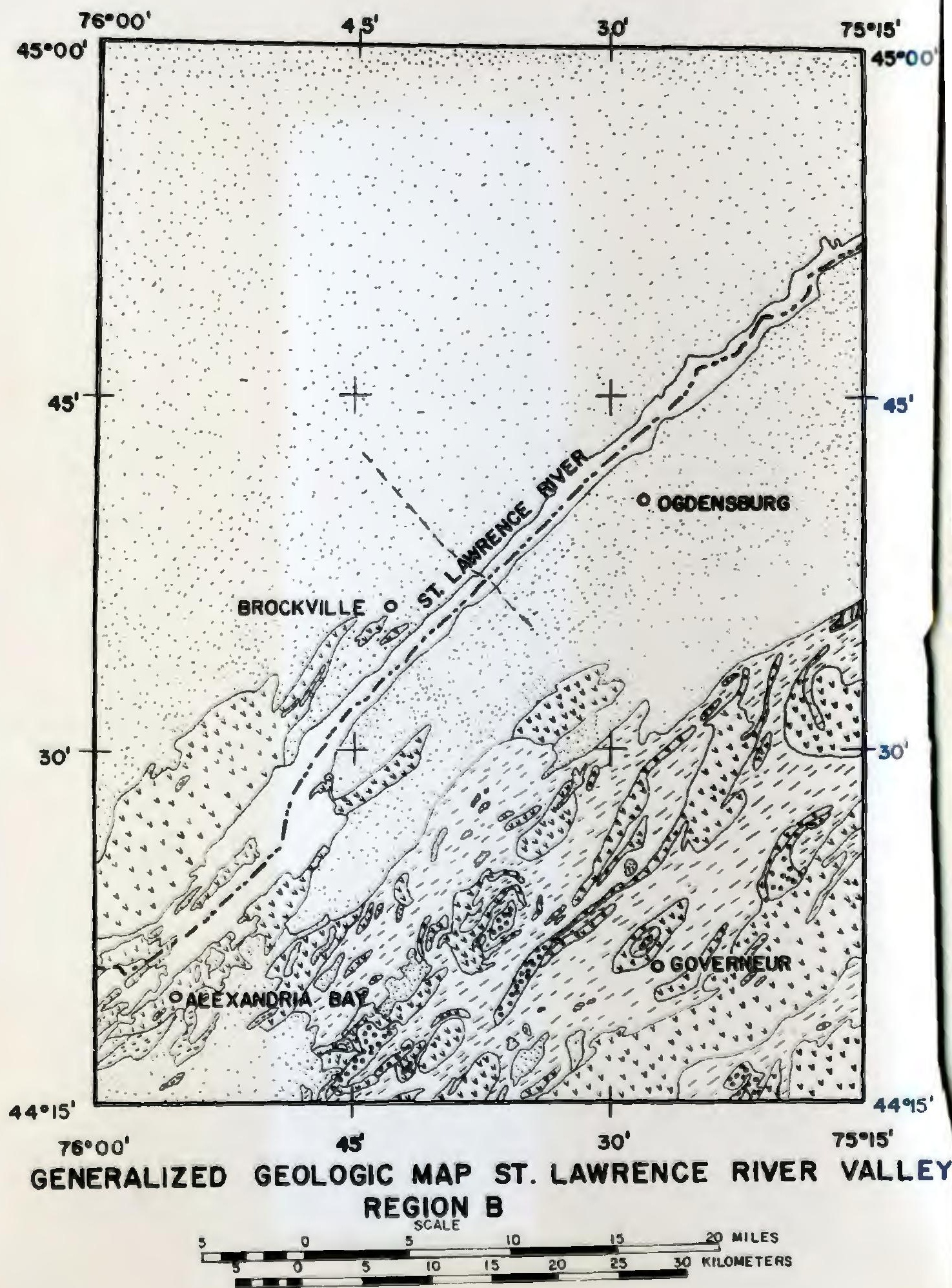